Universidade de São Paulo

Instituto de Biociências

Departamento de Genética e Biologia Evolutiva

Felippe Lourenço Claro

Estudos do DNA repetitivo no gênero

Eigenmannia

Studies of repetitive DNA in the genus

Eigenmannia

São Paulo

2013 
Felippe Lourenço Claro

\title{
Estudos do DNA repetitivo no gênero
}

\author{
Eigenmannia
}

\section{Studies of repetitive DNA in the genus}

\section{Eigenmannia}

Tese apresentada ao Instituto de Biociências da Universidade de São Paulo, para a obtenção de Título de Doutor em Ciências, na Área de Genética e Biologia Evolutiva.

Orientador(a): Lurdes Foresti de Almeida Toledo

São Paulo 


\section{Ficha Catalográfica}

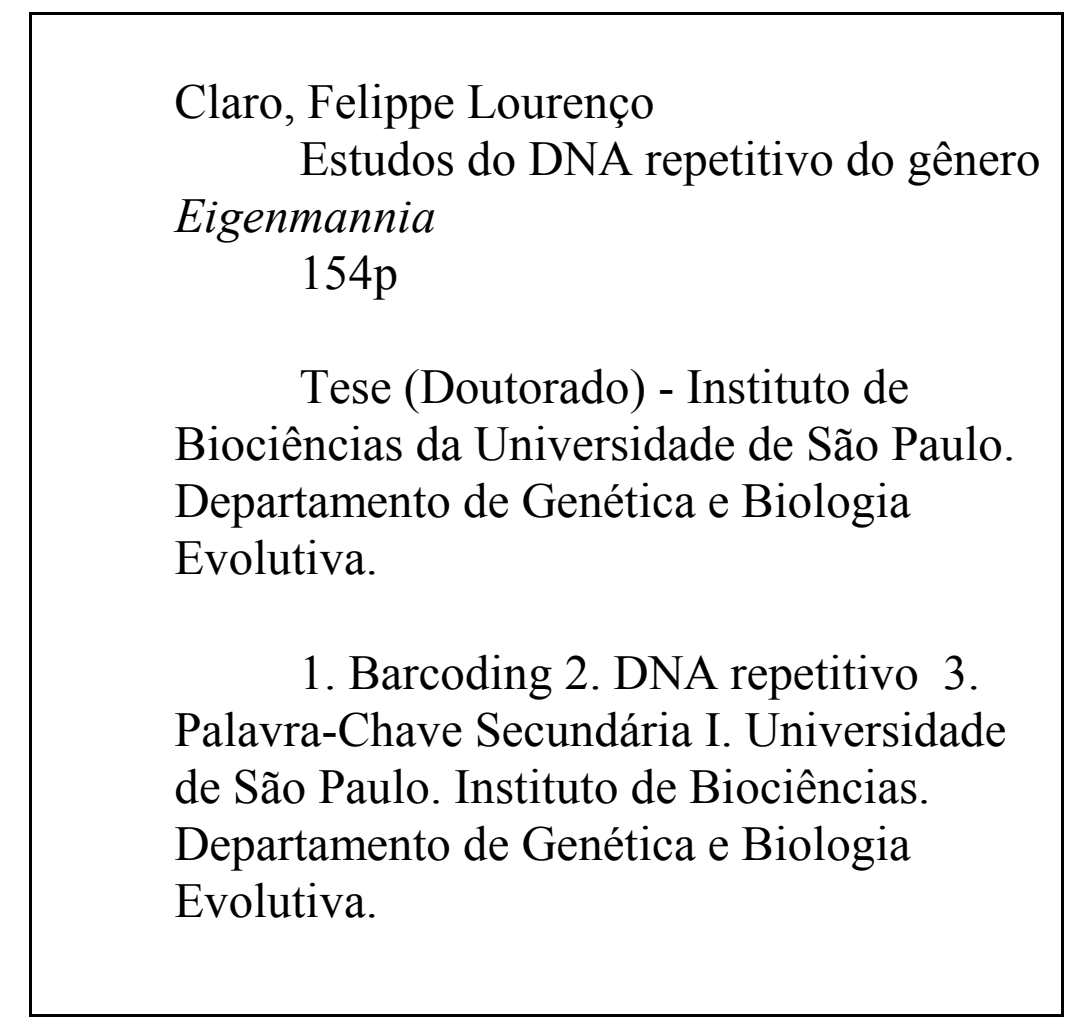

Comissão Julgadora:

Prof(a). Dr(a).

Prof(a). Dr(a).

\footnotetext{
Prof(a). Dr(a).
}

$\operatorname{Prof}(a) . \operatorname{Dr}(a)$ 
Dedicatória

Vô, essa é para você! 
"O futuro pertence àqueles que acreditam na beleza de seus sonhos." Elleanor Roosevelt 


\section{Agradecimentos}

Em primeiro lugar agradeço a FAPESP, a CAPES e ao CNPq pelo apoio financeiro, fundamental para o desenvolvimento do projeto de pesquisa.

À Prof. ${ }^{a}$ Lurdes Foresti de Almeida Toledo agradeço por toda a ajuda em todos esses anos, por todas as conversas, pelos incentivos, por essa amizade de tantos anos que teve como resultado esse trabalho incrível.

A meus pais, minha tia e meu avô (in memorian) que me acompanharam e vibraram com cada conquista e que sonharam com esse momento.

A minha esposa Denise por todo o amor, apoio, companheirismo, carinho. De, você me completa de uma forma única e sem dúvida essa conquista também é nossa, minha, sua e da nossa Carol.

Carlão, obrigado por todos os ensinamentos, não só do laboratório, mas sobre tudo. Com certeza essa convivência de tantos anos contigo me fez crescer muito.

Ju e Carol: é impossível ver meus dias no laboratório sem vocês. Foram muitos bons momentos e me sinto muito feliz por ter tido a oportunidade de trabalhar com vocês e ensinar tudo o que pude. Tenho certeza que vocês irão longe e não se esqueçam, sempre acreditem, nada é impossível.

Rodrigão você sabe o carinho especial que tenho por você. Vi um menino responsável, dedicado e extremamente inteligente dar seus primeiros passos na ciência e hoje já ganhou o mundo. Sempre vi o potencial que você tem e não tenho dúvidas que você terá sucesso em tudo o que desejar. Ter ensinado a você foi um privilégio e pode ter certeza o momento em que mais aprendi foi quando te ensinei e por isso preciso dizer, obrigado. 
Naila, sempre pronta para me ouvir a ajudar em tudo o que fosse possível, seja no laboratório seja em minha vida pessoal.

NaNe, Larissa, Toninha, Melinda, Henrique, Michel, obrigado por todos os bons momentos que passamos juntos!

Alberto, um dia chefe na disciplina, hoje uma pessoa que admiro muito e que me ensinou coisas incríveis. Obrigado por todas as conversas, conhecimentos, risadas, broncas, oportunidades...minha trajetória não teria sido a mesma sem você!

Márcio e Waldir, nem preciso falar o quanto gosto de vocês, não é? Obrigado pelas conversas, pelos incentivos, pelas ajudas, por tudo! Vocês são demais!

Mamones e Camila...só tenho a agradecer por todos os momentos incríveis que passamos juntos!

Aos funcionários do departamento, Helenice, Genoveva, Luzia, com as quais tive o prazer de conviver por todos esses anos.

Emerson a você agradeço pela grande oportunidade de trabalho na Nikon do Brasil. Trabalhar com microscopia sempre foi um sonho e hoje, vivencio esse sonho todos os dias ao lado de um time incrível! Obrigado Andreia, João, Flávio, Kleber e Alex, o time da Instruments e claro a todos da Nikon do Brasil!

Agradeço a todos aqueles que de uma forma ou de outra contribuíram para essa minha incrível jornada! Muito obrigado! 


\section{Índice}

Capítulo 1. Introdução Geral

Capítulo 2. DNA barcoding of the species complex Eigenmannia virescens (Teleostei: Gymnotiformes: Sternopygidae) from Upper Parana River basin

Capítulo 3. Molecular characterization and chromosomal mapping of two class of $5 \mathrm{~S}$ ribosomal gene in kariomorphs of the genus Eigenmannia.

Capítulo 4. Physical mapping and molecular studies of transposable elements in different caryomorphs of the genus Eigenmannia (Teleostei: Gymnotiformes: Sternopygidae) from Upper Parana River basin.

Capítulo 5. Telomeric sequences reveal no fusion sites in karyomorphs of the genus Eigenmannia.

Discussão Geral e Conclusões

Resumo

Abstract 
Capítulo 1

Introdução Geral 


\section{Introdução Geral}

Os peixes apresentam uma grande diversidade quanto à sua morfologia, seus habitats e também sua biologia. São encontrados em lagos, córregos, estuários e oceanos, constituindo assim mais de $50 \%$ do número total das aproximadamente 54.700 espécies de vertebrados conhecidas atualmente (Nelson, 2006). Grande parte dessa riqueza e diversidade encontra-se em águas tropicais (LOWE-McCONNELL, 1999), particularmente nas águas doces neotropicais, onde são encontradas 4.475 espécies válidas de peixes, as quais podem chegar a mais de 6.000 (dentre a 13.000 mundiais) se incluídas as novas espécies já reconhecidas por especialistas, porém ainda não descritas (LANGEANI et al, 2007).

A ordem Gymnotiformes compreende um grupo monofilético de peixes endêmicos da região Neotropical (Fig. 1) que representa um componente importante da ictiofauna de água doce. Nessa ordem estão incluídas cinco famílias: Sternopigydae, Rhamphichthyidae, Hypopomidae, Apteronotidae e Gymnotidae, com um total de 29 gêneros e mais de 130 espécies, muitas ainda não descritas (Albert, 2001). O conhecimento sobre esse grupo de peixes tem avançado com estudos sobre relações filogenéticas inter e intra-específicas baseados em dados morfológicos, moleculares, neuro-anatômicos, fisiológicos e de fósseis (Triques, 1993; Mago-Leccia, 1994; AlvesGomes et al., 1995; Albert \& Campos-da-Paz, 1998; Albert, 2001), bem como em estudos cromossômicos, em especial nos gêneros Eigenmannia e Gymnotus (Almeida Toledo et al., 1996, 2000, 2001, 2002; Fernandes-Matioli et al., 2005; Albert et al. 1999). Entretanto ainda há inúmeros problemas taxonômicos relevantes em diversos níveis da ordem Gymnotiformes, sendo que grande parte dos gêneros e espécies do grupo aguardam revisões (Campos-da-Paz, 1997). 


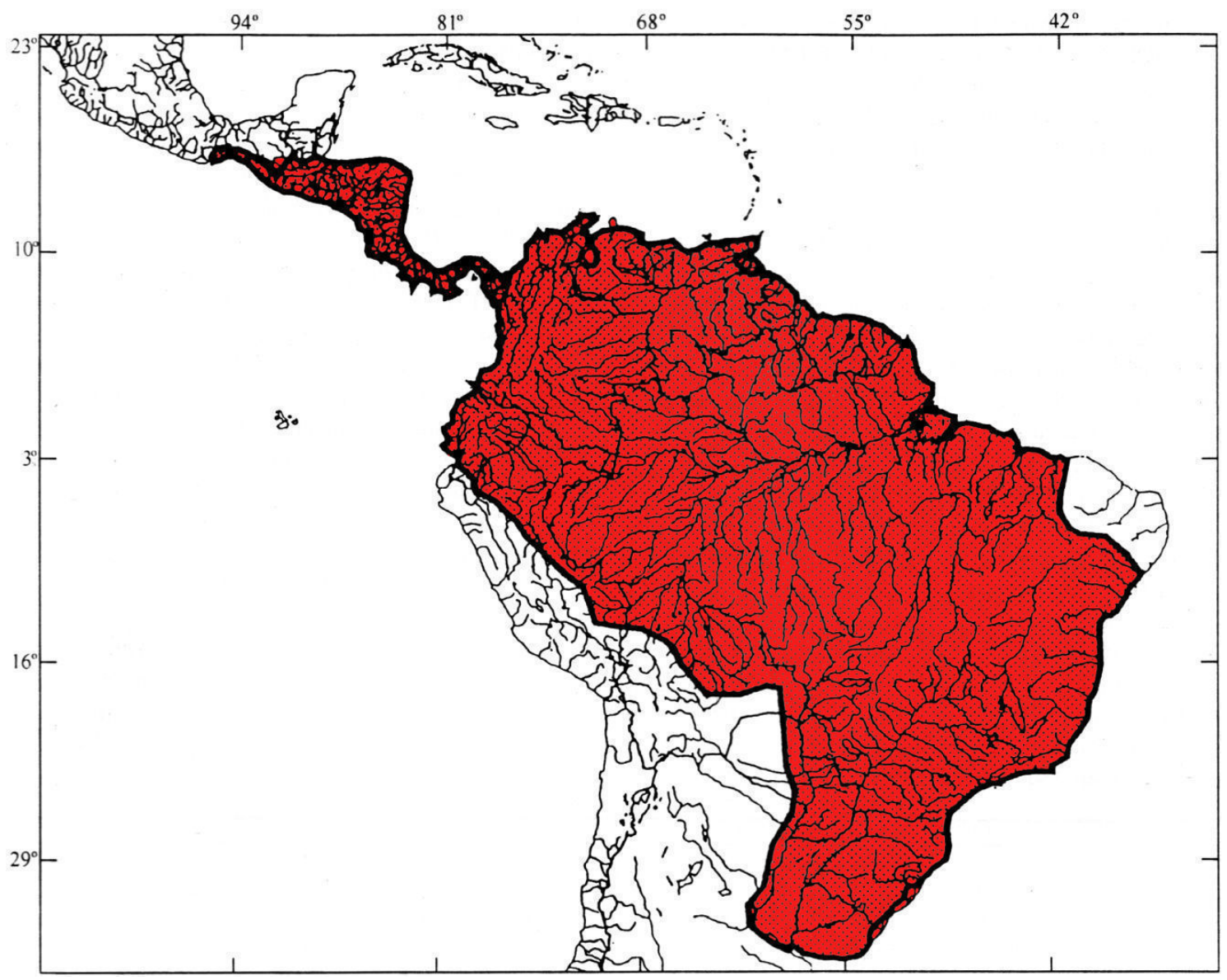

Figura 1: Mapa evidenciando região neotropical (adaptado de Albert \& Campos-da-Paz, 1998).

\section{O Gênero Eigenmannia}

O gênero Eigenmannia (Fig. 2) (Sternopygidae) faz parte da ordem Gymnotiformes, grupo no qual a morfologia das espécies é tipicamente serpentiforme e que apresenta distribuição exclusivamente neotropical (Albert, 2001). Uma característica desse grupo, notória nas espécies de Gymnotiformes, intimamente relacionada aos hábitos noturnos e ambientes de rios, é a emissão contínua de descargas elétricas de baixas voltagens, voltadas para as funções de eletro-localização (navegação, defesa e localização de presas) e eletro-comunicação (Alves-Gomes, 2001). 


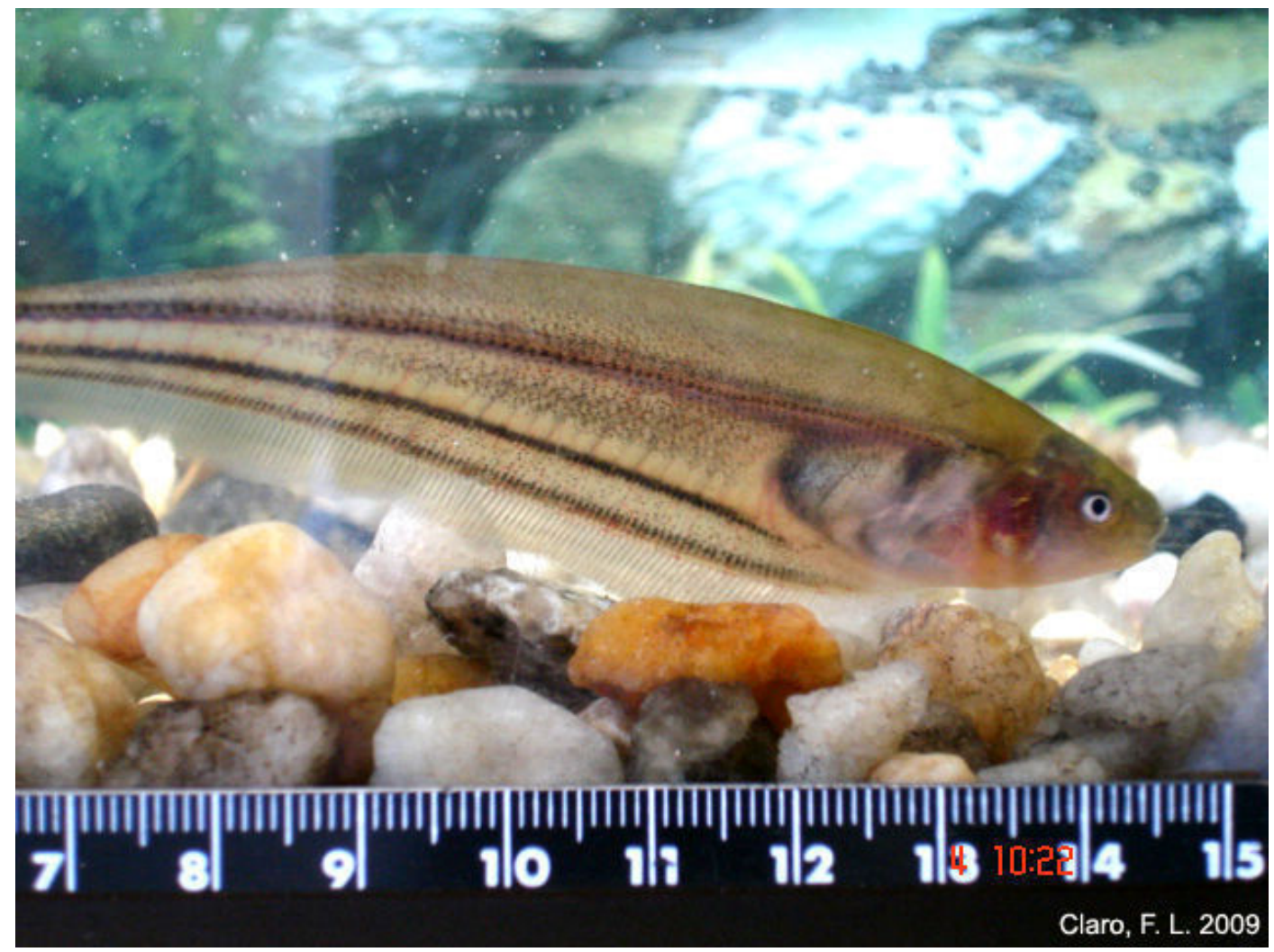

Figura 2: Exemplar do gênero Eigenmannia oriundo de Santa Albertina/SP

São descritas oito espécies válidas para o gênero Eigenmannia com data de separação estimada em 16Ma. A diversidade de espécies não pode ainda ser estabelecida devido à necessidade de uma revisão taxonômica no gênero e as espécies já descritas para esse gênero são, provavelmente, na realidade, grupos de espécies crípticas morfologicamente (Albert, 2003; Henning, 2010).

Um número expressivo de estudos citogenéticos já foi publicado sobre as populações de Eigenmannia, enfocando basicamente a Bacia Superior do Rio Paraná e a bacia do Rio São Francisco. As populações de Eigenmannia já descritas citogeneticamente apresentam ampla variabilidade cariotípica e diversos sistemas sexuais incluindo sistemas XY e ZW (Almeida-Toledo et al. 2002). Nas bacias dos rios Tietê, Paranapanema e Mogi-Guaçu (SP), ocorrem populações com cariótipos que apresentam números cromossômicos entre 28 e 38 com presença ou não de 
cromossomos sexuais heteromórficos (Almeida Toledo \& Foresti, 2001). Uma análise filogenética recente destes citótipos revelou um padrão de labilidade dos sistemas de determinação sexual e uma maior conservação do número cariotípico (Henning et al., 2010). Segundo Henning (2010), a reconstrução filogenética das diversas espécies de Eigenmannia com base em genes mitocondriais mostrou que aqueles que possuem sistemas sexuais agrupam com aqueles nos quais os sistemas não estão presentes. Esse seria um indício de que a diferenciação dos cromossomos sexuais é recente, levantando assim uma hipótese sobre a origem múltipla desse sistema, fato também verificado por Henning (2007), em estudo no qual a realização de um experimento com sondas específicas para os cromossomos sexuais não demonstrou similaridades entre espécies que possuem sistemas sexuais distintos, reforçando a possível origem múltipla do sistema.

\section{DNA Barcoding}

Uma nova abordagem para a identificação de espécies foi introduzida por Hebert et al. (2003), que propôs o uso de um pequeno fragmento do genoma mitocondrial para essa identificação através dos filos do reino animal e estabeleceu o termo DNA barcoding para essa abordagem. As razões para a escolha do DNA mitocondrial em detrimento ao DNA nuclear inclui a herança uniparental (maioria dos filos animais), elevada taxa evolutiva, ausência de introns e um número elevado de cópias por célula. A técnica de DNA barcoding, consiste no sequenciamento de uma região de aproximadamente 650 pare de bases do gene mitocondrial Citocromo Oxidase I (COI) (Hebert et al. 2003) é capaz de discriminar uma grande variedade de espécies animais. A variação da sequencia dentro das espécies é geralmente muito menor em relação entre espécies, permitindo que amostras desconhecidas sejam então sequenciadas e alocadas corretamente a uma dada espécie. A proposta da utilização do gene COI para o DNA 
barcoding não foi arbitrária, uma vez que foi verificado um sinal filogenético tanto para níveis acima e abaixo de espécie e que seus primers universais são capazes de recuperar a região 5' do gene COI em grande parte do filo animal. Essa técnica proposta por Heber et al. (2003), mostrou-se um marcador molecular valioso para a identificação de espécies, sendo sua eficácia evidenciada em inúmeros trabalhos (Barret \& Hebert, 2005, Hubert et al. 2008; Hebert et al., 2003, 2004a; Ward et al., 2005; Bucklin et al., 2007; Smith et al., 2008; Steinke et al., 2009a). De acordo com essa abordagem, as espécies podem ser identificadas baseadas no gap entre as distâncias genéticas intra e interespecíficas usando uma margem entre $2-3 \%$ ou o valor de 10 vezes para a delimitação de espécies (Herbert et al., 2004). Inúmeras espécies foram propostas, utilizando-se a técnica do DNA barcoding, as quais foram formalmente descritas posteriormente (Ward et al. 2008, Yassin et al. 2008, Witt et al. 2006). Apesar de suas limitações, como a baixa resolução em alguns casos (híbridos, espécies com divergência recente, complexos de espécies ou grupos com taxas evolutivas baixas), presença de pseudogenes (Song et al., 2008) contaminantes amplificados com primers universais (Siddall et al., 2004) ou casos de introgressão mitocondrial (Kemppainen et al., 2009) a técnica de DNA barcoding se tornou uma importante ferramenta para a investigação da biodiversidade através da identificação de espécimes em todos os estágios de vida, a partir de amostras frescas ou conservadas, casos de dimorfismo sexual ou potenciais espécies crípticas. Não especialistas são capazes de ter uma ferramenta de identificação rápida, de baixo custo e confiável com inúmeras aplicações práticas (Ivanova et al., 2009; Garland and Zimmer 2002). Para o estudo então da diversidade global, foi criado um projeto denominado Barcode of Life cujo intuito é a caracterização da biodiversidade global utilizando o gene COI para grupos animais e armazenar tal informação no Barcoding of life database (BOLD - Ratnasingham \& Hebert 2007) a 
qual permite comparações entre dados de diversos pesquisadores, revelando casos de sinonímias, potenciais espécies crípticas e populações geneticamente distintas.

\section{DNA Repetitivo}

O genoma dos organismos eucariotos, apesar de sua grande complexidade, pode ser subdividido, em dois grandes grupos, sendo um deles composto pelas sequências de cópia única, as quais constituem uma porção considerável dos genes funcionais, enquanto o outro grupo engloba as sequências de caráter repetitivo, fração considerável do genoma de muitos eucariotos (Wagner et al.1993). A classe repetitiva compõe uma fração significante do genoma eucarioto, incluindo mais da metade do genoma humano, exercendo importantes funções na organização estrutural dos cromossomos, regulação gênica e a dinâmica evolutiva desse genoma (Kidwell, M. G. and Lisch, D. R., 2000;

Lander, E. S. et al., 2001; Waterston, R. H. et al., 2002; Feschotte, C., 2008). É composta tanto por sequências funcionais, como é caso dos genes ribossômicos, quanto por sequências não codificantes, as quais podem estar dispersas no genoma, como no caso dos elementos transponíveis, ou arranjadas em cadeia, como nos casos dos mini e microssatélites, com repetições curtas não maiores do que 64 bases e do DNA satélite, que envolve repetições complexas com tamanhos superiores a 100kb.

Estudos recentes mostraram que alguns elementos repetitivos apresentam a conservação de um sítio para ligação de fatores de transcrição que muito provavelmente participam na regulação de genes específicos (Bourque G. et al., 2008, Wang T. et al., 2007). Muitos trabalhos têm por objetivo o isolamento e a caracterização dessas sequências de DNA repetitivo nos mais diversos grupos animais e vegetais. Essas sequências são relativamente homogêneas dentro de uma mesma espécie, apresentando, contudo, grandes diferenças quando tratamos de espécies distintas, mesmo considerando 
apenas um único gênero (Smith, 1976). Yamada et. al (2005) clonou famílias de sequências de DNA repetitivo de Mesocricetus auratus, e as caracterizou através do seqüenciamento e da hibridação in situ. As sequências foram obtidas através da digestão do DNA total com as enzimas $B g l$ II e $E c o$ RI e o padrão de hibridação foi coincidente com a distribuição das regiões bandas $\mathrm{C}$ positivas, que estão presentes em metade dos cromossomos autossomos, nos braços longos dos cromossomos 20 e $\mathrm{X}$ e no cromossomo Y por inteiro. Com esse estudo, foi possível determinar que o DNA satélite centromérico e as sequências repetitivas presentes em cromossomos sexuais e nas regiões teloméricas eram conservados dentro do gênero, mas diferiam em gêneros distintos. Foi possível verificar ainda que a sequência repetitiva nos braços heterocromáticos dos cromossomos apresenta similaridades com uma sequência LINE em roedores e se manteve conservada nas três subfamílias. As sequências repetitivas desse gênero ou subfamília, portanto, se mostraram excelentes marcadores taxonômicos e moleculares para a sistemática do grupo.

Utilizando-se dessa mesma abordagem, Parise-Maltempi et. al (2007) através da digestão pela enzima Spe I em Leporinus elongatus obteve um padrão de bandas, identificado através da técnica de Southern Blotting, padrão esse diferente entre machos e fêmeas, apresentando uma concentração mais elevada em fêmeas, um possível indicativo de um maior número de cópias. Posteriormente a clonagem e a hibridação in situ dos fragmentos corroboraram esta hipótese e evidenciaram a presença de um sistema sexual múltiplo $\left(\mathrm{Z}_{1} \mathrm{Z}_{1} \mathrm{Z}_{2} \mathrm{Z}_{2} / \mathrm{Z}_{1} \mathrm{~W}_{1} \mathrm{Z}_{2} \mathrm{~W}_{2}\right)$. A marcação em fêmeas foi visualizada em dois cromossomos exclusivos, $\mathrm{W}_{1}$ identificado pela morfologia e acúmulo de sequências repetitivas e heterocromáticas e $\mathrm{W}_{2}$ pela presença de dois blocos de sequências repetitivas em seu braço longo. No macho, verificou-se uma pequena marcação na região telomérica de apenas um par $\left(Z_{2} Z_{2}\right)$, marcação também presente na 
fêmea. Esse evento, no qual temos o acúmulo de elementos repetitivos sem a ocorrência de troca gênica, leva a cromossomos morfologicamente distintos e à fixação da determinação sexual heterogamética neste caso múltipla, demonstrando a importância das sequências repetitivas neste processo.

O gene ribossômico $5 \mathrm{~S}$ é uma das sequências repetitivas funcionais amplamente estudados do ponto de vista citogenético nos mais diferentes grupos (Phillips et al., 2012; Traldi et al., 2013; El-Twab \& Kondo, 2013). Esse gene é parte da família multigênica que codifica para o RNA ribossômico $5 \mathrm{~S}$ e consiste em uma região altamente conservada com aproximadamente $120 \mathrm{pb}$, cuja unidade transcripcional é separada por um espaçador não transcrito (NTS) (Long \& David, 1980) e organizada em repetições em tandem contendo de centenas a milhares de cópias. Além dessa caracterização da localização cromossômica inúmeros estudos têm utilizado o NTS como uma ferramenta para o estudo entre espécies intimamente relacionadas, fato esse diretamente associado à elevada dinâmica dessa região genômica, possuindo, portanto, uma grande quantidade de sítios informativos, os quais são utilizados na produção de filogenias (Baker et al., 2000; Baum et al., 2004; Kitamura et al., 2005; Baum \& Johnson, 2007). Em peixes o NTS foi utilizado em diversos grupos para a identificação de espécies intimamente relacionadas, subespécies, linhagens e híbridos (Pendas et al., 1995; Martins \& Wasko, 2004; Robles et al., 2005; Ferreira et al., 2007). Ainda há estudos onde foi verificada a presença de diferentes classes do rDNA 5S (Campo et al., 2009), evidenciando a complexidade dessa região do genoma. São escassos os estudos envolvendo o gene ribossômico 5S juntamente com seu NTS, na reconstrução das relações dentre os Gymnotiformes, sendo a grande maioria dos trabalhos relacionada apenas à localização física das sequências do gene determinadas através de hibridação in situ (Silva et al., 2011). 
Elementos transponíveis são sequências móveis capazes de se movimentar de um locus a outro no genoma no qual estão presentes. Tais elementos compõem duas grandes classes, os retrotransposons e os transposons de DNA. São abundantemente presentes no genoma eucarioto e eram comumente considerados parasitas do genoma. Esses elementos são potentes agentes evolutivos, impactando, por exemplo, a expressão gênica através da introdução de elementos regulatórios alternativos, exons and novos sítios para splicing (Jurka 1995; Speek 2001; Nigumann et al. 2002; Kazazian 2004; Peaston et al. 2004; Matlik et al. 2006; Babushok et al. 2007; Hasler et al. 2007). Porém, esses elementos não necessitam ser mobilizados de forma ativa para ter um efeito na estrutura do genoma. Os rearranjos mediados pelos elementos transponíveis através de recombinações não homólogas são bem documentados (Batzer and Deininger 2002; Lonnig and Saedler 2002; Eichler and Sankoff 2003; Hancks and Kazazian 2010) e deleções, duplicações, inversões, translocações e quebras cromossômicas estão todos ligados a presença de elementos transponíveis em uma grande gama de genomas (Weil and Wessler 1993; Lim and Simmons 1994; Mathiopoulos et al. 1998; Caceres et al. 1999; Gray 2000; Kidwell, 2002; Zhang and Peterson 2004). A questão mais intrigante é "Por que os elementos transponíveis são tolerados, se causam tantos problemas?" Claramente eles simplesmente podem ser muito adaptáveis para ser completamente eliminados, mas durante a recombinação, segregação independente e o sexo, as mutações mediadas por esses elementos são de grande importância na geração de variabilidade genética. Como mutagênicos potentes, os elementos transponíveis criam mutações genéticas, nas quais pode atuar o processo de seleção natural. Sua prevalência em genomas eucariotos pode indicar que tais elementos sejam seletivamente vantajosos, sendo que inúmeros estudos sugerem importantes contribuições a biologia do genoma 
(Vidal et al. 1993; Hamdi et al. 2000; Deininger and Roy-Engel 2002; Kidwell \& Lish, 2000; Nouaud et al. 2003; Lowe et al. 2007; Mikkelsen et al. 2007).

Apesar da identificação de inúmeros elementos transponíveis depois da descoberta dos transposons em milho (McClintock 1948, 1950), o primeiro sistema de classificação foi apenas em 1989, o qual propôs que os elementos fossem divididos em duas classes de acordo com seus mecanismos de transposição. Elementos que se utilizam do mecanismo de transposição "copy-and-paste" pertencem à classe I, enquanto aqueles que se utilizam do mecanismo “cut-and-paste” pertencem a classe II (Finnegan 1989). Nessa época a classe I era composta por dois elementos: os LTR (long terminal repeats) e non-LTR os quais não possuíam essa terminação longa ao final de sua sequencia. $\mathrm{O}$ crescimento dessa diversidade dos elementos transponíveis identificados em grupos distintos, bem como a descoberta de novos elementos, alavancou a proposta de uma classificação unificada para os elementos transponíveis (Wicker et al. 2007). Tal sistema mantinha as duas classes, enquanto incluía ao mesmo tempo níveis menores (classe, subclasse, ordem, superfamília, família e subfamília). Na classe I existem cinco ordens (LTR, DIRS, PLE, LINE, and SINE) com um total de 17 superfamílias (Copia, Gypsy, Bel-Pao, Retrovirus, ERV, DIRS, Ngaro, VIPER, Penelope, R2, RTE, Jockey, L1, I, tRNA, 7SL, and 5S). Já na classe II existem duas subclasses, a I (TIR and Crypton) e a II (Helitron and Maverick/Polinton), sendo que dentro dessas subclasses há um total de 12 superfamílias (Tc1/Mariner, hAT, Mutator, Merlin, Transib, P, PiggyBac, PIF/Harbinger, CACTA, Crypton, Helitron, and Maverick). Devido à necessidade de automação no processo de sequenciamento do genoma humano, uma convenção para a nomenclatura foi proposta de forma ao elemento ser precedido por um código, o qual refletiria o seu estado de classificação. Atualmente um sistema de classificação alternativo foi sugerido pelo Repbase, no qual propõe uma nomenclatura 
que reflita a superfamília, família, estrutura e espécie hospedeira (Kapitonov and Jurka 2008). Apesar das inúmeras formas de classificação desses elementos, estes podem ser classificados em dois tipos principais: os denominados autônomos, que codificam ou para a transposase ou para a transcriptase reversa e são capazes de deslocamento no genoma sem qualquer tipo de auxílio, e aqueles que carregam deleções ou mutações no gene da transposase ou transcriptase, sendo mobilizados apenas na presença de elementos transponíveis autônomos (Hurst \& Werren, 2001). Apesar de esses elementos conterem informações a princípio não significativas, sua capacidade de auto-replicação e a presença de diversas cópias no genoma devem ser consideradas como uma das forças que atuariam na evolução do genoma. São comumente encontrados nas porções heterocromáticas dos genomas ou ainda dispersos nos cromossomos (Capriglione et al. 2002).

Nos peixes, fragmentos de sequências LINE, um retrotransposon tipo non-LTR autônomo que acredita-se sejam finamente controlados por mecanismos de metilação e controle por RNAi mechanisms (Goodier and Kazazian, 2008), foram identificadas em Salmo gairdneri (Winkfein et al., 1998), Anguilla anguilla (Ohshima et al., 1996), Oryzia latipes (Duvernell \& Turner, 1998) e Danio rerio (Okada et al., 1997). Oliveira et al. (1999) identificaram em Oreochromis niloticus um elemento transponível do tipo LINE, o qual se assemelha ao LINE2 encontrado em mamíferos. Verificou-se, através da técnica de Southern Blotting, que sua distribuição genômica é ampla, estando presente em todas as espécies de Oreochromis, Tilapia e Sarotherodon amostradas, com pequenas variações nas intensidades das bandas obtidas. A distribuição cromossômica da sequência LINE2 foi determinada através da utilização da técnica de FISH e foram identificados pequenos blocos de sinais espalhados ao longo dos cromossomos, com maior concentração na sua porção terminal, o que de acordo com Higashiyama et al. 
(1997) atuaria de modo importante na estabilização dos telômeros ou mesmo atuaria como uma barreira de proteção à região cromossômica onde estão os localizados os genes.

Os elementos transponíveis podem ainda estar associados a regiões funcionais, tal qual o SINE3 identificado em Danio rerio, o qual compõe uma nova classe de SINE derivada do gene ribossomal 5S (Kapitonov \& Jurka 2003). Pertencentes à família AFC, os elementos que a compõem são SINEs clássicos, derivados do RNAt, cuja ocorrência já foi verificada em ciclídeos (Takahashi et al., 1998) e Gymnotiformes (Claro, 2008), apresentando a transposição mediada pela maquinaria enzimática do retrotransposon CR1 (Terai et al., 1998). A possível origem desse elemento corresponderia a uma composição acidental de parte do gene/pseudogene ribossômico $5 \mathrm{~S}$ e parte do retrotransposon $\mathrm{CR} 1$, aliado a uma mutação no sitio de término de transcrição, garantindo assim todos os elementos necessários para a transcrição, clivagem da região alvo e reinserção desse elemento, pontos fundamentais para a manutenção do SINE no genoma (Kapitonov \& Jurka 2003).

Além da associação com regiões funcionais e regiões heterocromáticas, os elementos transponíveis podem estar associados a cromossomos sexuais. Morescalchi et al. (1996) verificaram essa associação entre o transposon Tc1, isolado em Chinodraco hamatus, espécie pertencente à subordem de Perciformes, endêmica nos oceanos do leste (Eastman, 1993). A localização desse elemento transponível restringiu-se a regiões heterocromáticas, porém foi verificado ainda um sinal na região terminal no braço longo do cromossomo Y, o que sugere que esse transposon esteja relacionado à diferenciação dos cromossomos sexuais. O elemento Tc1 pertence a uma superfamília de elementos transponíveis, que possui repetições terminais invertidas com sequências altamente conservadas. Integram-se em locais onde há ocorrência da sequência TA e possuem um 
quadro de leitura que codifica para a transposase (Henikoff, 1992). Capriglione et al (2002) amplificaram e caracterizaram o elemento Tc1 na família Nototheniade. Nos resultados de hibridação genômica verificou-se uma conservação desse elemento, entretanto a amplificação por PCR revelou uma grande variabilidade entre as espécies da família, fato que o torna o elemento Tc1 um potencial marcador para essas espécies. Como marcadores genéticos, os elementos transponíveis apresentam certas vantagens em relação a outros marcadores mais amplamente utilizados e tem se mostrado como marcadores ideais para análises filogenéticas e de genética de populações. (Murata et al. 1993, 1998; Stoneking et al. 1997; Tatout et al. 1999; Nikaido et al. 2001; Kawai et al. 2002; Xiao et al. 2002; Terai et al. 2003, 2004; Nishihara et al. 2005, 2006; Schmitz et al. 2005; Xing et al. 2005, 2007; Witherspoon et al. 2006)

$\mathrm{O}$ estudo de sequências repetitivas, em cariomorfos do gênero Eigenmannia, portanto, deverá permitir uma melhor compreensão da importância, conservação e evolução dessa porção do genoma entre os diferentes cariomorfos do gênero, bem como permitirá verificar sua relação com regiões heterocromáticas e cromossomos sexuais pela identificação de marcadores citogenéticos e moleculares para cada uma das espécies a serem estudadas. 


\section{Objetivos}

O presente trabalho visa uma melhor compreensão das relações existentes entre cinco cariomorfos do gênero Eigenmannia, o qual acredita-se compõe um complexo de espécies, presentes na bacia do alto paraná, através da utilização da técnica de barcoding, bem como a identificação e caracterização de regiões repetitivas no genoma de forma a identificar a representatividade desses elementos na dinâmica evolutiva dos cariomorfos em estudo.

São objetivos específicos do trabalho:

- Testar o potencial de discriminação da técnica de barcoding e estabelecer as relações existentes entre os cariomorfos do gênero Eigenmannia estudados;

- Caracterizar o gene ribossômico 5S juntamente com seu NTS e verificar sua conservação das espécies através de um mapeamento cromossômico através de hibridação in situ;

- Identificar e caracterizar elementos transponíveis em cinco cariomorfos do gênero Eigenmannia presentes na bacia do Paraná e averiguar se há associação entre esses elementos e cromossomos sexuais e regiões heterocromáticas;

- Verificar evidências de fusões cromossômicas nos cariomorfos estudados através da utilização de sequências teloméricas. 


\section{Referências}

ABD EL-TWAB M. H. AND KONDO K. 2012 Physical mapping of 5S and 45S rDNA in Chrysanthemum and related genera of the Anthemideae by FISH, and species relationships. J. Genet. 91, 245-249

ALBERT, J. S., 2001. Species diversity and phylogenetic systematics of American knifefishes (Gymnotiformes, Teleostei), Division of Ichthyology, Museum of Zoology, Univ. of Michigan.

ALBERT, J. S., CAMPOS-DA-PAZ, R., 1998. Phylogenetic systematics of Gymnotiformes with diagnoses of 58 clades: a review of avaible data. In: MALABARBA, L. R., REIS, R. E., VARI, R. P., LUCENA, Z. M., LUCENA, C. A. (Eds.). Phylogeny and classification of Neotropical fishes, p. 419-446, EDIPUCRS, Porto Alegre.

AlBERT, J. S., FERNANDES-MATIOLI, F. M. C., AlMEIDA-TOLEDO, L. F., 1999. New species of Gymnotus (Gymnotiformes, Teleostei) from southeastern Brazil: toward the deconstruction of Gymnotuscarapo. Copeia 1999 (2): 410-421.

ALBERT, J.S., 2003. Sternopygidae (Glass knifefishes,Rattailknifefishes). p. 487-491. In: R.E. Reis, S.O. Kullander and C.J. Ferraris, Jr. (eds.) Checklist of the Freshwater Fishes of South and Central America. Porto Alegre: EDIPUCRS, Brasil

ALMEIDA-TOLEDO, L. F., STOCKER, A. J., FORESTI, F., TOLEDO-FILHO, S. A., 1996. Fluorescent in situ hybridization with rDNA probes on chromosomes of two nucleolus organizer region phenotypes of a species of Eigenmannia (Pisces, Gymnotoidei, Sternopygidae). Chromosome Res. 4: 301-305.

ALMEIDA-TOLEDO, L. F., FORESTI, F., DANIEL, M. F. Z., TOLEDO-FILHO, S. A., 2000. Sex chromosome evolution in fish: the formation o the neo-Y chromosome in Eigenmannia (Gymnotiformes).Chromosoma 109: 197-200.

ALMEIDA-TOLEDO L. F., FORESTI F., PEQUIGNOT E. V. AND DANIEL-SILVA M. F., 2001a.XX:XY sex chromosome system with X heterochromatinization: an early stage of sex chromosome differentiation in the Neotropic electric eel Eigenmannia virescensCytogenetics and Cell Genetics 95(1-2): 73-8. 
ALMEIDA TOLEDO L. F., FORESTI F., 2001b. Morphologically differentiated sex chromosomes in Neotropical freshwater fish Genetica 111(1-3): 91-100.

ALMEIDA TOLEDO L. F., DANIEL-SILVA M. F., MOYSES, C. B., FONTELES, S. B., LOPES, C. E., AKAMA, A., FORESTI, F., 2002. Chromosome evolution in fish: sex chromosome variability in Eigenmannia virescens (Gymnotiformes: Sternopygidae) Cytogenetic and Genome Research 99(1-4): 164-9.

ALVES-GOMES, J. A., ORTÍ, G., HAYGOOD, M., HEILINGENBERG, W., MEYER, A., 1995. Phylogenetic analysis of the South American Eletric Fishes (Order Gymnotiformes) and the evolution of their eletrogenic system: a synthesis based on morphology, eletrophysiology, and mitochondrial sequence data. Mol. Biol. Evol. 12: 298-318.

ALVES-GOMES, J. A., 2001. The evolution of electroreception and bioelectrogenesis in teleost fish: a phylogenetic perspective Journal of Fish Biology 58(6): 1489-511.

BABUSHOK DV, OSTERTAG EM, KAZAZIAN HH JR. 2007. Current topics in genome evolution: molecular mechanisms of new gene formation. ell Mol Life Sci 64: $542-554$.

BAKER, W. J., HEDDERSON, T. A., DRANSFIELD, J., 2000. Molecularphylogenetics of Calamus (Palmae) and related rattan genera based on 5SnrDNA spacer sequence data. Mol. Phylogenet. Evol. 14: 218-231.

BARRET, R. D. H., HEBERT, P. D. N., 2005. Identifying spiders through DNA barcodes.Can. J. Zool. 83: 481-491.

BATZER M A, DEININGER P L. 2002. Alu repeats and human genomic diversity. Nat Rev Genet 3: 370-379.

BAUM, B. R., BAILEY, L. G., BELYAYEV, A., RASKINA, O., NEVO, E., 2004. Theutility of the nontranscribed spacer of $5 \mathrm{~S}$ rDNA units grouped into unitclassesassignd to haplomes - a test on cultivated wheat and wheatprogenitors. Genome 47: 590-599. 
BAUM, B. R., JOHNSON, D. A., 2007. The 5S DNA sequences in Hordeumbogdaniiand in the $\mathrm{H}$. brevisubulatum complex, and the evolution and the geographicdispersal of the diploid Hordeum species (Triticeae: Poaceae). Genome 50:114.

BICKFORD D, LOHMAN DJ, SODHI NS, NG PKL, MEIER R, WINKER K, INGRAM KK, DAS I. 2006. Cryptic species as a window on diversity and conservation. Trends in Ecology and Evolution 22(3): 148-155.

BOURQUE G, LEONG B, VEGA VB, CHEN X, LEE YL, SRINIVASAN KG, CHEW JL, RUAN Y, WEI CL, NG HH, LIU ET, 2008. Evolution of the mammalian transcription factor binding repertoire via transposable elements. Genome Res 18:17521762 .

BUCKLIN, A., WIEBE, P.H., SMOLENACK, S.B., COPLEY, N.J., BEAUDET, J.G., BONNER, K.G., F“ARBER-LORDA, J., PIERSON, J.J., 2007. DNA barcodes for species identification of euphausiids (Euphausiacea, Crustacea). Journal of Plankton Research 29, 483-493.

CACERES M, RANZ JM, BARBADILLA A, LONG M, RUIZ A. 1999. Generation of a widespread Drosophila inversion by a transposable element. Science 285 : 415-418.

CAMPO D, MACHADO-SCHIAFFINO G, HORREO JL, GARCIA-VAZQUEZ E, 2009. Molecular organization and evolution of 5S rDNA in the genus Merluccius and their phylogenetic implications. J Mol Evol 68: 208-216.

CAMPOS-DA-PAZ, R., 1997. Sistemática e taxonomia dos peixes elétricos das bacias dos rios Paraguai, Paraná e São Francisco, com notas sobre espécies presentes em rios costeiros do leste do Brasil (Teleostei: Ostariophysi: Gymnotiformes). Tese de Doutoramento. Instituto de Biociências, Universidade de São Paulo, São Paulo.

CAPriglione, T., OdiernA, G., CAPUTO, V., CANAPA, A., OlMO, E., 2002. Characterization of a Tcl-like transposon in the Antartic ice fish, Chinodraco hamatus. Gene 295: 193-198. 
CLARO, F. L., 2008. Gymnotus carapo e Gymnotus sylvius (Teleostei:

Gymnotidae): uma abordagem citogenético-molecular Dissertação de Mestrado, Universidade de São Paulo.

DEININGER P L, ROY-ENGEL A M. 2002. Mobile elements in animal and plant genomes. InMobileDNAII (ed. NLCraig et al.) ASMPress, Washington, DC.

DUVERNELL, D. D., TURNER, B. J., 1998. Swimer 1, a new LINE family in teleost genomes with sequence similarity by mammalian L1. Mol Biol Evol 15: 1791-1793.

EICHLER EE, SANKOFF D. 2003. Structural dynamics of eukaryotic chromosome evolution. Science 301: 793-797.

EASTMAN, J. T., DAVIDSON, W., 1994. Antartic Fish Biology. In: Hecht, M. K. (Ed.) Academic Press, San Diego.

SILVA, M., MATOSO, D.A., VICARI, M.R., DE ALMEIDA, M.C., MARGARIDO, V.P., ARTONI, R.F., 2011. Physical Mapping of 5S rDNA in Two Species of Knifefishes: Gymnotus pantanal and Gymnotus paraguensis (Gymnotiformes). Cytogenet Genome Res June 3

FESCHOTTE C, 2008. Transposable elements and the evolution of regulatory networks. Nat Rev Genet 9:397-405.

FERREIRA, I. A., OLIVEIRA, C., VENERE, P. C., GALETTI JR, P. M., MARTINS, C., 2007. 5S rDNA variation and its phylogenetic inference in the genus Leporinus (Characiformes: Anostomidae). Genetica 129: 253-257.

FERNANDES-MATIOLI, F. M. C., ALBERT, J. S., LOPES, C. E., CRAMPTON, W. G. R., ALMEIDA-TOLEDO, L. F., 2005. A new Gymnotus (Teleostei: Gymnotiformes: Gymnotidae) from the Pantanal Matogrossense of Brazil and adjacent drainages: continued documentation of a cryptic fauna. Zootaxa 933: 1-14.

FINNEGAN D J (1989). Eukaryotic transposable elements and genome evolution. Trends Genet 5(4):103-107 
GARLAND ED, ZIMMER CA (2002) Techniques for the identiWcation of bivalve larvae. Mar Ecol Prog Ser 225:299-310.

GOODIER, J.L., AND KAZAZIAN, H.H., JR. 2008. Retrotransposons revisited: the restraint and rehabilitation of parasites. Cell 135, 23-35.

GRAY Y H. 2000. It takes two transposons to tango: transposableelement- mediated chromosomal rearrangements. Trends Genet 16: 461-468.

HAMDI HK, NISHIO H, TAVIS J, ZIELINSKI R, DUGAICZYK A. 2000. Alumediated phylogenetic novelties in gene regulation and development. J Mol Biol 299: 931-939.

HANCKS DC, KAZAZIAN HH JR. 2010. SVA retrotransposons: evolution and genetic instability. Semin Cancer Biol 20: 234-245.

HASLER J, SAMUELSSON T, STRUB K. 2007. Useful “junk”: Alu RNAs in the human transcriptome. Cell Mol Life Sci 64: 1793-1800.

HEBERT, P.D.N., CYWINSKA, A., BALL, S.L., DEWAARD, J.R., 2003. Biological identifications through DNA barcodes. In: Proceedings of the Royal Society of London Series B, Biological Sciences 270, 313-321.

HEBERT, P.D.N.; STOECKLE, M.Y.; ZEMLAK, T.S.; FRANCIS, C.M. Identification of birds through DNA barcodes. PLoS Biol. 2004, 2, 1657-1663.

HEBERT, P.D.N., PENTON, E.H., BURNS, J.M., JANZEN, D.H., HALLWACHS, W., 2004a. Ten species in one: DNA barcoding reveals cryptic species in the neotropical skipper butterfly Astraptes fulgerator. In: Proceedings of the National Academy of Sciences of the United States of America101,14812-14817.

HENNING, F., MOYSÉS, C. B., CALCAGNOTTO, D., MEYER, A., ALMEIDATOLEDO, L. F., 2010.Independent fusions and recent origins of sex chromosomes in the evolution and diversification of glass knife fishes (Eigenmannia).Heredity (2010): $1-10$.

HENNING, F., 2007. Evolução dos cromossomos sexuais no gênero Eigenmannia (Teleostei: Gymnotiformes) Dissertação de Mestrado, Universidade de São Paulo. 
HEBERT, P. D. N, RATNASINGHAM, S., DEWAARD, J. R. 2003b. Barcoding animal life: cytochrome $c$ oxidase 1 divergences among closely related species. Proc. R. Soc. Lond. B Biol. Sci. 270(Suppl.): S596-S599.

HUBERT, N., HANNER, R., HOLM., E, MANDRAK, N. E., TAYLOR, E., BURRIDGE, M, WATKINSON, D., DUMONT, P., CURRY, A., BENTZEN, P., ZHANG, J., APRIL, J., BERNATCHEZ, L., 2008. Identifying Canadian freshwater fishes through DNA barcodes.PLoS ONE 3(6): e 2490.

HEBERT, P. D. N., PENTON, E. H., BURNS, J. M., JANZEN, D. H., HALLWACHS, W., 2004b. Ten species in one: DNA barcoding reveals cryptic species in the neotropical skipper butterfly Astrapesfulgerator. PNAS USA 101(41): 14812-14817.

HEBERT, P. D. N., STOECKLE, M. Y., ZEMLAK, T. S., FRANCIS, C. M., 2004a. Identification of birds through DNA barcodes.PLoS Biol. 2: 1657-1663.

HIGASHIYAMA, T., NOUTOSHI, Y., FUJIE, M., YAMADA, T., 1997. Zeep, a LINE-like retrotransposon accumulated in the Chlorella telomeric region. EMBO J 16: $3715-3723$.

HOGG, I. D., HEBERT, P. D. N. 2004. Biological identifications of springtails (Hexapoda: Collembola) from the Canadian Arctic using mitochondrial DNA barcodes. Can J. Zool. 82(5): 749-754.

HURST, G. D. D., WERREN, J. H., 2001. The Role of Selfish Genetic Elements in Eukariotic Evolution. Nature Reviews 2: 597-606.

IVANOVA, N.V.; BORISENKO, A.V.; HEBERT, P.D.N. Express barcodes: racing from specimen to identification. Mol. Ecol. Resour. 2009, 9, 35-41.

JURKA J. 1995. Origin and evolution of Alu repetitive elements. In Impact of short interspersed elements (SINEs) on the host genome (ed. RJ Maraia), pp. 25-41. Landes Company, Austin, TX.

KAPITONOV, V. V., JURKA, J., 2003. A novel class of SINE derived from 5S rRNA. Mol Biol Evol 20 (5): 694-702. 
KAPITONOV V, JURKA J (2008) A universal classification of eukaryotic transposable elements implemented in Repbase Nat Rev Genet 9(5):411-412

KAZAZIAN H H JR. 2004. Mobile elements: drivers of genome evolution. Science 303: $1626-1632$.

KAWAI K, NIKAIDO M, HARADA M, MATSUMURA S, LIN LK,WU Y, HASEGAWA M, OKADA N. 2002. Intra- and interfamily relationships of Vespertilionidae inferred by variousmolecular markers including SINE insertion data.JMol Evol 55: 284-301.

KEMPPAINEN, P.; PANOVA, M.; HOLlANDER, J.; JOHANNESSON, K. Complete lack of mitochondrial divergence between two species of NE Atlantic marine intertidal gastropods. J. Evol. Biol. 2009, 22, 2000-2011

KIDWELL, M. G., LISH, D. R., 2000. Transposable elements and host genome evolution. Trends Ecol. Evol. 15: 95-99.

KIDWELL, M. G., 2002. Transposable elements and the evolution of genome size ineukaryotes. Genetica 115: 49-63.

KITAMURA, S., TANAKA, A., INOUE, M., 2005. Genomic relationships among Nicotiana species with different ploidy levels revealed by 5S rDNA spacersequences and FISH/GISH. Genes Genet. Syst. 80:251-260.

KOMIYA, H., AND TAKEMURA, S., 1979. Nucleotide sequence of 5S ribosomal RNA from rainbow trout (Salmogairdneri) liver.J. Biochem. 86: 1067-1080.

LANDER ES, LINTON LM, BIRREN B, NUSBAUM C, ZODY MC, BALDWIN J, DEVON K, DEWAR K, DOYLE M, FITZHUGH W, FUNKE R, GAGE D, HARRIS K, HEAFORD A, HOWLAND J, KANN L, LEHOCZKY J, LEVINE R, MCEWAN P, MCKERNAN K, MELDRIM J, MESIROV JP, MIRANDA C, MORRIS W, NAYLOR J, RAYMOND C, ROSETTI M, SANTOS R, SHERIDAN A, SOUGNEZ C. Initial sequencing and analysis of the human genome. Nature 2001, 409:860-921.

LANGEANI, F., CASTRO, R.M.C., OYAKAWA, O.T., SHIBATTA, O.A., PAVANELLI, C.S., CASATTI, L., 2007.Diversidade da ictiofauna do Alto Rio Paraná: 
composição atual e perspectivas futuras. Biot. Neotrop. 7(3):181-197, http://www.biotaneotropica.org.br/v7n3/pt/fullpaper?bn03407032007+pt (último acesso em 29/07/2010).

LIM JK, SIMMONS MJ. 1994. Gross chromosome rearrangements mediated by transposable elements in Drosophila melanogaster. Bioessays 16: 269-275.

LONNIG WE, SAEDLER H. 2002. Chromosome rearrangements and transposable elements. Annu Rev Genet 36: 389-410.

LONG, E. O., David, I. D. 1980.Repeated genes in eukaryotes.Annu.Rev. Biochem. 49: $727-764$.

LOWE-MCCONNELL, R.H., 1999. Estudos ecológicos de comunidades de peixes tropicais. Edusp, São Paulo.

LOWE CB, BEJERANO G, HAUSSLER D. 2007. Thousands of human mobile element fragments undergo strong purifying selection near developmental genes. Proc Natl Acad Sci 104: 8005-8010.

MAGO-LECCIA, F., 1994.Eletric fishes of the continental waters of America. Bibl de La Acad. Cienc. Fis. Mat. Nat. 29: 1-225. Caracas, Venezuela.

MATLIK K, REDIK K, SPEEK M. 2006. L1 antisense promoter drives tissue-specific transcription of human genes. J Biomed Biotechnol 1: 1-16.

MATHIOPOULOS KD, DELLA TORRE A, PREDAZZI V, PETRARCA V, COLUZZI M. 1998. Cloning of inversion breakpoints in the Anopheles gambiae complex traces a transposable element at the inversion junction. Proc Natl Acad Sci 95: $12444-12449$.

MARTINS C, WASKO A P, 2004. Organization and evolution of 5S ribosomal DNA in the fish genome. In Williams CR (Ed) Focus on Genome Research. Nova Science Publishers Hauppauge NY 335-363.

MCCLINTOCK B (1948) Mutable loci in maize. Carnegie Institute of Washington Year Book 47:155-169 
MCCLINTOCK B (1950) The origin and behavior of mutable loci in maize. Proc Natl Acad Sci USA 36(6):344-355

MIKKELSEN TS,WAKEFIELD MJ, AKEN B, AMEMIYA CT, CHANG JL, DUKE S, GARBER M, GENTLES AJ, GOODSTADT L, HEGER A. 2007. Genome of the marsupial Monodelphis domestica reveals innovation in non-coding sequences. Nature 447: $167-177$.

MORESCALCHI, A., CAPRIGLIONE, T., LANNA, R., MORESCALCHI, M.A., ODIERNA, G., OLMO, E., 1996. Genome structure in notothenioid fish from the Ross Sea. Proc. Third Meeting on Antartic Biology, PP. 365-379.

MURATA S, TAKASAKI N, SAITOH M, OKADA N. 1993. Determination of the phylogenetic relationships among Pacific salmonids by using short interspersed elements (SINEs) as temporal landmarks of evolution. Proc Natl Acad Sci 90: 69956999.

MURATA S, TAKASAKI N, OKAZAKI T, KOBAYASHI T, NUMACHI K, CHANG K-H, OKADA N. 1998. Molecular evidence from short interspersed elements (SINEs) that Onchorhynchus masou (cherry salmon) is monophyletic. Can J Fish Aquat Sci 55: $1864-1870$.

NELSON, J.S., 2006. Fishes of the world.Third Edition.New York, John Willey \& Sons, Inc. $600 \mathrm{p}$.

NIGUMANN P, REDIK K, MATLIK K, SPEEK M. 2002. Many human genes are transcribed from the antisense promoter of L1 retrotransposon. Genomics 79: 628-634.

NIKAIDO M, MATSUNO F, HAMILTON H, BROWNELL R L JR, CAO Y,DING W, ZUOYAN Z, SHEDLOCK AM, FORDYCE RE, HASEGAWA M, et al. 2001. Retroposon analysis of major cetacean lineages: The monophyly of toothed whales and the paraphyly of river dolphins. Proc Natl Acad Sci 98: 7384-7389.

NISHIHARA H, SATTA Y, NIKAIDO M, THEWISSEN JGM, STANHOPE MJ, OKADA N. 2005. A retroposon analysis of Afrotherian phylogeny. Mol Biol Evol 22: $1823-1833$. 
NISHIHARA H, HASEGAWA M, OKADA N. 2006. Pegasoferae, an unexpected mammalian clade revealed by tracking ancient retroposon insertions. Proc Natl Acad Sci 103: 9929-9934.

NOUAUD D, QUESNEVILLE H, ANXOLABEHERE D. 2003. Recurrent exon shuffling between distant P-element families. Mol Biol Evol 20: 190-199.

OKADA N, HAMADA M, OGIWARA I, OHSHIMA K, 1997. SINEs and LINEs share common 3'sequences: a review. Gene 205(1-2):229-243

OLIVEIRA, C., CHEW, J. S. K., PORTO-FORESTI, F., DOBSON, M. J., WRIGHT, J.M., 1999. A LINE2 repetitive DNA sequence from the cichlid fish, Oreochromis niloticus: sequence analysis and chromosomal distribution. Chromosoma 108: 457-468.

OHSHIMA, K. HAMADA, M., TERAI, Y., OKADA, N., 1996. The 3' end of rRNAderived short interspersed repetitive elements are derived from the 3' ends Fo long interspersed repetitive elements. Mol Cell Biol 16: 3765-3764.

PARISE-MAlTEMPI, P. P., MARTINS, C., OLIVEIRA, C., FORESTI, F., 2007. Identification of a new repetitive element in the sex chromosomes of Leporinus elongatus (Teleostei: Characiformes: Anostomidae): new insights into the sex chromosomes of Leporinus. Cytogenet Genome Res 116: 218-223.

PEASTON AE, EVSIKOV AV, GRABER JH, DE VRIES WN, HOLBROOK AE, SOLTER D, KNOWLES BB. 2004. Retrotransposons regulate host genes in mouse oocytes and preimplantation embryos. Dev Cell 7: 597-606.

EL-TWAB M. H. AND KONDO K., 2012. Physical mapping of 5S and 45S rDNA in Chrysanthemum and related genera of the Anthemideae by FISH, and species relationships. J. Genet. 91, 245-249

PHILLIPS, R. B., FABER-HAMMOND, J., LUCKENBACH, J. A. 2012. The sablefish (Anoplopoma fimbria) karyotype including the location of $5 \mathrm{~S}$ and $18 \mathrm{~S}$ rDNA and information on cell culture conditions. Aquaculture Research 2012, 1-4.

TRALDI, J. B., BLANCO, D. R., VICARI, M. R., MARTINEZ, J. F., LUI, R. I., BARROS, A. V., ARTONI, R. F., MOREIRA-FILHO, O. 2013. Chromosomal 
diversity in Hypostomus (Siluriformes, Loricariidae) with emphasis on physical mapping of 18S and 5S rDNA sites. Genet. Mol. Res. 12 (1): 463-471

PENDÁS, A.M., MÓRAN, P., MARTÍNEZ, J.L., GARCIA-VÁSQUEZ, E. 1995. Applications of 5S rDNA in Atlantic salmon, brown trout, and in Atlanticsalmon $\times$ brown trout hybrid identification. Mol. Ecol. 4: 275-276.

ROBLES, F., DE LA HERRAN, R., LUDWIG, A., RUIZ-REJON C, RUIZ-REJON, M., GARRIDO RAMOS M (2005) Genomic organization and evolution of the 5S ribosomal DNA in the ancient fish sturgeon. Genome 48:18-28.

SMITH, G.P., 1976. Evolution of repeated DNA sequences by unequal crossover. Science, v.191, p.528-35

SMITH, P.J., STEINKE, D., MCVEAGH, S.M., STEWART, A.L., STRUTHERS, C.D., ROBERTS, C.D., 2008. Molecular analysis of Southern Ocean skates (Bathyraja) reveals a new species of Antarctic skate. Journal of Fish Biology 73,1170-1182.

SCHMITZ J, ROOS C, ZISCHLER H. 2005. Primate phylogeny: molecular evidence from retroposons. Cytogenet Genome Res 108: 26-37.

SPEEK M. 2001. Antisense promoter of human L1 retrotransposon drives transcription of adjacent cellular genes. Mol Cell Biol 21: 1973-1985.

STEINKE, D., ZEMLAK, T.S., HEBERT, P.D.N., 2009a. Barcoding Nemo: DNAbased identifications for the ornamental fish trade. PLoSOne 4, e6300.

STONEKING M, FONTIUS JJ, CLIFFORD SL, SOODYALL H, ARCOT SS, SAHA N, JENKINS T, TAHIR MA, DEININGER PL, BATZERMA. 1997. Alu insertion polymorphisms and human evolution: evidence for a larger population size in Africa. Genome Res 7: 1061-1071.

SIDDALL, M.E.; FONTANELLA, F.M.; WATSON, S.C.; KVIST, S.; ERSÉUS, C. Barcoding bamboozled by Bacteria: convergence to metazoan mitochondrial primer targets by marine microbes. Syst. Biol. 2009, 58, 445-451. 
TAMURA K, DUDLEY J, NEI M, KUMAR S. 2007. MEGA 4: Molecular Evolutionary Genetics Analysis (MEGA) Software Version 4.0. Molecular BiologyEvolution 24: 1596-1599.

TAKAHASHI, K., Y. TERAI, M. NISHIDA, AND N. OKADA., 1998. A novel family of short interspersed repetitive elements (SINEs) from cichlids: the patterns of insertion of SINEs at orthologous loci support the proposed monophyly of four major groups of cichlid fishes in Lake Tanganyika. Mol. Biol. Evol. 15:391-407.

TATOUT C, WARWICK S, LENOIR A, DERAGON JM. 1999. SINE insertions as clade markers for wild crucifer species. Mol Biol Evol 16: 1614-1621.

TERAI, Y., K. TAKAHASHI, AND N. OKADA., 1998. SINE cousins: the 39-end tails of the two oldest and distantly related families of SINEs are descended from the 39 ends of LINEs with the same genealogical origin. Mol. Biol. Evol. 15:1460-1471.

TRIQUES, M. L., 1993. Filogenia dos gêneros de Gymnotiformes (Actinopterygii, Ostariophysi), com base em caracteres esqueléticos. Comum. Mus. Ciênc. PUCRS, sér Zool. 6: 85-130.

WANG T, ZENG J, LOWE CB, SELLERS RG, SALAMA SR, YANG M, BURGESS SM, BRACHMANN RK, HAUSSLER D, 2007. Species-specific endogenous retroviruses shape the transcriptional network of the human tumor suppressor protein p53. Proc Natl Acad Sci USA 104:18613-18618.

WARD, R. D., ZEMLAK, T. S., INNES, B. H., LAST, P. R., HEBERT, P. D. N. 2005. DNA barcoding Australia’s fish species. Phil. Trans. R. Soc. B 360: 1847-1857.

WATERSTON RH, LINDBLAD-TOH K, BIRNEY E, ROGERS J, ABRIL JF, AGARWAL P, AGARWALA R, AINSCOUGH R, ALEXANDERSSON M, AN P, ANTONARAKIS SE, ATTWOOD J, BAERTSCH R, BAILEY J, BARLOW K, BECK S, BERRY E, BIRREN B, BLOOM T, BORK P, BOTCHERBY M, BRAY N, BRENT MR, BROWN DG, BROWN SD, BULT C, BURTON J, BUTLER J, CAMPBELL RD, CARNINCI P. Initial sequencing and comparative analysis of the mouse genome. Nature 2002, 420:520-562. 
WEIL CF,WESSLER SR. 1993. Molecular evidence that chromosome breakage by Ds elements is caused by aberrant transposition. Plant Cell 5: 515-522.

WITHERSPOON DJ, MARCHANI EE,WATKINS WS, OSTLER CT,WOODING SP, ANDERS BA, FOWLKES JD, BOISSINOT S, FURANO AV, RAY DA. 2006. Human population genetic structure and diversity inferred from polymorphic L1(LINE-1) and Alu insertions. Hum Hered 62: 30-46.

WITT JDS, THRELOFF DL, HEBERT PDN. 2006. DNA barcoding reveals extraordinary cryptic diversity in an amphipode genus: implications for desert spring conservation. Molecular Ecology 15: 3073-3082.

YAMADA, K., KAMIMURA E., KONDO, M., TSUCHIYA, K., NISHIDAUMEHARA, C., MATSUDA, Y., 2005. Nem familes of site-specific repetitive DNA sequences that comprise contitutive hetrochromatin of the Syrian hamster (Mesocricetus auratus, Cricetinae, Rodentia). Chromosoma 115: 36-49.

YASSIN, A, CAPY, P., MADI-RAVAZZI, L., OGEREAU, D., DAVID, J. R. 2008. DNA barcode discovers two cryptic species and two geographical radiations in the invasive drosophilid Zaprionusindianus. Molecular Ecology Resources 8: 491-501.

PHILLIPS, R. B., FABER-HAMMOND, J., LUCKENBACH, J. A. 2012. The sablefish (Anoplopoma fimbria) karyotype including the location of $5 \mathrm{~S}$ and $18 \mathrm{~S}$ rDNA and information on cell culture conditions. Aquaculture Research 2012, 1-4.

RATNASINGHAM S, HEBERT P. D. N, 2007. BOLD: the Barcode of Life Data System (www.barcodinglife.org). Molecular Ecology Notes, 7, 355-364.

SONG, H.; BUHAY, J.E.; WHITING, M.F.; CRANDALL, K.A. Many species in one: DNA barcoding overestimates the number of species when nuclear mitochondrial pseudogenes are coamplified. Proc. Natl. Acad. Sci. USA 2008, 105, 13486-13491.

TERAI, Y., K. TAKAHASHI, AND N. OKADA., 1998. SINE cousins: the 39-end tails of the two oldest and distantly related families of SINEs are descended from the 39 ends of LINEs with the same genealogical origin. Mol. Biol. Evol. 15:1460-1471. 
TRALDI, J. B., BLANCO, D. R., VICARI, M. R., MARTINEZ, J. F., LUI, R. I., BARROS, A. V., ARTONI, R. F., MOREIRA-FILHO, O. 2013. Chromosomal diversity in Hypostomus (Siluriformes, Loricariidae) with emphasis on physical mapping of 18S and 5S rDNA sites. Genet. Mol. Res. 12 (1): 463-471

VIDAL F, MOUGNEAU E, GLAICHENHAUS N, VAIGOT P, DARMON M, CUZIN F. 1993. Coordinated posttranscriptional control of gene expression by modular elements including Alu-like repetitive sequences. Proc Natl Acad Sci 90: 208-212.

WAGNER, R. P., MAGUiRE, M. P., STAllingS, R. L., 1993. Chromosomes: a stynthesis. Wiley-Liss, Inc., New York.

WICKER T, MATTHEWS DE, KELLER B (2002) TREP: a database for Triticeae repetitive elements. Trends Plant Sci 7(12):561-562

WINKFEIN, R. J., MOIR, R. D., KRAWETZ, A. S., BLANCO, J., STATES J. C., DIXON, G. H., 1998. A new family of repetitive, retrotransposon-like sequences in the genome of the raibow trout. Eur J Biochem 176: 255-264.

XIAO FX, YANG JF, CASSIMAN JJ, DECORTE R. 2002. Diversity at eight polymorphic Alu insertion loci in Chinese populations shows evidence for European admixture in an ethnic minority population from northwest China. Hum Biol 74: 555568.

XING J, WANG H, HAN K, RAY DA, HUANG CH, CHEMNICK LG, STEWART CB, DISOTELL TR, RYDER OA, BATZER MA. 2005. A mobile element based phylogeny of Old World monkeys. Mol Phylogenet Evol 37: 872-880.

XING J, WANG H, ZHANG Y, RAY DA, TOSI AJ, DISOTELL TR, BATZER MA. 2007. A mobile element-based evolutionary history of guenons (tribe Cercopithecini). BMC Biol 5: 5.

ZHANG J, PETERSON T. 2004. Transposition of reversed Ac element ends generates chromosome rearrangements in maize. Genetics 167: 1929-1937. 


\section{Capítulo 2}

DNA barcoding of the species complex Eigenmannia

virescens (Teleostei: Gymnotiformes: Sternopygidae) from Upper Paraná River Basin 


\section{Introdução}

A ordem Gymnotiformes compreende um grupo monofilético de peixes endêmicos da região Neotropical que representa um componente importante da ictiofauna de água doce. Nessa ordem estão incluídas cinco famílias, com um total de 29 gêneros e mais de 130 espécies, muitas ainda não descritas (Albert, 2001). O conhecimento sobre esse grupo de peixes tem avançado com estudos sobre relações filogenéticas inter e intra-específicas, baseados em dados morfológicos, moleculares, neuro-anatômicos, fisiológicos e de fósseis (Triques, 1993; Mago-Leccia, 1994; AlvesGomes et al., 1995; Albert \& Campos-da-Paz, 1998; Albert, 2001, bem como em estudos cromossômicos, em especial nos gêneros Eigenmannia e Gymnotus (Almeida Toledo et al., 1996, 2000, 2001a, 2001b, 2002; Fernandes-Matioli et al., 2005; Albert et al. 1999. Entretanto ainda há vários problemas taxonômicos relevantes em diversos níveis da ordem Gymnotiformes, sendo que grande parte dos gêneros e espécies do grupo aguarda revisões (Campos-da-Paz, 1997).

O gênero Eigenmannia (Sternopygidae) faz parte da ordem Gymnotiformes, grupo no qual a morfologia das espécies é tipicamente serpentiforme e que apresenta distribuição exclusivamente neotropical (Albert, 2001). São reconhecidas oito espécies válidas para o gênero Eigenmannia com data de separação estimada em 16Ma. A diversidade de espécies não pode ainda ser estabelecida devido à necessidade de uma revisão taxonômica no gênero e pelo fato de as espécies já descritas para esse gênero serem, provavelmente, na realidade, grupos de espécies crípticas (Albert, 2003; Henninget al., 2010).

Um número expressivo de estudos citogenéticos já foi publicado sobre populações locais de Eigenmannia, com enfoque basicamente na bacia superior do Rio 
Paraná e na bacia do Rio São Francisco. As populações de Eigenmannia já descritas citogeneticamente apresentam ampla variabilidade cariotípica e diversos sistemas sexuais incluindo sistemas XY e ZW (Almeida-Toledo et al. 2002). Nas bacias dos rios Tietê, Paranapanema e Mogi-Guaçu (SP), ocorrem populações com cariótipos que apresentam números cromossômicos variando entre 28 e 38 com presença ou não de cromossomos sexuais heteromórficos (Almeida Toledo \& Foresti, 2001). Uma análise filogenética recente destes citótipos revelou um padrão de labilidade dos sistemas de determinação sexual e uma maior conservação do número cariotípico (Henning et al., 2010). Segundo Henning et al. (2010), a reconstrução filogenética das diversas espécies de Eigenmannia com base em genes mitocondriais mostrou que aquelas que possuem sistemas sexuais agrupam com aquelas nos quais os sistemas não estão presentes. Esse seria um indício de que a diferenciação dos cromossomos sexuais é recente, levantando assim uma hipótese sobre a origem múltipla desse sistema, fato também verificado por Henning (2007), em estudo no qual a realização de um experimento com sondas específicas para os cromossomos sexuais não demonstrou similaridades entre espécies que possuem sistemas sexuais distintos, reforçando a possível origem múltipla do sistema.

Inúmeros estudos têm utilizado o espaçador não transcrito (NTS) presente na família multigênica que codifica para o RNA ribossômico $5 \mathrm{~S}$ como uma ferramenta para o estudo entre espécies intimamente relacionadas, fato esse diretamente associado à elevada dinâmica dessa região genômica, apresentando, portanto, uma grande quantidade de sítios informativos, os quais são utilizados na reconstrução de filogenias (Baker et al., 2000; Baumet al., 2004; Kitamura et al., 2005; Baum \& Johnson, 2007). Em peixes o NTS foi utilizado em diversos grupos para a identificação de espécies intimamente relacionadas, subespécies, linhagens e híbridos (Pendas et al., 1995; 
Martins \& Wasko, 2004; Robles et al., 2005; Irani et al., 2007). São escassos os estudos envolvendo o gene ribossômico $5 \mathrm{~S}$ juntamente com seu NTS, na reconstrução das relações dentre os Gymnotiformes, sendo a grande maioria dos trabalhos relacionada apenas à localização física das sequências do gene determinadas através de hibridação in situ (Silva et al., 2011). Uma nova abordagem para a identificação de espécies foi introduzida por Hebert et al. (2003), que propôs o uso de um pequeno fragmento do genoma mitocondrial para essa identificação através dos filos do reino animal e estabeleceu o termo DNA barcoding para essa abordagem. As razões para a escolha do DNA mitocondrial em detrimento ao DNA nuclear inclui a herança uniparental (maioria dos filos animais), elevada taxa evolutiva, ausência de introns e um número elevado de cópias por célula. A proposta da utilização do gene COI para o DNA barcoding não foi arbitrária, uma vez que foi verificado um sinal filogenético tanto para níveis acima e abaixo de espécie e que seus primers universais são capazes de recuperar a região 5' do gene COI em grande parte do filo animal. Essa técnica proposta por Hebert et al. (2003), mostrou-se um marcador molecular valioso para a identificação de espécies, sendo sua eficácia evidenciada em inúmeros trabalhos (Ward et al. 2005, Barret \& Hebert, 2005, Hubert et al. 2008; Hebert et al., 2003, 2004a; Ward et al., 2005; Bucklin et al., 2007; Smith et al., 2008; Steinke et al., 2009a). De acordo com essa abordagem, as espécies podem ser identificadas baseadas no gap entre as distâncias genéticas intra e interespecíficas usando uma margem entre 2-3\% ou o valor de 10 vezes para a delimitação de espécies (Herbert et al., 2004). Inúmeras espécies foram propostas, utilizando-se a técnica do DNA barcoding, as quais foram formalmente descritas posteriormente (Ward et al. 2008, Yassin et al. 2008, Witt et al. 2006).

Tendo em vista o potencial uso das sequências de DNA para a identificação de espécies (DNA barcode), o presente trabalho tem por objetivo avaliar o potencial de 
discriminação e identificação de espécies do gênero Eigenmannia utilizando-se o gene mitocondrial COI. Propõe-se também utilizar o NTS do gene ribossômico 5S como uma região controle, de modo a verificar a eficiência do gene COI na discriminação de espécies para o gênero em estudo.

\section{Material e Métodos}

No presente trabalho foram analisados 30 espécimes do gênero Eigenmannia da Bacia Superior do Rio Paraná (Fig. 1) Os exemplares foram obtidos em coletas do Laboratório de Ictiogenética, tendo como foco principal, a bacia do Paranapanema, na região de São Miguel Arcanjo e proximidades, local de ocorrência do citótipo $2 n=38$ $X Y$, e a bacia do alto e médio Tietê, local de ocorrência dos citótipos $2 n=38,2 n=36$, $2 n=31 / 32 \quad X_{1} X_{2} Y$ e $2 n=28$ (Tabela 1, Fig. 2). Foram também analisados materiais de tecidos e suspensões de células de espécies do gênero Eigenmannia disponíveis no Laboratório de Ictiogenética IB-USP. 


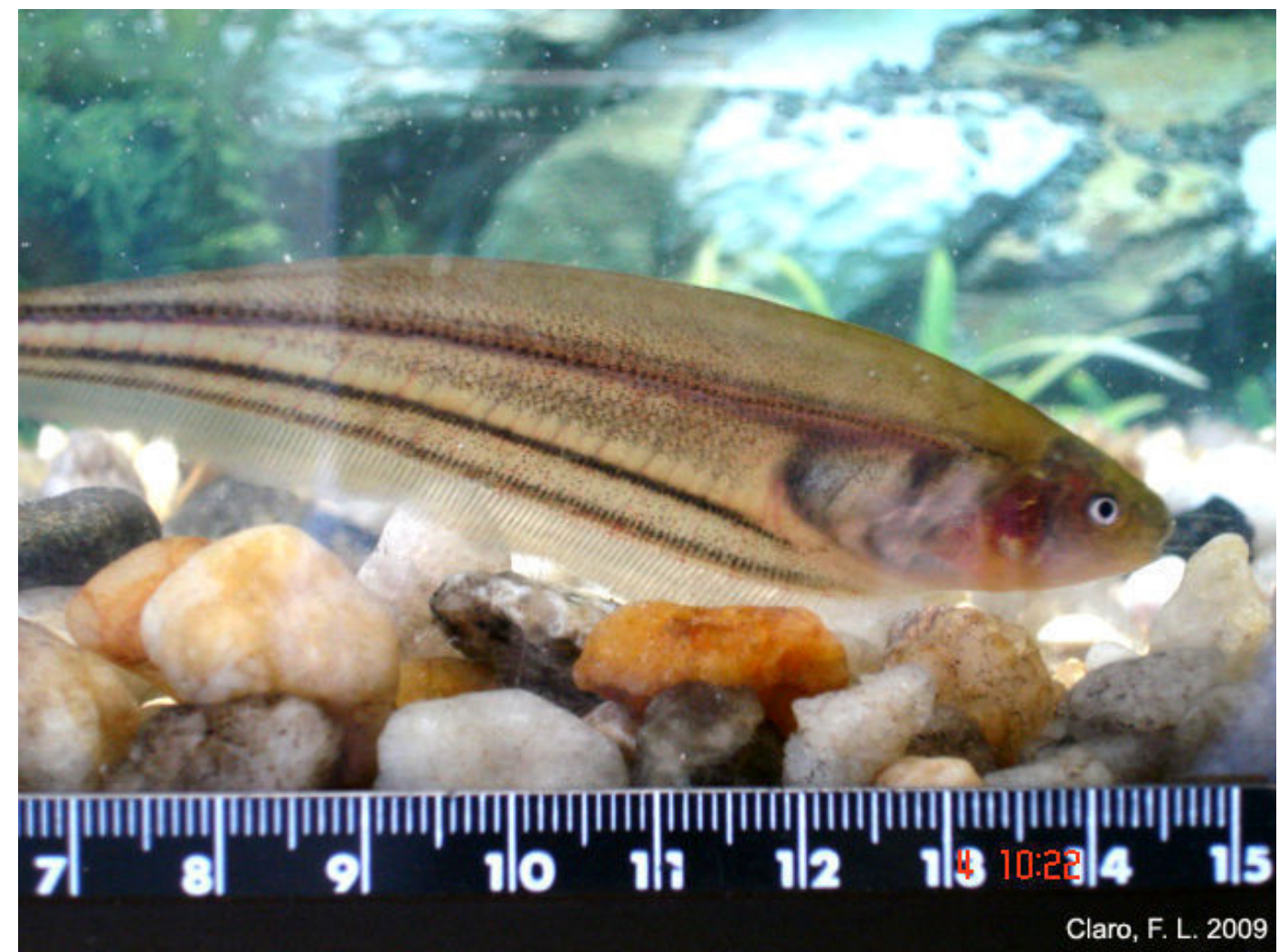

Figura 1: Exemplar do gênero Eigenmannia oriundo de Santa Albertina/SP

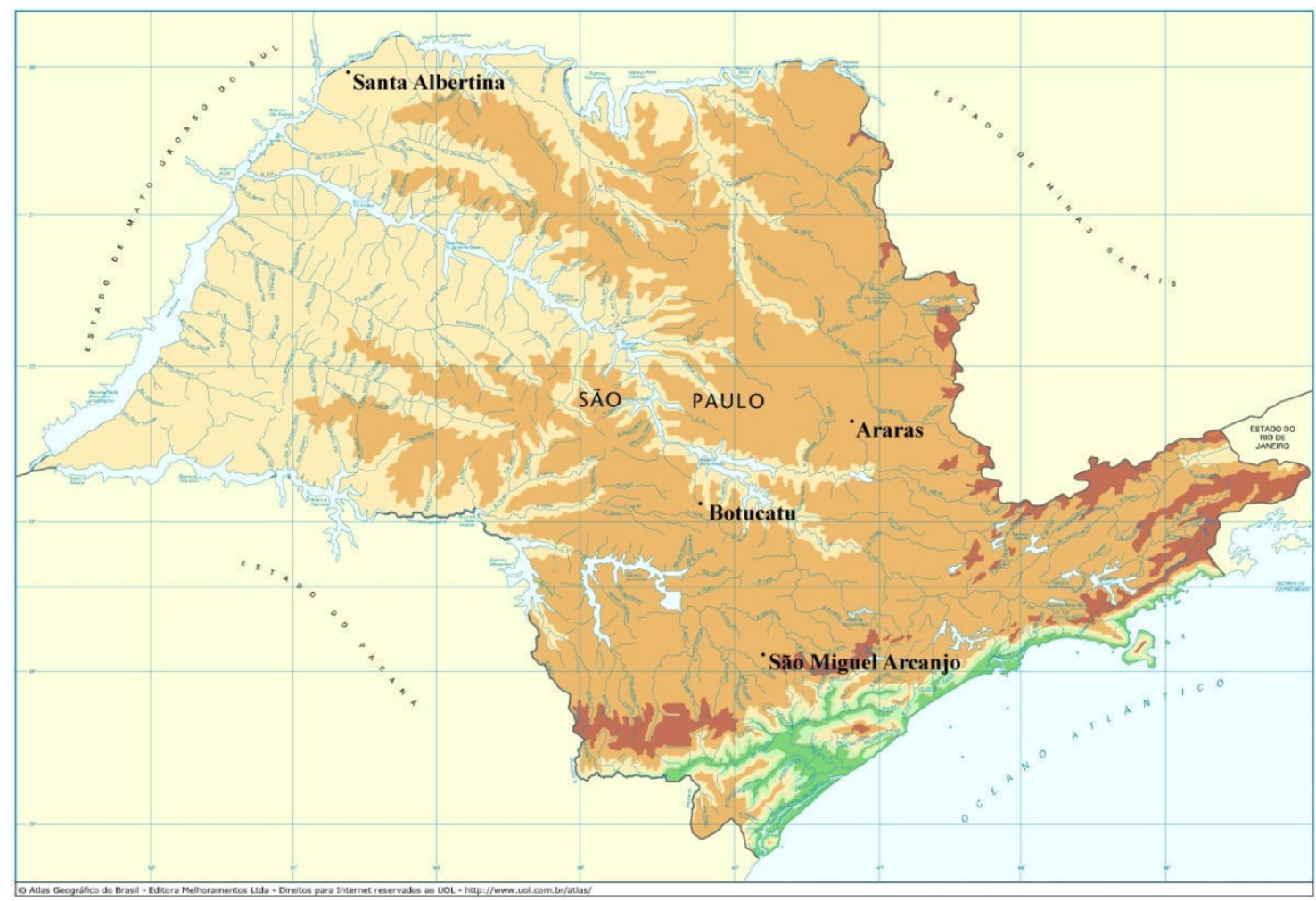

Figura 2: Mapa apontando os pontos de coleta das diversas amostras do gênero Eigenmannia no estado de São Paulo. 


\begin{tabular}{|c|c|c|}
\hline Cariomorfos & Localidade & Coordenadas GPS \\
\hline $2 \mathrm{n}=36$ & Santa Albertina & $19^{\circ} 57^{\prime} \mathrm{S} 50^{\circ} 45^{\prime} \mathrm{W}$ \\
\hline $2 \mathrm{n}=38$ e $2 \mathrm{n}=28$ & Araras & $22^{\circ} 23^{\prime} \mathrm{S} 47^{\circ} 25^{\prime} \mathrm{W}$ \\
\hline $2 \mathrm{n}=31 / 32 \mathrm{X}_{1} \mathrm{X}_{2} \mathrm{Y}$ & Botucatu & $22^{\circ} 44^{\prime} \mathrm{S} 48^{\circ} 28^{\prime} \mathrm{W}$ \\
\hline $2 \mathrm{n}=38 \mathrm{XY}$ & São Miguel Arcanjo & $20^{\circ} 11^{\prime} \mathrm{S} 49^{\circ} 41^{\prime} \mathrm{W}$ \\
\hline
\end{tabular}

Tabela 1: Relação de ocorrência de cariomorfos do gênero Eigenmannia no Estado de São Paulo.

\section{Extração do DNA Genômico}

O DNA total dos exemplares foi extraído utilizando-se o protocolo de extração salina (Aljanabi \& Martinez, 1997). Amostras a partir de tecidos do fígado, coração ou sangue, preservados em álcool 96\%, foram homogeneizadas em tampão salino $(\mathrm{NaCl}$ 0.6M, 10mM Tris- $\mathrm{HCl} \mathrm{pH} 8.0,2 \mathrm{mM}$ EDTA $\mathrm{pH} 8.0$ ), ao qual foi posteriormente adicionada proteinase K $(400 \mu \mathrm{g} / \mathrm{ml})$ e uma solução de SDS $20 \%$ (concentração final de 2\%). Após esse passo as amostras sofreram duas incubações consecutivas, sendo a primeira a $65^{\circ} \mathrm{C}$ por aproximadamente 1 hora e a segunda com a adição de RNase, a solução $(0.25 \mathrm{mg} / \mathrm{ml})$ por 1 hora a $37^{\circ} \mathrm{C}$. Foi então adicionada às amostras uma solução de $\mathrm{NaCl} 6 \mathrm{M}$ (concentração final de $2.38 \mathrm{M}$ ) e em seguida estas foram levadas ao vortex em alta velocidade por aproximadamente 1 minuto, sendo então centrifugadas a 10000G a $4^{\circ} \mathrm{C}$ por 30 minutos. O sobrenadante foi transferido para um tubo limpo, ao qual se adicionou o dobro de volume de isopropanol, misturando bem por inversão do tubo. Feito isso as amostras foram então incubadas a $-20^{\circ} \mathrm{C}$ por aproximadamente 1 hora e novamente centrifugadas a $10,000 \mathrm{~g} \mathrm{a} 4^{\circ} \mathrm{C}$ por 20 minutos. Terminado o processo, o sobrenadante foi descartado e o pellet lavado em etanol 70\% em uma centrifugação a $10,000 \mathrm{~g} \mathrm{a} 4^{\circ} \mathrm{C}$ por 10 minutos. O sobrenadante foi novamente descartado, o pellet 
secado ao ar e adicionado volume de água, para eluição do pellet, não superior a $50 \mu 1$, sendo esse volume determinado de acordo com o tamanho do pellet obtido.

\section{Amplificação do gene Citocromo Oxidase I e do gene ribossômico 5S}

A amplificação do gene mitocondrial COI foi feita utilizando-se os primers FISH F1 e FISH R1 (Ward et al., 2005). A reação teve o volume final de $25 \mu 1$, tendo como concentrações finais $1.5 \mathrm{mM}$ de $\mathrm{Mg}^{2+}, 0.4 \mathrm{pmol}$ para cada primer, $1 \mathrm{x}$ de tampão Taq Polimerase, 0.04mM dNTP Mix, 0.1U de Taq Polimerase. O ciclo básico para o gene mitocondrial COI consistiu em uma desnaturação a $94^{\circ} \mathrm{C}$ por 4 minutos, seguida de 40 ciclos de 1 minuto a $92^{\circ} \mathrm{C}, 1$ minuto a $50^{\circ} \mathrm{C}, 1$ minuto a $72^{\circ} \mathrm{C}$ e uma extensão final de 10 minutos a $72^{\circ} \mathrm{C}$. As sequências foram obtidas de modo direto, utilizando-se na reação de sequenciamento o produto de PCR, utilizando-se o kit BigDye ${ }^{\circledR}$ Terminator v3.1 CycleSequencing Kit (Life Technologies ${ }^{\mathrm{TM}}$ ), de acordo com as especificações do fabricante.

O gene ribossômico 5S, por sua vez, foi amplificado através da técnica de PCR (Polimerase Chain Reaction) utilizando-se os primers 5SA e 5SB (Komiya \& Takemura 1979). A reação foi realizada com volume final de $25 \mu 1$ tendo como concentrações finais $1 \mathrm{mM}$ de $\mathrm{Mg}^{2+}, 0.4 \mathrm{ng}$ de DNA genômico, 0.4 pmol de cada primer, $0.1 \mathrm{U}$ de Taq Polimerase, $0.04 \mathrm{mM}$ de dNTPmix, 1x de tampão Taq Polimerase. O ciclo básico para amplificação dessa região consiste em uma desnaturação a $94^{\circ} \mathrm{C}$ por 5 minutos, seguida de 24 ciclos de 1 minuto a $95^{\circ} \mathrm{C}, 30$ segundos a $61^{\circ} \mathrm{C}, 1$ minuto a $72^{\circ} \mathrm{C}$ e uma extensão final de 10 minutos a $72^{\circ} \mathrm{C}$. Posteriormente os produtos obtidos foram submetidos a nova amplificação, dessa vez utilizando-se uma polimerase proofreading ( $P f x 50^{\mathrm{TM}} \mathrm{DNA}$ Polymerase - Invitrogen). A reação foi feita para um volume final de $25 \mu 1$, tendo como concentrações finais $0.3 \mathrm{mM}$ dNTPmix, $0.3 \mathrm{pmol}$ de cada primer, $10 \mathrm{x}$ Pfx $50{ }^{\mathrm{TM}} \mathrm{PCR}$ Mix, 
0.1U Pfx50 ${ }^{\text {тм }}$ DNA Polymerase, 0.4 ng produto de PCR. O programa utilizado corresponde a uma desnaturação a $94^{\circ} \mathrm{C}$ por 5 minutos, seguida de 19 ciclos de 30 segundos a $94^{\circ} \mathrm{C}, 30$ segundos a $68^{\circ} \mathrm{C}, 15$ segundos a $72^{\circ} \mathrm{C}$ e um passo final de 5 minutos a $72^{\circ} \mathrm{C}$. Essa reação produzirá fragmentos de ponta cega, permitindo então a clonagem através do kit Zero Blunt TOPO $^{\circledR}$ (Invitrogen), realizada de acordo com as especificações do fabricante. Após a clonagem, uma reação de PCR utilizando-se os primers M13fe M13r foi feita para verificação da eficiência da clonagem e escolha das amostras, as quais estão dentro do tamanho esperado. A reação foi realizada com volume final de $25 \mu$, tendo como concentrações finais $1 \mathrm{mM}$ de $\mathrm{Mg}^{2+}, 0.04 \mathrm{mM}$ dNTP Mix, 0.1U de Taq Polimerase, 1x de tampão Taq Polimerase (NH4) ${ }_{2} \mathrm{SO}_{3}$ e $0.4 \mathrm{pmol}$ de cada primer (M13f e M13r). Uma vez feito o mix de reação, utilizou-se a técnica de toothpick para transferir parte da colônia diretamente ao tubo de reação com auxílio de uma ponteira estéril, não sendo, portanto necessária a extração do plasmídeo para realização da reação. Determinados os clones que possuem o tamanho esperado de banda, foi feito o sequenciamento utilizando-se o kit BigDye ${ }^{\circledR}$ Terminator v3.1 CycleSequencing Kit de acordo com as especificações do fabricante.

\section{Análises das sequências}

As sequências foram editadas e analisadas através da utilização do programa CodonCodeAligner v. 3.5.7, utilizando-se o algoritmo MUSCLE para a obtenção dos alinhamentos entre as sequências obtidas. $\mathrm{O}$ cálculo das distâncias intra e interespecíficas foi feito utilizando-se o programa MEGA 5.0 (Tamura et al., 2011), com o modelo K2P (Kimura 2 Parâmetros), modelo este comumente utilizado em análises em peixes e, para a construção das árvores filogenéticas e cálculo de bootstrap, utilizou-se o modelo de máxima verossimilhança. 


\section{Resultados}

A amplificação do gene mitocondrial COI foi levada a efeito em cinco indivíduos de cada cariomorfo, com um tamanho aproximado de 550pb (Fig. 3), totalizando 30 indivíduos analisados da bacia superior do Rio Paraná. A análise dessas sequências permitiu verificar ocorrência abundante de transições entre as espécies, com total aproximado de $72,5 \%$ para os sítios informativos em comparação aos $27,5 \%$ de transversões encontradas (Fig. 4). A análise do gene COI permitiu a identificação de cinco grupos distintos, delimitados pela construção de uma árvore filogenética utilizando-se o modelo de máxima verossimilhança, perfeitamente congruente com os números cromossômicos que esses indivíduos apresentam $2 n=28,2 n=31 / 32,2 n=36$, $2 n=38$ e $2 n=38 X Y$ (Fig. 5). Uma vez verificada a presença natural dos grupos, estes foram então delimitados através da utilização do programa MEGA 5.0 e foram calculadas as distâncias genéticas utilizando-se o modelo de distância Kimura-2Parâmetros entre os indivíduos de um mesmo grupo (Tabela 2) e a distância entre grupos (Tabela 3). O cálculo da distância genética dentro dos grupos evidenciou pequenas distâncias, sendo o maior valor encontrado entre os espécimes com número cromossômico $2 n=28$ com valor igual a 0.0039 . Já o cálculo da distância entre grupos de espécimes, por sua vez, resultou em valores mais elevados com exceção para os grupos $2 n=38 X Y$ e $2 n=38$ nos quais a distância se mostrou baixa, com valor igual a 0.0042 , valor esse muito próximo ao da maior variação dentro do grupo $2 \mathrm{n}=28$. 


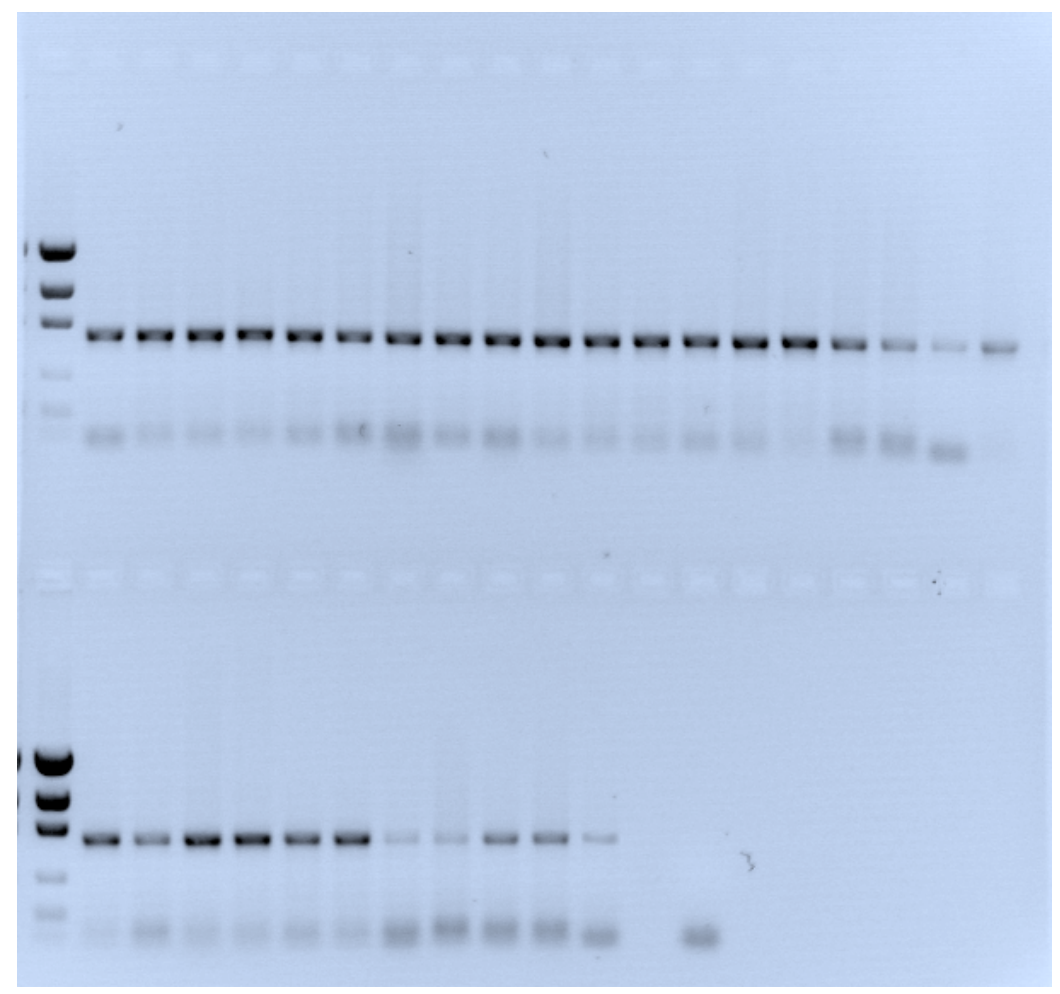

Figura 3: Gel de amplificação de todos os indivíduos utilizados para análise molecular do gene COI para espécies do gênero Eigenmannia. À esquerda, marcador de peso molecular Low DNA Mass ${ }^{\mathrm{TM}}$ Ladder (2000, 1200, 800, 400, 200 e 100pb). 
CodonCode Aligner: COI Alinhamento, COI

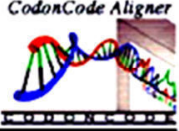

Page 1 of 5

(1)

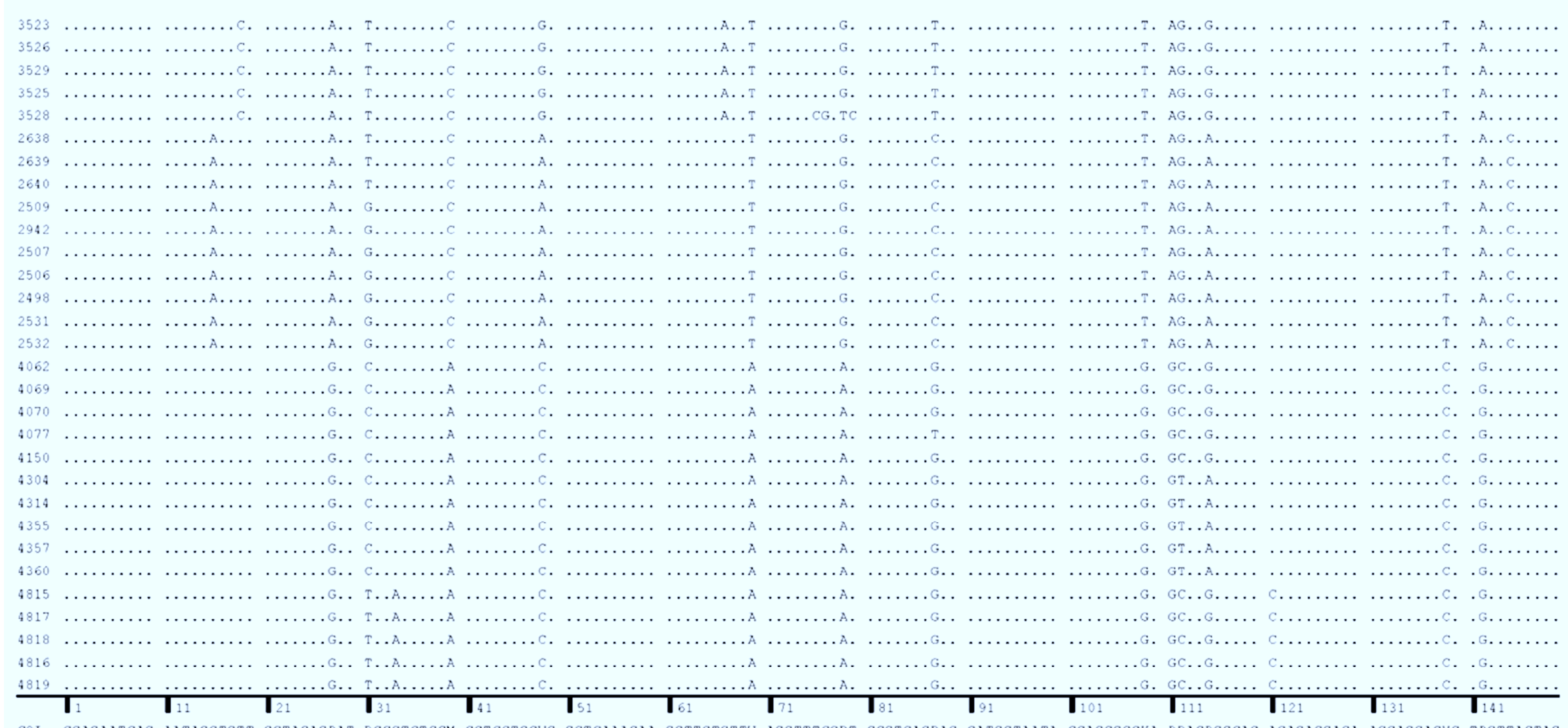

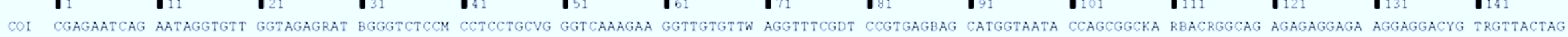


CodonCode Aligner: COI Alinhamento, COI

Page 2 of 5

3523 G..c..............

3526 G..C............G.

3529 G...

3525 G..C.............

3528 G...............

2639 G..G............

2509 G.................

2942 G..G............

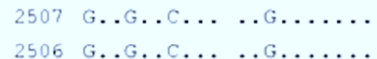

2498 G..G..C....G.....

2532 G..G..... .........

4062 T..A..... A . A..C.A.

4069 T.A.....A ..A.C.A..

4070 T..A....A ..A..C.A..

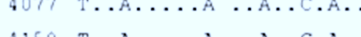

4304 T........ .......A.

4314 T..A.....A ..A..C.A.

4355 T.A.A...A ..A.C.A.

4357 T..A....A ..A.C.A..

4300 T.A. . . . . A.C.A.

$4815 \mathrm{~T}$.

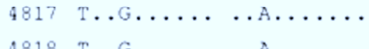

C
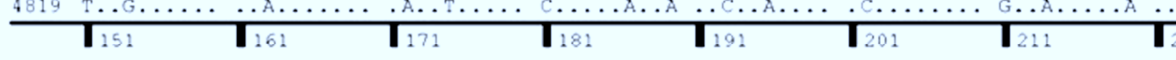

...G....

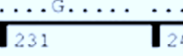

$\mathbf{I}_{241}$ $\mathbf{I}_{251} \mathbf{I}_{26}$ $\mathbf{T} 27$ 
CodonCode Aligner: COI Alinhamento, COI

Page 3 of 5

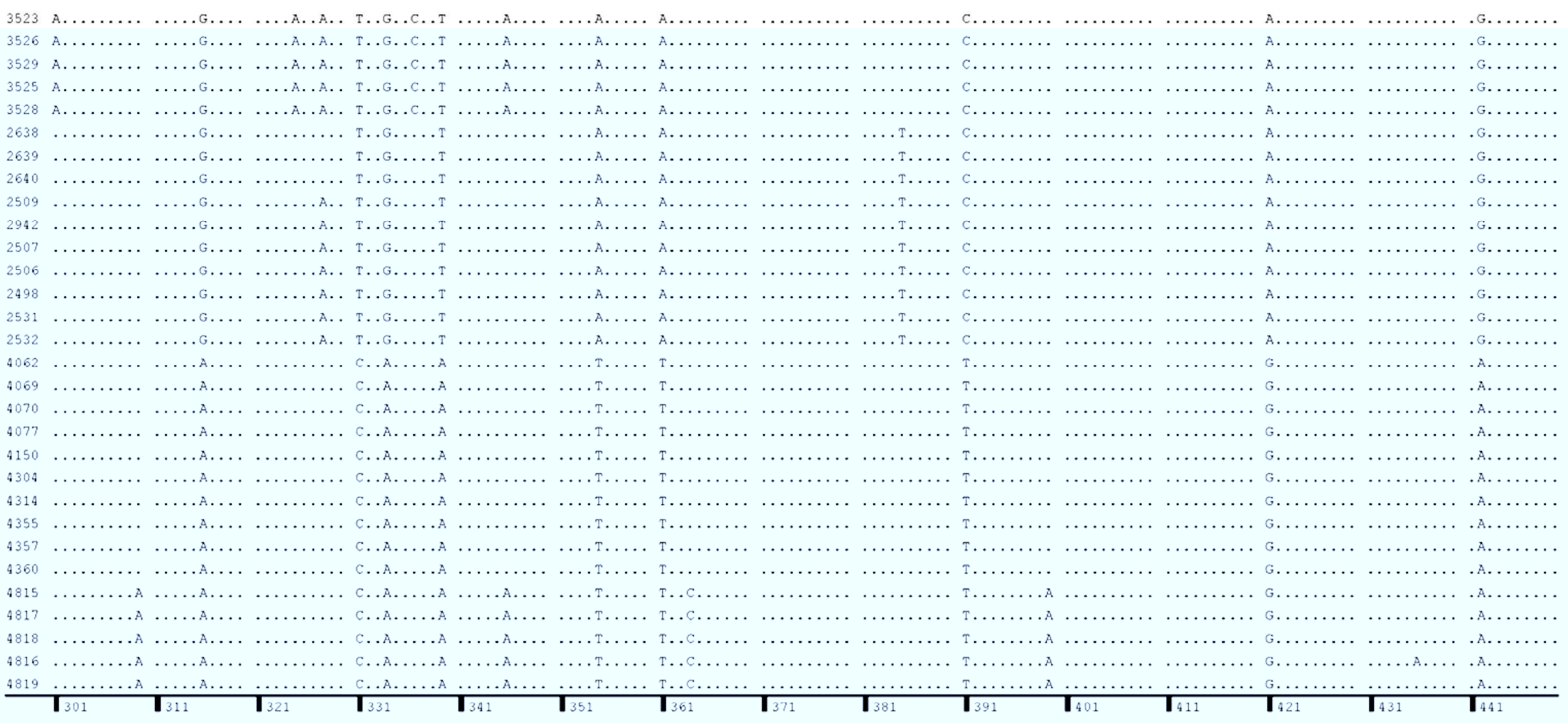

COI GTGGGCGAGG TTTCCRGCAA GAGGGGGGTA YACRGTTCAN CCTGTGCCTG CCCCWGCTTC WACTCCAGAG GAGGCAAGAA GAAGCAGGAA YGAAGGGGGG AGGAGTCAGA agCTTATGTT RTTTATTCGT GGGAAGGCCA TRTCGGGGGC 
CodonCode Aligner: COI Alinhamento, COI

Page 4 of 5

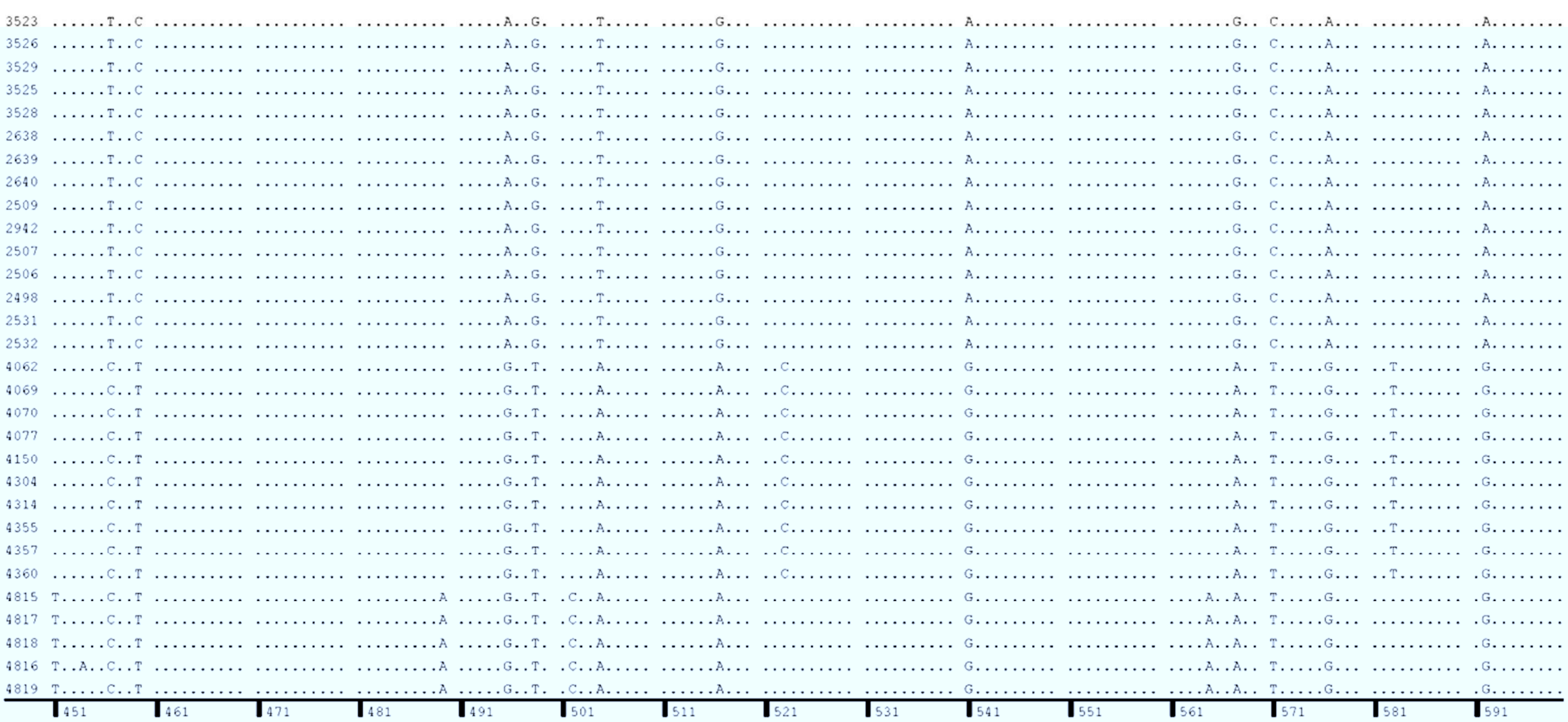

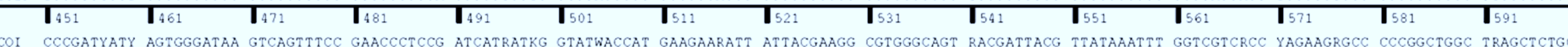


CodonCode Aligner: COI Alinhamento, COI

Page 5 of 5
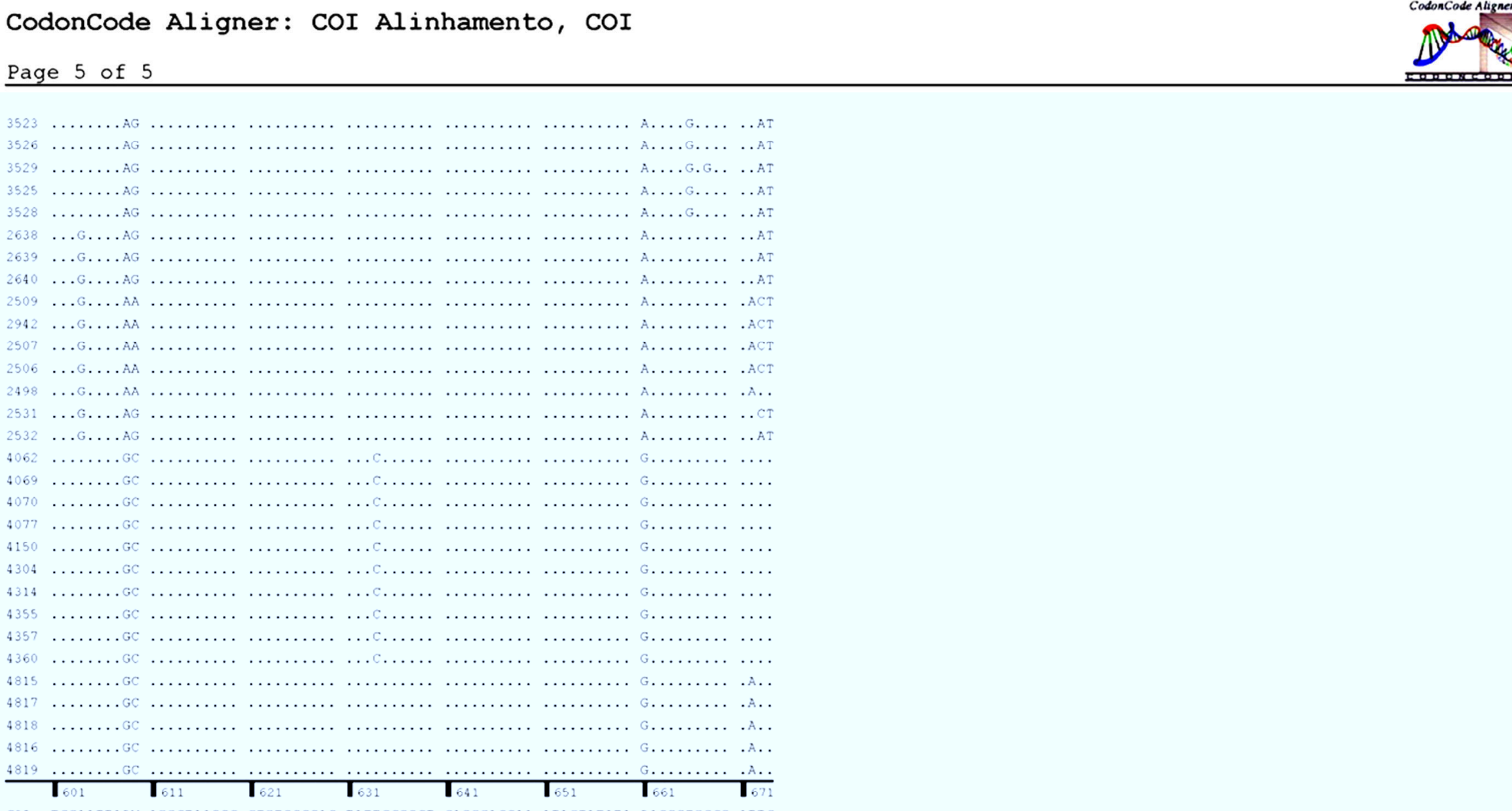

Figura 4:Alinhamento das sequências do gene mitocondrial COI. Pontos indicam bases iguais e traços indicam deleções. Abaixo sequência consenso entre as espécies, determinado pelo programa CodonCodeAligner. 


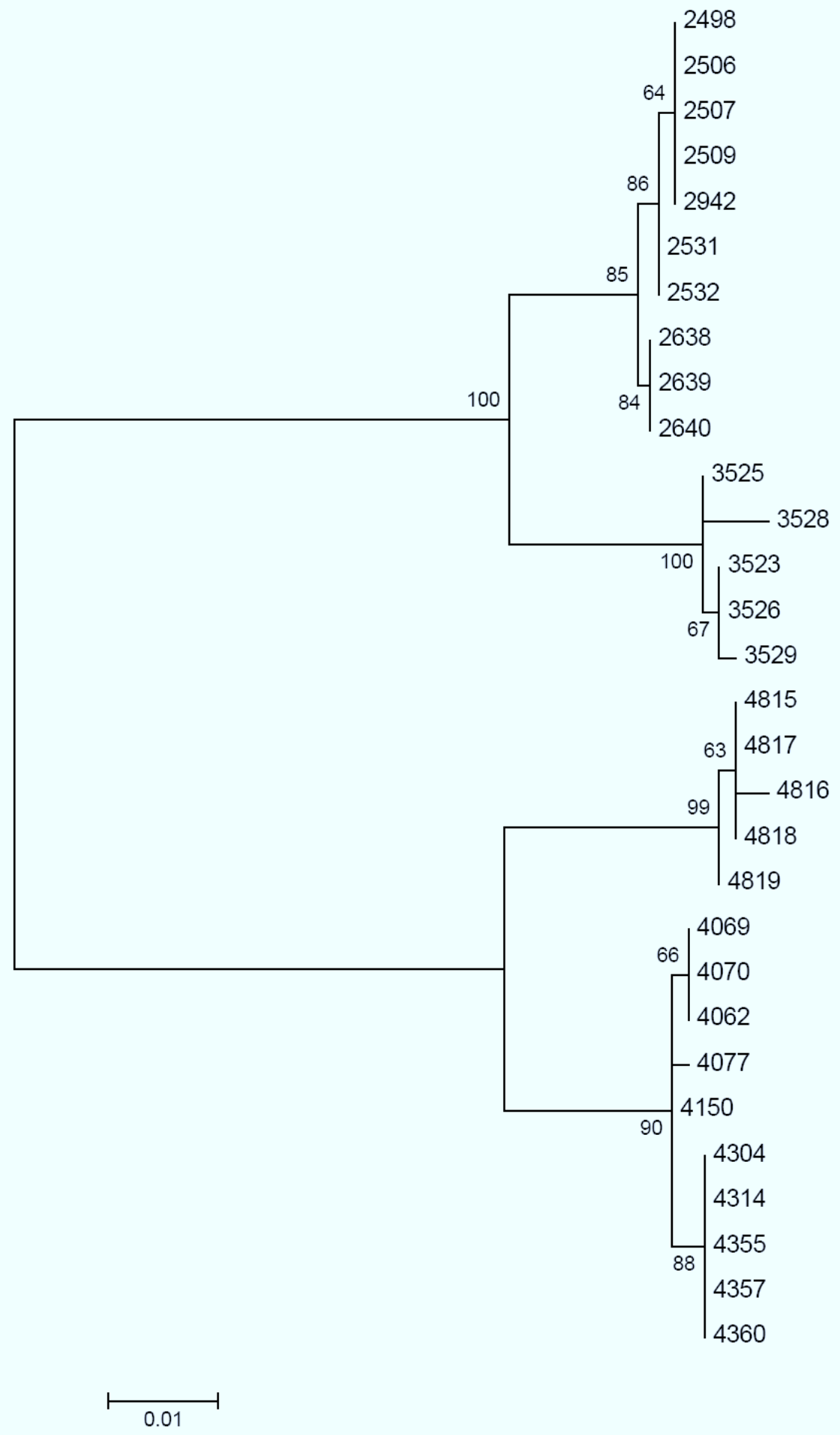

Figura 5: Árvore de máxima verossimilhança com cálculo de bootstrap para o gene mitocondrial COI para as espécies em estudo. 


\begin{tabular}{|l|c|c|c|c|c|}
\hline & $2 \mathrm{n}=38$ & $2 \mathrm{n}=38 \mathrm{XY}$ & $2 \mathrm{n}=36$ & $2 \mathrm{n}=31 / 32$ & $2 \mathrm{n}=28$ \\
\hline distância & 0.0015 & 0.0000 & 0.0018 & 0.0022 & 0.0039 \\
\hline
\end{tabular}

Tabela 2: Distâncias genéticas calculadas para o gene COI utilizando-se o modelo de distância Kimura-2-Parâmetros entre indivíduos do mesmo grupo delimitados no programa MEGA 5.0.

\begin{tabular}{|l|c|c|c|c|c|}
\hline & $2 n=38$ & $2 n=38 X Y$ & $2 n=36$ & $2 n=31 / 32$ & $2 n=28$ \\
\hline $2 n=38$ & - & & & & \\
\hline $2 n=38 X Y$ & 0.0042 & - & & & \\
\hline $2 n=36$ & 0.0387 & 0.0406 & - & & \\
\hline $2 n=31 / 32$ & 0.1123 & 0.1116 & 0.1193 & - & \\
\hline $2 n=28$ & 0.1184 & 0.1217 & 0.1226 & 0.0339 & - \\
\hline
\end{tabular}

Tabela 3: Distâncias genéticas calculadas para o gene COI utilizando-se o modelo de distância Kimura-2-Parâmetros entre os grupos de espécies delimitados no programa MEGA 5.0.

Foi levado a efeito o seqüenciamento do gene ribossômico $5 \mathrm{~S}$ e de modo geral as espécies apresentaram uma sequência com um tamanho total de 294pb(Fig. 6), tendo o gene ribossômico funcional um tamanho aproximado de $100 \mathrm{pb}$ e seu espaçador um tamanho total de $194 \mathrm{pb}$. O gene ribossômico, mostrou-se altamente conservado, fato esse já esperado devido à elevada conservação desse gene (Long\& David, 1980), enquanto que seu NTS se mostrou informativo apresentando 33 dos 37 sítios variáveis do gene ribossômico 5S juntamente com seu NTS. Dentre os sítios variáveis, a taxa de transversão foi de aproximadamente 55,25\%, ligeiramente maior do que a de transição, aproximadamente $44,25 \%$, bem como a presença de inserções/deleções na região do NTS (Fig. 7). Acreditava-se que essa variabilidade seria suficiente para a delimitação de 
possíveis (Ferreira et al., 2007), bem como para o esboço da relação entre elas. Sendo assim com o auxílio do programa MEGA 5.0, tal qual feito para o gene mitocondrial COI, foi construída uma árvore filogenética utilizando-se o método de verossimilhança com cálculo de bootstrap utilizando-se todos os indivíduos. Novamente foram obtidos cinco agrupamentos (Fig. 8) que correspondem aos números cromossômicos dessas espécies e o suporte associado aos ramos mostrou-se elevado, evidenciando uma topologia bem resolvida. Uma vez determinada essa relação, foram calculadas com modelo de distância Kimura-2-Parâmetros (Tamuraet al. 2007) as distâncias genéticas entre os grupos (Tabela 4), sendo as mais próximas as espécies $2 n=38 X Y$ e $2 n=38$ (distância de 0.0035) e as mais distantes as espécies $2 \mathrm{n}=28$ e 2n=36 (distância de 0.1208).

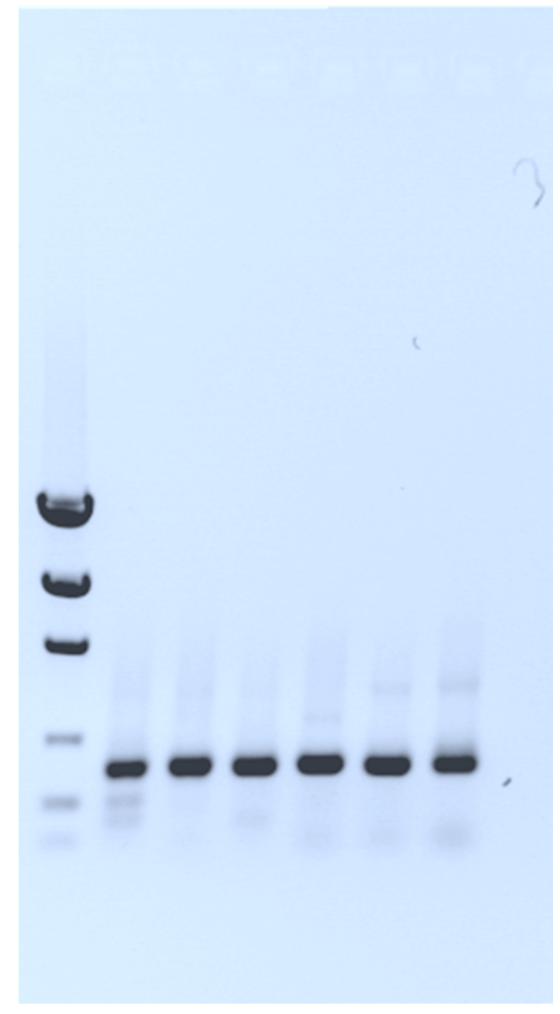

Figura 4: Amplificação da banda de menor tamanho isolada de todas as espécies em estudo. À esquerda, marcador de peso molecular LowDNA MassLadder TM (2000, $1200,800,400,200$ e 100pb). 
CodonCode Aligner: 5S Alinhamento, 5S

Page 1 of 1

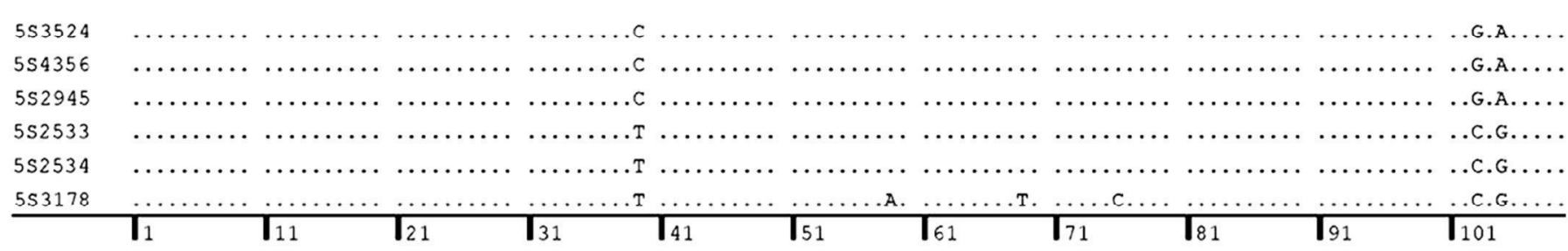

5S TACGCCCGAT CTCGTCCGAT CTCGGAAGCT AAGCAGGGTY GGGCCTGGTC AGTACTTGGA TGGGAGACCG CCTGGGAATA CCAGGTGCTG TAGGCTTTTT GCSARTCAAG

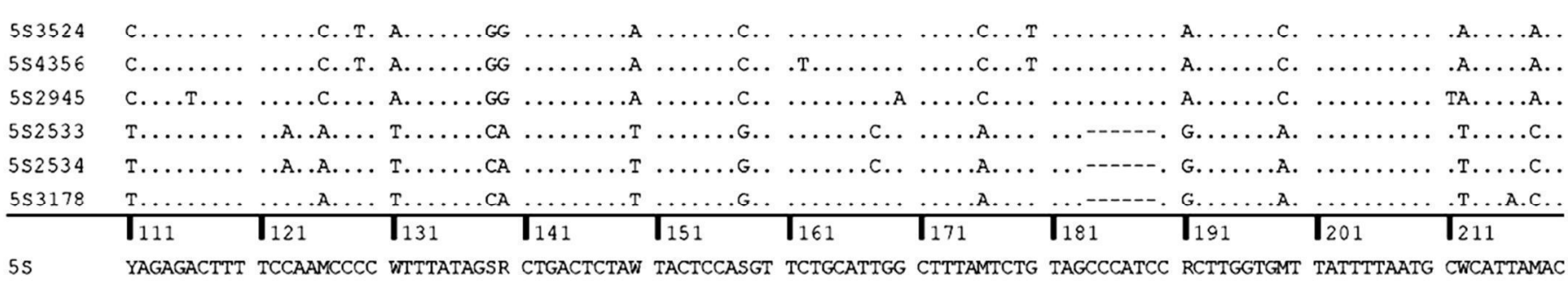

5s YAGAGACTTT TCCAAMCCCC WTTTATAGSR CTGACTCTAW TACTCCASGT TCTGCATTGG CTTTAMTCTG TAGCCCATCC RCTTGGTGMT TATTTTAATG CWCATTAMAC

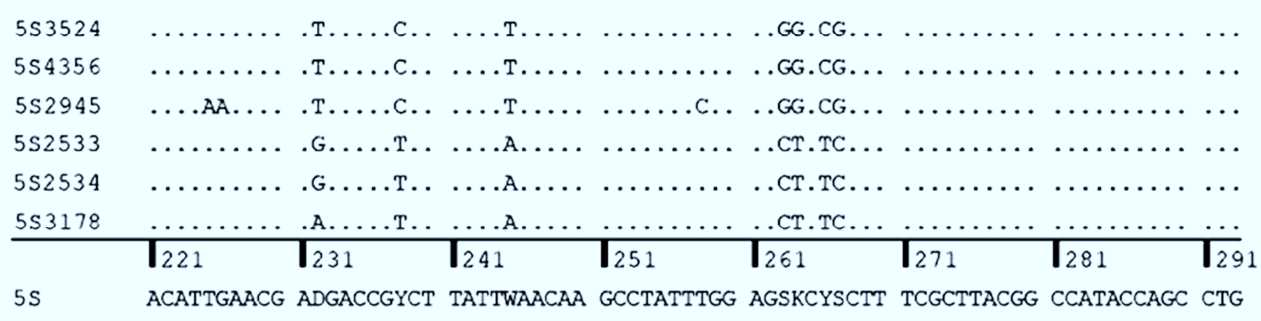

Figura 7: Alinhamento das sequências do gene ribossômico 5S juntamente com seu NTS. Pontos indicam bases iguais e traços indicam deleções. Abaixo sequência consenso entre as espécies determinado pelo programa CodonCodeAligner. 


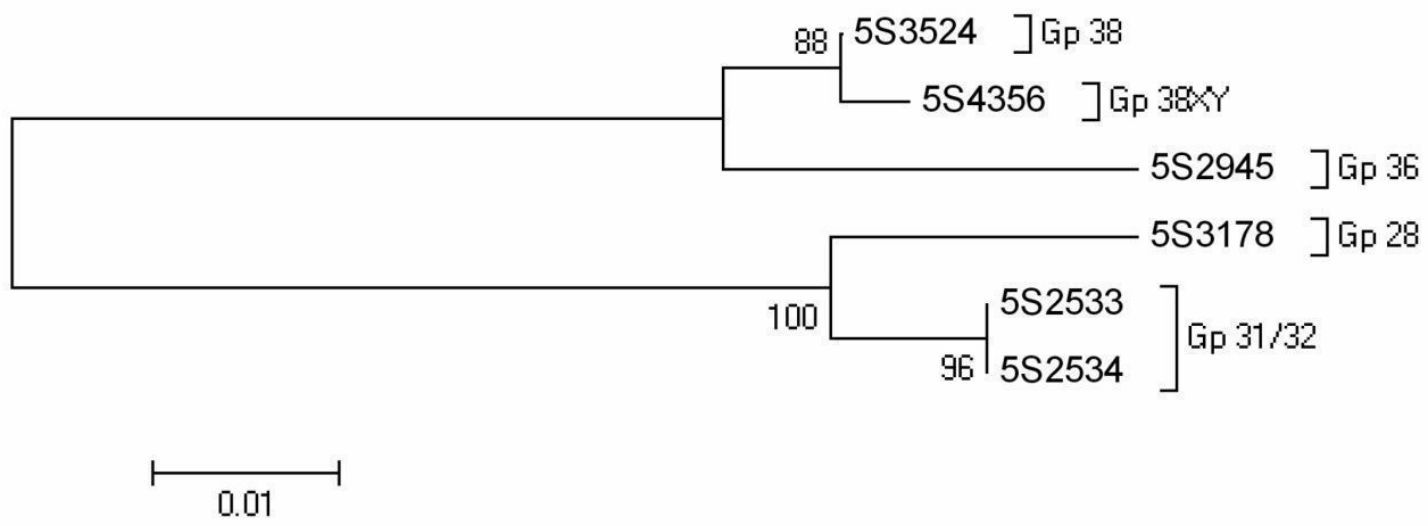

Figura 8: Árvore de máxima verossimilhança com cálculo de bootstrap para o gene ribossômico $5 \mathrm{~S}$ juntamente com seu NTS para as espécies em estudo.

\begin{tabular}{|l|c|l|l|l|c|}
\hline & $2 \mathrm{n}=38$ & $2 \mathrm{n}=38 \mathrm{XY}$ & $2 \mathrm{n}=36$ & $2 \mathrm{n}=31 / 32$ & $2 \mathrm{n}=28$ \\
\hline $2 \mathrm{n}=38$ & - & & & & \\
\hline $2 \mathrm{n}=38 X Y$ & 0.0035 & - & & & \\
\hline $2 \mathrm{n}=36$ & 0.0285 & 0.0321 & - & & \\
\hline $2 \mathrm{n}=31 / 32$ & 0.0965 & 0.1005 & 0.1126 & - & \\
\hline $2 \mathrm{n}=28$ & 0.1045 & 0.1086 & 0.1208 & 0.0248 & - \\
\hline
\end{tabular}

Tabela 4: Distâncias genéticas calculadas para o gene ribossômico 5S utilizando-se o modelo de distância Kimura-2-Parâmetros entre os grupos de espécies delimitados no programa MEGA 5.0.

O esboço das relações por sua vez permitiu a delimitação de dois grandes grupos, um deles englobando as espécies com menor número cromossômico $(2 n=28$ e $2 n=31 / 32)$ e o outro as espécies de maior número cromossômico $(2 n=36,2 n=38$ e $2 n=38 X Y)$.

\section{Discussão}

A análise das distâncias genéticas mostrou uma grande homogeneidade dentro dos grupos obtidos a partir da construção da árvore de verossimilhança, fato 
evidenciado pela pequena distância genética obtida dentro desses grupos, utilizando-se o modelo de distância Kimura-2-Parâmetros (Tamura et al. 2007). Quando calculada a distância entre grupos, utilizando-se o mesmo modelo de distância, foi possível observar valores de distância significativos entre os grupos delimitados, sendo tais valores próximos daqueles obtidos para o gene ribossômico 5S juntamente com seu NTS. A distância obtida entre os grupos $2 \mathrm{n}=38$ e $2 \mathrm{n}=38 \mathrm{XY}$ para o gene mitocondrial COI, mostrou-se muito pequena, quando comparada conjuntamente com as distâncias par a par dos outros grupos. Esse fato pode ser um reflexo de um processo de especiação recente, no qual houve a diferenciação dos cromossomos sexuais nos indivíduos 2n=38XY, fato esse já descrito na literatura (Hening et al., 2010) e, além disso, a topologia da árvore recuperada é congruente com dados prévios para o gênero em questão (Hening et al., 2010) indicando um elevado grau de confiabilidade do gene mitocondrial COI na discriminação de espécies próximas.

A análise das distâncias genéticas do gene ribossômico $5 \mathrm{~S}$ demonstrou que apesar da elevada taxa de conservação da região do gene em si, fato esse já esperado (Long \& David, 1980), a pequena variabilidade que a região do NTS foi suficientemente informativa para a delimitação também de cinco grupos monofiléticos, estes obtidos utilizando-se os mesmos parâmetros para o gene mitocondrial COI. Esse resultado corrobora dados obtidos por Henning et al. (2010) utilizando outros marcadores mitocondriais, bem como valida a hipótese de que o NTS do gene ribossômico 5S apresenta excelente potencial para estabelecer as relações filogenéticas entre espécies próximas, no caso desse trabalho possíveis espécies delimitadas fundamentalmente pelo seu número cromossômico. A utilização do NTS para a delimitação entre espécies próximas foi já amplamente utilizada, como no caso do gênero Leporinus (Irani et al., 2007), trabalho no qual a utilização do espaçador não 
transcrito não só permitiu a delimitação de espécies próximas, como também teve resolução suficiente para delimitá-las em dois grandes grupos, um deles onde há a presença de cromossomos sexuais e outro no qual estes cromossomos, não são morfologicamente distintos. Sendo assim, o gene ribossômico 5S juntamente com seu espaçador podem ser utilizados como um bom parâmetro para a validação do potencial de discriminação do gene mitocondrial COI para os citótipos analisados.

Comparando-se as distâncias obtidas nos grupos como entre eles tanto para o gene mitocondrial COI quanto para o gene ribossômico 5S, as distâncias obtidas se mostraram muito próximas, recuperando assim a mesma topologia em ambos os casos, concluímos que ambos os genes apresentam uma capacidade resolutiva similar, no caso do gênero em questão.

O sucesso na utilização do gene mitocondrial COI é notório e já foi verificado nos mais diversos grupos incluindo os peixes e não se mostra diferente no caso do gênero Eigenmannia. Sendo assim corroboramos a hipótese de que o gene mitocondrial COI é capaz de delimitar potenciais espécies. Com base nos dados obtidos sugere-se então uma revisão taxonômica no grupo, uma vez que na região da bacia superior do Rio Paraná, onde os espécimes foram coletados, existem pelo menos 5 espécies distintas pertencentes ao gênero Eigenmannia, já evidenciadas por estudos citogenéticos (referências) e atualmente também por estudos moleculares (Hening et al., 2010). Sendo assim, acreditamos que a utilização do gene mitocondrial COI fornecerá dados que auxiliarão no processo de identificação taxonômica das espécies, não só no gênero Eigenmannia, mas nos mais diversos grupos animais.

\section{Referências}


ALBERT, J. S., 2001. Species diversity and phylogenetic systematics of American knifefishes (Gymnotiformes, Teleostei), Division of Ichthyology, Museum of Zoology, Univ. of Michigan.

ALBERT, J. S., CAMPOS-DA-PAZ, R., 1998. Phylogenetic systematics of Gymnotiformes with diagnoses of 58 clades: a review of avaible data. In: MALABARBA, L. R., REIS, R. E., VARI, R. P., LUCENA, Z. M., LUCENA, C. A. (Eds.). Phylogeny and classification of Neotropical fishes, p. 419-446, EDIPUCRS, Porto Alegre.

ALBERT, J. S., FERNANDES-MATIOLI, F. M. C., ALMEIDA-TOlEDO, L. F., 1999. New species of Gymnotus (Gymnotiformes, Teleostei) from southeastern Brazil: toward the deconstruction of Gymnotuscarapo. Copeia 1999 (2): 410-421.

ALBERT, J.S., 2003. Sternopygidae (Glass knifefishes, Rattailknifefishes). p. 487-491. In: R.E. Reis, S.O. Kullander and C.J. Ferraris, Jr. (eds.) Checklist of the Freshwater Fishes of South and Central America. Porto Alegre: EDIPUCRS, Brasil

ALMEIDA-TOLEDO, L. F., STOCKER, A. J., FORESTI, F., TOLEDO-FILHO, S. A., 1996. Fluorescent in situ hybridization with rDNA probes on chromosomes of two nucleolus organizer region phenotypes of a species of Eigenmannia (Pisces, Gymnotoidei, Sternopygidae). Chromosome Res. 4: 301-305.

ALMEIDA-TOLEDO, L. F., FORESTI, F., DANIEL, M. F. Z., TOLEDO-FILHO, S. A., 2000. Sex chromosome evolution in fish: the formation o the neo-Y chromosome in Eigenmannia (Gymnotiformes).Chromosoma 109: 197-200.

ALMEIDA-TOLEDO L. F., FORESTI F., PEQUIGNOT E. V. AND DANIEL-SILVA M. F., 2001a.XX:XY sex chromosome system with X heterochromatinization: an early stage of sex chromosome differentiation in the Neotropic electric eel Eigenmannia virescensCytogenetics and Cell Genetics 95(1-2): 73-8. 
ALMEIDA TOLEDO L. F., FORESTI F., 2001b. Morphologically differentiated sex chromosomes in Neotropical freshwater fish Genetica 111(1-3): 91-100.

ALMEIDA TOLEDO L. F., DANIEL-SILVA M. F., MOYSES, C. B., FONTELES, S. B., LOPES, C. E., AKAMA, A., FORESTI, F., 2002. Chromosome evolution in fish: sex chromosome variability in Eigenmannia virescens (Gymnotiformes: Sternopygidae) Cytogenetic and Genome Research 99(1-4): 164-9.

ALVES-GOMES, J. A., ORTÍ, G., HAYGOOD, M., HEILINGENBERG, W., MEYER, A., 1995. Phylogenetic analysis of the South American Eletric Fishes (Order Gymnotiformes) and the evolution of their eletrogenic system: a synthesis based on morphology, eletrophysiology, and mitochondrial sequence data. Mol. Biol. Evol. 12: 298-318.

ALVES-GOMES, J. A., 2001. The evolution of electroreception and bioelectrogenesis in teleost fish: a phylogenetic perspective Journal of Fish Biology 58(6): 1489-511.

BAKER, W. J., HEDDERSON, T. A., DRANSFIELD, J., 2000. Molecularphylogenetics of Calamus (Palmae) and related rattan genera based on 5SnrDNA spacer sequence data. Mol. Phylogenet. Evol. 14: 218-231.

BARRET, R. D. H., HEBERT, P. D. N., 2005. Identifying spiders through DNA barcodes.Can. J. Zool. 83: 481-491.

BAUM, B. R., BAILEY, L. G., BELYAYEV, A., RASKINA, O., NEVO, E., 2004. Theutility of the nontranscribed spacer of $5 \mathrm{~S}$ rDNA units grouped into unitclassesassignd to haplomes - a test on cultivated wheat and wheatprogenitors. Genome 47: 590-599.

BAUM, B. R., JOHNSON, D. A., 2007. The 5S DNA sequences in Hordeumbogdaniiand in the $\mathrm{H}$. brevisubulatum complex, and the evolution and the geographicdispersal of the diploid Hordeum species (Triticeae: Poaceae). Genome 50:114. 
BICKFORD D, LOHMAN DJ, SODHI NS, NG PKL, MEIER R, WINKER K, INGRAM KK, DAS I. 2006. Cryptic species as a window on diversity and conservation. Trends in Ecology and Evolution 22(3): 148-155.

BUCKLIN, A., WIEBE, P.H., SMOLENACK, S.B., COPLEY, N.J., BEAUDET, J.G., BONNER, K.G., F“ARBER-LORDA, J., PIERSON, J.J., 2007. DNA barcodes for species identification of euphausiids (Euphausiacea, Crustacea). Journal of Plankton Research 29, 483-493.

CAMPOS-DA-PAZ, R., 1997. Sistemática e taxonomia dos peixes elétricos das bacias dos rios Paraguai, Paraná e São Francisco, com notas sobre espécies presentes em rios costeiros do leste do Brasil (Teleostei: Ostariophysi:

Gymnotiformes). Tese de Doutoramento. Instituto de Biociências, Universidade de São Paulo, São Paulo.

DA SILVA,M., MATOSO, D.A., VICARI, M.R., DE ALMEIDA, M.C., MARGARIDO, V.P., ARTONI, R.F., 2011. Physical Mapping of 5S rDNA in Two Species of Knifefishes: Gymnotus pantanal and Gymnotus paraguensis (Gymnotiformes). Cytogenet Genome Res June 3

FERNANDES-MATIOLI, F. M. C., ALBERT, J. S., LOPES, C. E., CRAMPTON, W. G. R., ALMEIDA-TOLEDO, L. F., 2005. A new Gymnotus (Teleostei: Gymnotiformes: Gymnotidae) from the Pantanal Matogrossense of Brazil and adjacent drainages: continued documentation of a cryptic fauna. Zootaxa 933: 1-14.

HEBERT, P.D.N., CYWINSKA, A., BALL, S.L., DEWAARD, J.R., 2003. Biological identifications through DNA barcodes. In: Proceedings of the Royal Society of London Series B, Biological Sciences 270, 313-321.

HEBERT, P.D.N.; STOECKLE, M.Y.; ZEMLAK, T.S.; FRANCIS, C.M. Identification of birds through DNA barcodes. PLoS Biol. 2004, 2, 1657-1663.

HEBERT, P.D.N., PENTON, E.H., BURNS, J.M., JANZEN, D.H., HALLWACHS, W., 2004a. Ten species in one: DNA barcoding reveals cryptic species in the neotropical skipper butterfly Astraptes fulgerator. In: Proceedings of the National Academy of Sciences of the United States of America101,14812-14817. 
HENNING, F., MOYSÉS, C. B., CALCAGNOTTO, D., MEYER, A., ALMEIDATOLEDO, L. F., 2010.Independent fusions and recent origins of sex chromosomes in the evolution and diversification of glass knife fishes (Eigenmannia).Heredity (2010): $1-10$.

HENNING, F., 2007. Evolução dos cromossomos sexuais no gênero Eigenmannia (Teleostei: Gymnotiformes) Dissertação de Mestrado, Universidade de São Paulo.

HEBERT, P. D. N., CYWINSKA, A, BALL, S. L., DEWAARD, J. R., 2003.Biological identifications through DNA barcodes. Proc. R. Soc. Lond. B 270: 313-321.

HEBERT, P. D. N, RATNASINGHAM, S., DEWAARD, J. R. 2003b. Barcoding animal life: cytochrome $c$ oxidase 1 divergences among closely related species. Proc. R. Soc. Lond. B Biol. Sci. 270(Suppl.): S596-S599.

HUBERT, N., HANNER, R., HOLM., E, MANDRAK, N. E., TAYLOR, E., BURRIDGE, M, WATKINSON, D., DUMONT, P., CURRY, A., BENTZEN, P., ZHANG, J., APRIL, J., BERNATCHEZ, L., 2008. Identifying Canadian freshwater fishes through DNA barcodes.PLoS ONE 3(6): e 2490.

HEBERT, P. D. N., PENTON, E. H., BURNS, J. M., JANZEN, D. H., HALLWACHS, W., 2004b. Ten species in one: DNA barcoding reveals cryptic species in the neotropical skipper butterfly Astrapesfulgerator. PNAS USA 101(41): 14812-14817.

HEBERT, P. D. N., STOECKLE, M. Y., ZEMLAK, T. S., FRANCIS, C. M., 2004a. Identification of birds through DNA barcodes.PLoS Biol. 2: 1657-1663.

HOGG, I. D., HEBERT, P. D. N. 2004. Biological identifications of springtails (Hexapoda: Collembola) from the Canadian Arctic using mitochondrial DNA barcodes. Can J. Zool. 82(5): 749-754.

KITAMURA, S., TANAKA, A., INOUE, M., 2005. Genomic relationships among Nicotiana species with different ploidy levels revealed by 5S rDNA spacersequences and FISH/GISH. Genes Genet. Syst. 80:251-260.

KOMIYA, H., AND TAKEMURA, S., 1979. Nucleotide sequence of 5S ribosomal RNA from rainbow trout (Salmogairdneri) liver.J. Biochem. 86: 1067-1080. 
LANGEANI, F., CASTRO, R.M.C., OYAKAWA, O.T., SHIBATTA, O.A., PAVANELLI, C.S., CASATTI, L., 2007.Diversidade da ictiofauna do Alto Rio Paraná: composição atual e perspectivas futuras. Biot. Neotrop. 7(3):181-197, http://www.biotaneotropica.org.br/v7n3/pt/fullpaper?bn03407032007+pt (último acesso em 29/07/2010).

LONG, E. O., David, I. D. 1980.Repeated genes in eukaryotes.Annu.Rev. Biochem. 49: $727-764$.

LOWE-MCCONNELL, R.H., 1999. Estudos ecológicos de comunidades de peixes tropicais. Edusp, São Paulo.

MAGO-LECCIA, F., 1994.Eletric fishes of the continental waters of America. Bibl de La Acad. Cienc. Fis. Mat. Nat. 29: 1-225. Caracas, Venezuela.

NELSON, J.S., 2006. Fishes of the world.Third Edition.New York, John Willey \& Sons, Inc. $600 \mathrm{p}$.

PENDÁS, A.M., MÓRAN, P., MARTÍNEZ, J.L., GARCIA-VÁSQUEZ, E. 1995. Applications of 5S rDNA in Atlantic salmon, brown trout, and in Atlanticsalmon $\times$ brown trout hybrid identification. Mol. Ecol. 4: 275-276.

ROBLES, F., DE LA HERRAN, R., LUDWIG, A., RUIZ-REJON C, RUIZ-REJON, M., GARRIDO RAMOS M (2005) Genomic organization and evolution of the 5S ribosomal DNA in the ancient fish sturgeon. Genome 48:18-28.

SMITH, P.J., STEINKE, D., MCVEAGH, S.M., STEWART, A.L., STRUTHERS, C.D., ROBERTS, C.D., 2008. Molecular analysis of Southern Ocean skates (Bathyraja) reveals a new species of Antarctic skate. Journal of Fish Biology 73,1170-1182.

SONG, H.; BUHAY, J.E.; WHITING, M.F.; CRANDALL, K.A. Many species in one: DNA barcoding overestimates the number of species when nuclear mitochondrial pseudogenes are coamplified. Proc. Natl. Acad. Sci. USA 2008, 105, 13486-13491.

STEINKE, D., ZEMLAK, T.S., HEBERT, P.D.N., 2009a. Barcoding Nemo: DNAbased identifications for the ornamental fish trade. PLoSOne 4, e6300. 
TAMURA K, DUDLEY J, NEI M, KUMAR S. 2007. MEGA 4: Molecular Evolutionary Genetics Analysis (MEGA) Software Version 4.0. Molecular BiologyEvolution 24: 1596-1599.

TRIQUES, M. L., 1993. Filogenia dos gêneros de Gymnotiformes (Actinopterygii, Ostariophysi), com base em caracteres esqueléticos. Comum. Mus. Ciênc. PUCRS, sér Zool. 6: 85-130.

WARD, R. D., ZEMLAK, T. S., INNES, B. H., LAST, P. R., HEBERT, P. D. N. 2005. DNA barcoding Australia's fish species. Phil. Trans. R. Soc. B 360: 1847-1857.

WITT JDS, THRELOFF DL, HEBERT PDN. 2006. DNA barcoding reveals extraordinary cryptic diversity in an amphipode genus: implications for desert spring conservation. Molecular Ecology 15: 3073-3082.

YASSIN, A, CAPY, P., MADI-RAVAZZI, L., OGEREAU, D., DAVID, J. R. 2008. DNA barcode discovers two cryptic species and two geographical radiations in the invasive drosophilid Zaprionusindianus. Molecular Ecology Resources 8: 491-501. 


\section{Capítulo 3}

Molecular characterization and chromosomal mapping of two classes of $5 \mathrm{~S}$ ribosomal gene in kariomorphs of the genus Eigenmannia. 


\section{Introdução}

Os peixes apresentam uma grande diversidade quanto à sua morfologia, seus habitats e também sua biologia. São encontrados em lagos, córregos, estuários e oceanos, constituindo assim mais de $50 \%$ do número total das, aproximadamente, 54.700 espécies de vertebrados conhecidas atualmente (Nelson, 2006). Grande parte dessa riqueza e diversidade encontra-se em águas tropicais (LOWE-McCONNELL, 1999), particularmente nas águas doces neotropicais, onde são encontradas 4.475 espécies válidas de peixes, número que pode chegar a mais de 6.000 (dentre a 13.000 mundiais) se incluídas as novas espécies já reconhecidas por especialistas, porém ainda não descritas (LANGEANI et al, 2007).

A ordem Gymnotiformes compreende um grupo monofilético de peixes endêmicos da região Neotropical (Fig. 1) que representa um componente importante da ictiofauna de água doce. Nessa ordem estão incluídas cinco famílias: Sternopigydae, Rhamphichthyidae, Hypopomidae, Apteronotidae e Gymnotidae, com um total de 29 gêneros e mais de 130 espécies, muitas das quais ainda não descritas (Albert, 2001). O conhecimento sobre esse grupo de peixes tem avançado com estudos sobre relações filogenéticas inter e intra-específicas baseados em dados morfológicos, moleculares, neuro-anatômicos, fisiológicos e de fósseis (Triques, 1993; Mago-Leccia, 1994; AlvesGomes et al., 1995; Albert \& Campos-da-Paz, 1998; Albert, 2001), bem como em estudos cromossômicos, em especial nos gêneros Eigenmannia e Gymnotus (Almeida Toledo et al., 1996, 2000, 2001, 2002; Fernandes-Matioli et al., 2005; Albert et al. 1999). Entretanto ainda há vários problemas taxonômicos relevantes em diversos níveis da ordem Gymnotiformes, sendo que grande parte dos gêneros e espécies do grupo aguarda revisões (Campos-da-Paz, 1997). 


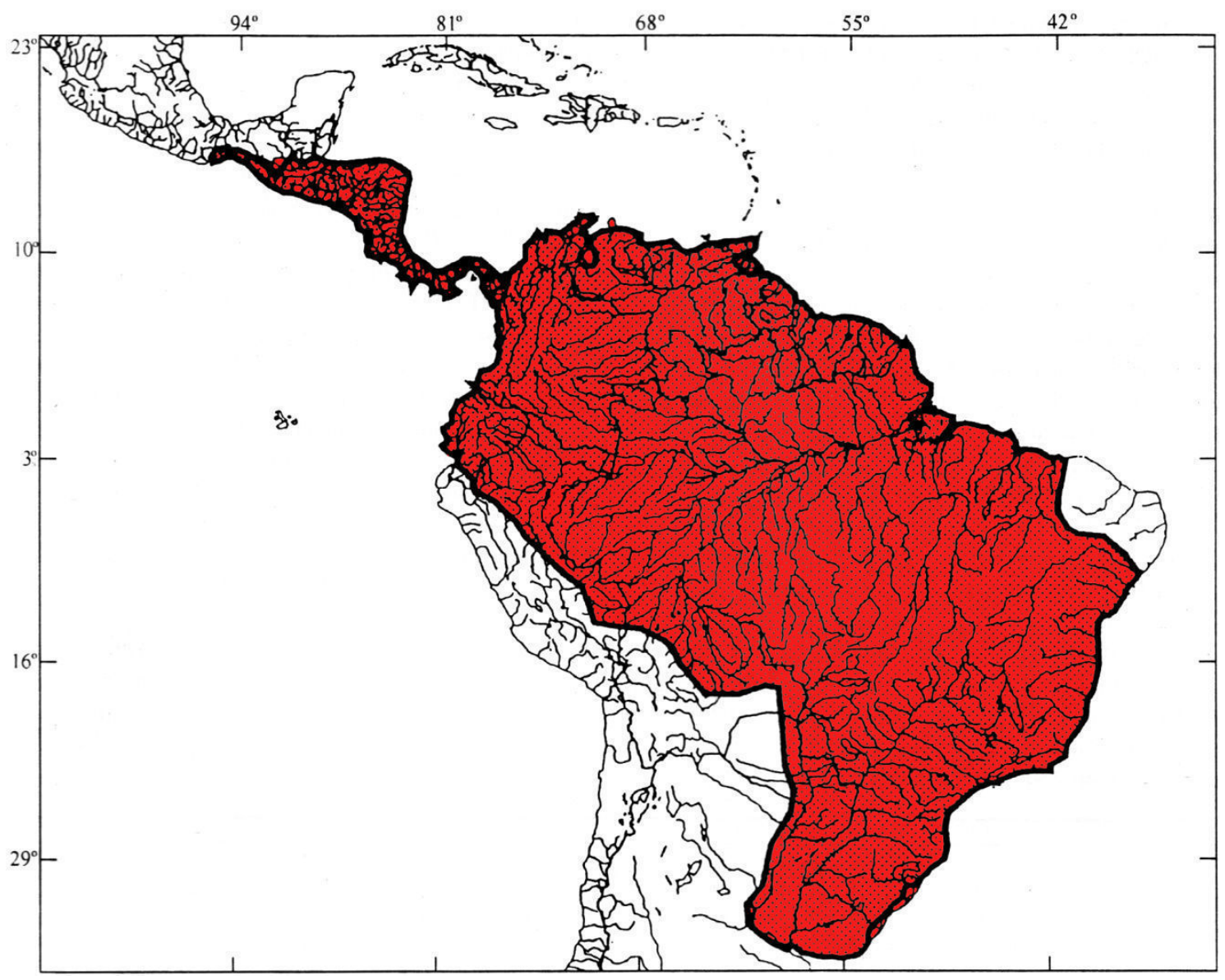

Figura 1: Mapa evidenciando região neotropical (adaptado de Albert \& Campos-da-Paz, 1998).

\section{O Gênero Eigenmannia}

O gênero Eigenmannia (Sternopygidae) faz parte da ordem Gymnotiformes, grupo no qual a morfologia das espécies é tipicamente serpentiforme e que apresenta distribuição exclusivamente neotropical (Fig. 2) (Albert, 2001). Uma característica notória nas espécies de Gymnotiformes, a qual está intimamente relacionada aos hábitos noturnos e ambientes de rios, é a emissão contínua de descargas elétricas de baixas voltagens, voltadas para as funções de eletro-localização (navegação, defesa e localização de presas) e eletro-comunicação (Alves-Gomes, 2001). 


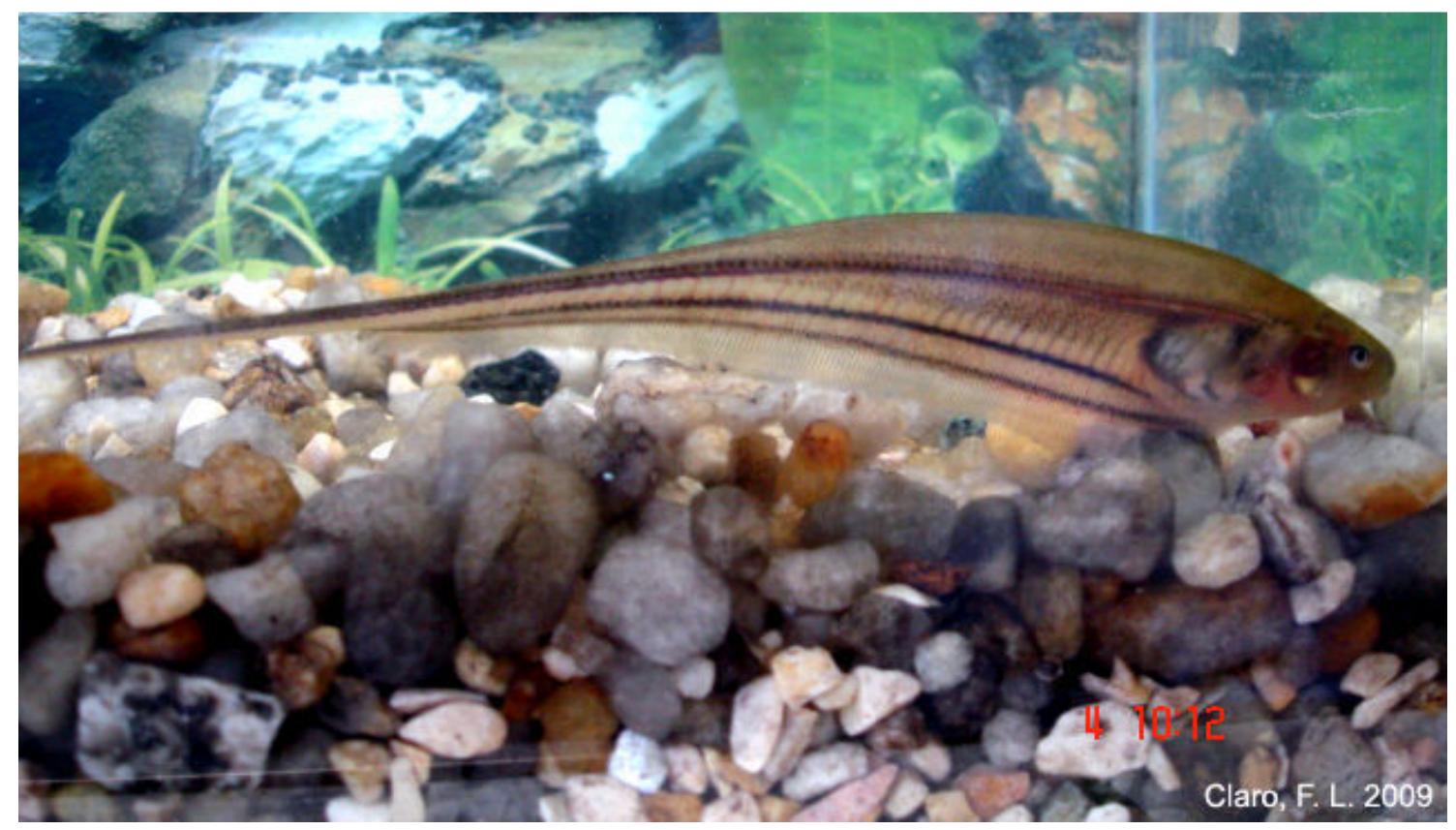

Figura 2: Imagem de um exemplar do gênero Eigenmannia oriundo da região de Santa Albertina/SP e mantido em laboratório.

São descritas oito espécies válidas para o gênero Eigenmannia com data de separação estimada em 16Ma. A diversidade de espécies não pode ainda ser estabelecida devido à necessidade de uma revisão taxonômica no gênero sendo que as espécies já descritas para esse gênero são, provavelmente, na realidade, grupos de espécies crípticas morfologicamente (Albert, 2003; Henning et al., 2010).

Um número expressivo de estudos citogenéticos foi já publicado sobre as populações de Eigenmannia, com enfoque basicamente na bacia superior do Rio Paraná e na bacia do Rio São Francisco. As populações de Eigenmannia já descritas citogeneticamente apresentam ampla variabilidade cariotípica e diversos sistemas sexuais incluindo sistemas XY e ZW (Almeida-Toledo et al. 2002). Nas bacias dos rios Tietê, Paranapanema e Mogi-Guaçu (SP), ocorrem populações com cariótipos que apresentam números cromossômicos variando entre 28 e 38 com presença ou não de cromossomos sexuais heteromórficos (Almeida Toledo \& Foresti, 2001). Uma análise 
filogenética recente destes citótipos revelou um padrão de labilidade dos sistemas de determinação sexual e uma maior conservação do número cariotípico (Henning et al., 2010). Segundo Henning (2010), a reconstrução filogenética das diversas espécies de Eigenmannia com base em genes mitocondriais mostrou que as espécies que possuem sistemas sexuais agrupam com aqueles nos quais os sistemas não apresentam cromossomos sexuais morfologicamente distintos. Esse seria um indício de que a diferenciação dos cromossomos sexuais é recente, levantando assim uma hipótese sobre a origem múltipla desse sistema, fato também verificado por Henning (2007), em estudo no qual a realização de um experimento com sondas específicas para os cromossomos sexuais não demonstrou similaridades entre espécies que possuem sistemas sexuais distintos, reforçando a possível origem múltipla do sistema.

\section{rDNA 5S}

O gene ribossômico $5 \mathrm{~S}$ é uma das sequências repetitivas funcionais amplamente estudados do ponto de vista citogenético nos mais diferentes grupos (Ruth et al., 2012; Traldi et al., 2013; El-Twab \& Kondo, 2013). Esse gene é parte da família multigênica que codifica para o RNA ribossômico $5 \mathrm{~S}$ e consiste em uma região altamente conservada com aproximadamente $120 \mathrm{pb}$, cuja unidade transcripcional é separada por um espaçador não transcrito (NTS) (Long \& David, 1980) e organizada em repetições em tandem contendo de centenas a milhares de cópias. Além dessa caracterização da localização cromossômica inúmeros estudos têm utilizado o NTS como uma ferramenta para o estudo entre espécies intimamente relacionadas, fato esse diretamente associado à elevada dinâmica dessa região genômica, possuindo, portanto, uma grande quantidade de sítios informativos, os quais são utilizados na produção de filogenias (Baker et al., 2000; Baum et al., 2004; Kitamura et al., 2005; Baum \& Johnson, 2007). Em peixes o 
NTS foi utilizado em diversos grupos para a identificação de espécies intimamente relacionadas, subespécies, linhagens e híbridos (Pendas et al., 1995; Martins \& Wasko, 2004; Robles et al., 2005; Irani et al., 2007). Ainda há estudos onde foi verificada a presença de diferentes classes do rDNA 5S (Campo et al., 2009), evidenciando a complexidade dessa região do genoma. São escassos os estudos envolvendo o gene ribossômico 5S juntamente com seu NTS, na reconstrução das relações dentre os Gymnotiformes, sendo a grande maioria dos trabalhos relacionada apenas à localização física das sequências do gene determinadas através de hibridação in situ (Silva et al., 2011).

A análise da família multigênica rDNA 5S permitirá uma melhor compreensão da sua dinâmica evolutiva não só do rDNA 5S, mas também da dinâmica e conservação dessa região no cariomorfos estudados do gênero Eigenmannia. O objetivo do presente trabalho é caracterizar do ponto de vista molecular, ambas as sequências, uma vez que a região do espaçador do gene ribossômico $5 \mathrm{~S}$ apresenta variabilidade acentuada e que essa região tem se mostrado informativa para muitos estudos entre espécies próximas (Zhu et al., 2008).

\section{Materiais e Métodos}

\section{Extração do DNA Genômico}

O DNA total dos exemplares foi extraído utilizando-se o protocolo de extração salina segundo Aljanabi \& Martinez, 1997. Amostras a partir de tecidos do fígado, coração ou sangue, preservados em álcool 96\%, foram homogeneizadas em tampão 
salino $(\mathrm{NaCl}$ 0.6M, 10mM Tris- $\mathrm{HCl} \mathrm{pH} 8.0,2 \mathrm{mM}$ EDTA $\mathrm{pH} 8.0)$, as quais foram posteriormente adicionadas, proteinase $\mathrm{K}(400 \mu \mathrm{g} / \mathrm{ml})$ e uma solução de SDS $20 \%$ (concentração final de 2\%). Após esse passo as amostras sofreram duas incubações consecutivas, sendo a primeira a $65^{\circ} \mathrm{C}$ por aproximadamente 1 hora e a segunda com a adição de RNase à solução $(0.25 \mathrm{mg} / \mathrm{ml})$ por 1 hora a $37^{\circ} \mathrm{C}$. Foi então adicionada às amostras uma solução de $\mathrm{NaCl} 6 \mathrm{M}$ (concentração final de $2.38 \mathrm{M}$ ) e, em seguida, estas foram levadas ao vortex em alta velocidade por aproximadamente 1 minuto, sendo então centrifugadas a $10.000 \mathrm{G}$ a $4^{\circ} \mathrm{C}$ por 30 minutos. $\mathrm{O}$ sobrenadante foi transferido para um tubo limpo, ao qual se adicionou o dobro de volume de isopropanol, misturando bem por inversão do tubo. Feito isso as amostras foram então incubadas a $20^{\circ} \mathrm{C}$ por aproximadamente 1 hora e novamente centrifugadas a $10.000 \mathrm{G}$ a $4^{\circ} \mathrm{C}$ por 20 minutos. Terminado o processo, o sobrenadante foi descartado e o pellet lavado em etanol $70 \%$ em uma centrifugação a $10.000 \mathrm{G}$ a $4^{\circ} \mathrm{C}$ por 10 minutos. O sobrenadante foi novamente descartado, o pellet secado ao ar e adicionado volume de água não superior a $50 \mu 1$ para eluição, sendo esse volume determinado de acordo com o tamanho do pellet obtido.

\section{Gene Ribossômico 5S}

O gene ribossômico 5S foi amplificado através da técnica de PCR (Polimerase Chain Reaction) utilizando-se os primers 5'-TACGCCCGATCTCGTCCGATC-3' e 5'CAGGCTGGTATGGCCGTAAGC-3, os quais foram desenvolvidos para a região de rDNA de Salmo gairdneri (Komiya \& Takemura 1979). A reação foi realizada com volume final de $25 \mu 1$ tendo como concentrações finais $1 \mathrm{mM}$ de $\mathrm{Mg}^{2+}, 0.4 \mathrm{ng}$ de DNA genômico, 0.4 pmol de cada primer, 0.1U de Taq Polimerase, 0.04mM de dNTP mix, 1x de tampão Taq Polimerase $\mathrm{KCl}, 1 \mathrm{x}$ de tampão Taq Polimerase $(\mathrm{NH} 4)_{2} \mathrm{SO}_{3}$. O ciclo 
básico para amplificação dessa região consistiu em uma denaturação a $94^{\circ} \mathrm{C}$ por 5 minutos, seguida de 24 ciclos de 1 minuto a $95^{\circ} \mathrm{C}, 30$ segundos a $61^{\circ} \mathrm{C}, 1$ minuto a $72^{\circ} \mathrm{C}$ e uma extensão final de 10 minutos a $72^{\circ} \mathrm{C}$. Posteriormente os produtos obtidos foram submetidos a nova amplificação, dessa vez utilizando-se uma polimerase proofreading (Pfx $50^{\mathrm{TM}}$ DNA Polymerase - Invitrogen). A reação é feita para um volume final de $25 \mu 1$, tendo como concentrações finais $0.3 \mathrm{mM}$ dNTP mix, $0.3 \mathrm{pmol}$ de cada primer, $10 \mathrm{x}$ Pfx $50{ }^{\mathrm{TM}}$ PCR Mix, 0.1U Pfx $50{ }^{\mathrm{TM}}$ DNA Polymerase, 0.4ng produto de PCR. O ciclo utilizado corresponde a uma denaturação a $94^{\circ} \mathrm{C}$ por 5 minutos, seguida de 19 ciclos de 30 segundos a $94^{\circ} \mathrm{C}, 30$ segundos a $68^{\circ} \mathrm{C}, 15$ segundos a $72^{\circ} \mathrm{C}$ e um passo final de 5 minutos a $72^{\circ} \mathrm{C}$. Essa reação produziriu fragmentos de ponta cega, permitindo então a clonagem através do kit Zero Blunt TOPO $^{\circledR}$ (Invitrogen), realizada de acordo com as especificações do fabricante. Após a clonagem, uma reação de PCR utilizando-se os primers M13f (5' - GTA AAA CGA CGG CCA GT - 3') e M13r (5' - GTA AAA CGA CGG CCA GT - 3') foi feita, para verificação da eficiência da clonagem e escolha das amostras, as quais estão dentro do tamanho esperado. A reação foi realizada com volume final de $25 \mu 1$, tendo como concentrações finais $1 \mathrm{mM}$ de $\mathrm{Mg}^{2+}, 0.04 \mathrm{mM}$ dNTP Mix, 0.1U de Taq Polimerase, 1x de tampão Taq Polimerase (NH4) ${ }_{2} \mathrm{SO}_{3}$ e $0.4 \mathrm{pmol}$ de cada primer (M13f e M13r). Uma vez feito o mix de reação, utilizou-se a técnica de toothpick para transferir parte da colônia diretamente ao tubo de reação com auxílio de uma ponteira estéril, não sendo, portanto necessária a extração do plasmídeo para realização da reação. Determinados os clones que apresentam o tamanho esperado de banda, foi feito o sequenciamento utilizando-se o kit BigDye ${ }^{\circledR}$ Terminator v3.1 Cycle Sequencing Kit, de acordo com as especificações do fabricante.

\section{Hibridação in situ}


A hibridação in situ, realizada conforme Conway (1996), incluiu um pré tratamento das lâminas que consiste em uma incubação em solução a $100 \mu \mathrm{g} / \mathrm{ml}$ de RNase, seguida de uma lavagem em solução de $10 \mathrm{mM}$ de $\mathrm{HCl}$ contendo $0.02 \%$ de pepsina e um passo de pós fixação em PBS contendo $50 \mathrm{mM}$ de $\mathrm{MgCl} 2$ e $1 \%$ de formaldeído. Uma vez feito o pré tratamento, as lâminas foram denaturadas numa solução de formamida $70 \%$ em $2 x \operatorname{SSC}$ a $72^{\circ} \mathrm{C}$ e a sonda a $100^{\circ} \mathrm{C}$ em uma solução contendo $50 \%$ de formamida, $10 \%$ de sulfato de dextrano e 2XSSC. Para a hibridação as lâminas foram incubadas overnight em câmara úmida a $37^{\circ} \mathrm{C}$. A amplificação do sinal, consistiu em duas incubações com Fitc-Avidina e uma com Anti-Avidina-Biotina a $37^{\circ} \mathrm{C}$ em câmara úmida, seguida após cada incubação, de uma lavagem em solução contendo $0.5 \%$ de Tween 20 e 4xSSC. O passo final consistiu na desidratação das lâminas e posterior montagem com antifade contendo DAPI.

\section{Análise das sequências}

As sequências foram editadas e analisadas através utilizando o programa CodonCode Aligner v. 3.5.7. Para o cálculo do melhor modelo evolutivo, construção das árvores de máxima verossimilhança, máxima parcimônia e Neighbor-Joining, bem como o cálculo das distâncias entre os cariomorfos em estudo, foi utilizou o programa MEGA 5.10.

\section{Resultados}

A amplificação do gene ribossômico $5 \mathrm{~S}$, juntamente com seu NTS permitiu a visualização de duas bandas (Fig. 3) com aproximadamente 300pb e 500pb. Os cariomorfos apresentaram uma sequência com um tamanho total de $294 \mathrm{pb}$ para a banda de menor tamanho, tendo o gene ribossômico funcional um tamanho aproximado de 
$100 \mathrm{pb}$ e seu espaçador um total de 194pb (Fig. 4), enquanto para a banda de maior tamanho a sequência total apresentava um tamanho de $478 \mathrm{pb}$, dentre as quais $378 \mathrm{pb}$ correspondem ao NTS (Fig. 5). O gene ribossômico em si, mostrou-se altamente conservado entre os cariomorfos, enquanto que o espaçador mostrou-se informativo em ambas as sequências de maior e menor tamanho. Foi feita ainda uma comparação par a par das sequências, de modo a identificar suas principais diferenças (Figs. 6, 7, 8 e 9) e foi possível verificar que essas diferenças concentram-se basicamente no espaçador não transcrito, sendo o gene altamente conservado, fato esse já observado na literatura (Long \& David, 1980; Suzuki et al., 1994). De modo complementar, uma análise mais abrangente foi levada a efeito, sendo possível verificar que a sequência de maior tamanho apresenta aproximadamente $13 \%$ dos sítios variáveis, enquanto que a sequência de menor tamanho, cerca de 14,7\%. O melhor modelo evolutivo foi calculado, utilizando-se o programa MEGA 5.10 e para as sequências de menor tamanho, foi determinado o modelo Jukes-Cantor, apresentando o menor BIC (Bayesian Information Criterion) com valor de 1269.593 enquanto que para as sequências de maior tamanho o melhor modelo evolutivo calculado foi Kimura-2-parâmetros, com BIC de 1808.992. Determinados os modelos, foram então construídas as tabelas de distância entre os cariomorfos para ambas as sequências (Tabelas 1 e 2), bem como foram construídas as árvores de Máxima Verossimilhança (MV) (Fig. 10a e 10b), Máxima Parcimônia (MP) (Fig. 11a e 11b) e Neighbor-Joining (NJ) (Fig. 12a e 12b) com cálculo de bootstrap para verificação do suporte dos ramos. Verificou-se que para os testes utilizados, no caso da banda de maior tamanho recuperou-se exatamente a mesma topologia na reconstrução. Com relação a banda de menor tamanho a árvore de máxima parcimônia diferiu das de NJ e MV, apresentando uma topologia distinta no que diz respeito aos cariomorfos $2 n=31 / 32$ e $2 n=28$, sendo o último considerado o mais 
ancestral, enquanto que nas outras árvores estes formam um ramo e compartilham um ancestral comum com o outro ramo que engloba os cariomorfos $2 n=36,2 n=38$ e $2 \mathrm{n}=38 X Y$.

O cálculo e a análise das distâncias genéticas utilizando-se como modelo Kimura 2 parâmetros demonstrou que apesar da pequena variabilidade essa região do gene ribossômico 5S juntamente com seu NTS, correspondente à banda de menor tamanho, foram suficientemente informativos para a delimitação de cinco grupos monofiléticos, os quais correspondem aos cariomorfos em estudo. Dentre eles, os mais próximos são os cariomorfos $2 \mathrm{n}=38 \mathrm{XY}$ e $2 \mathrm{n}=38$ (distância de 0.0035 ) e os mais distantes $2 \mathrm{n}=28$ e 2n=36 (distância de 0.1208). O esboço das relações por sua vez permitiu a delimitação de dois grandes grupos, um deles englobando os cariomorfos de menor número cromossômico $(2 n=28$ e $2 n=31 / 32)$ e o outro, os de maior número cromossômico $(2 n=36,2 n=38$ e $2 n=38 X Y)$. O suporte associado aos ramos mostrou-se elevado, evidenciando uma topologia bem resolvida. A amplificação da banda maior do gene ribossômico $5 \mathrm{~S}$ foi efetuada em todas as espécies em estudo. A espécie $2 \mathrm{n}=31 / 32$, contudo não apresentou essa banda (Fig. 3). As distâncias genéticas entre os cariomorfos foram calculadas (Tabela 2) e, do mesmo modo que foi obtido para a sequência de menor tamanho associada ao gene ribossômico $5 \mathrm{~S}$, foi possível observar uma pequena variabilidade entre as sequências, variabilidade essa associada apenas ao NTS, sendo os cariomorfos mais próximos geneticamente $2 \mathrm{n}=38 \mathrm{XY} / 2 \mathrm{n}=38$ (distância de 0.007 ) e os mais distantes $2 \mathrm{n}=36 / 2 \mathrm{n}=28$ (distância de 0.085). Comparando valores obtidos para a sequência de maior tamanho e a de menor tamanho (Tabela 3), foi possível verificar que ambas apresentam valores de distâncias próximos, um possível indicativo da recente separação entre os cariomorfos. 
Além da análise molecular, as sequências do gene ribossômico $5 \mathrm{~S}$ foram hibridadas in situ para o mapeamento cromossômico dessa região do genoma entre as espécies do grupo (Fig. 13). Foi observada uma grande conservação com relação à posição do sítio, comumente encontrados muito próximos aos centrômeros de cromossomos acrocêntricos. Apresentaram variação três dos cariomorfos estudados, $2 n=28$ com marcação terminal em um cromossomo metacêntrico e no braço de um cromossomo acrocêntrico, $2 \mathrm{n}=38$ com marcação no braço curto de um cromossomo submetacêntrico e $2 n=31 / 32$ com marcação no macho $2 n=31$ em um cromossomo metacêntrico. Quanto ao número de sítios entre as espécies, foi verificada uma grande variabilidade, com o mínimo de dois sítios e com o máximo de 18 sítios. Não foi observada qualquer relação entre o número cromossômico e a quantidade de sítios presentes, bem como uma correlação entre os dois grandes grupos (maior e menor número cromossômico) determinados pela análise da sequência do gene ribossômico $5 \mathrm{~S}$ e a quantidade de sítios presentes nas espécies em estudo. Apesar disso, foi possível identificar variações no número de sítios entre machos e fêmeas nas espécies 2 n=38XY e $2 n=31 / 32$, sendo que em ambos os casos, o macho apresenta um sítio a menos do que as fêmeas. No caso da espécie $2 \mathrm{n}=38 \mathrm{XY}$, foi verificado que dois dos 18 sítios encontrados nas fêmeas estão associados ao cromossomo X (Fig. 14a), facilmente identificável pela presença de blocos heterocromáticos grandes em um de seus braços. Quando hibridado o macho dessa mesma espécie, verificou-se a presença de apenas 17 sítios (Fig. 14b). Com relação à espécie $2 n=31 / 32$ onde o macho apresenta 2 n=31 e a fêmea $2 \mathrm{n}=32$, a fêmea apresenta um total de quatro sítios, todos em cromossomos acrocêntricos (Fig. 15a), enquanto que o macho, como já citado anteriormente, possui um sítio em um cromossomo metacêntrico em uma região próxima ao centrômero e 
outros dois em cromossomos acrocêntricos (Fig. 15b), também próximos ao centrômero.

Figura 3: Gel de agarose 1\% evidenciando a ausência da banda de maior tamanho no cariomorfo $2 n=31 / 32$ (correspondentes às duas últimas raias à direita), em relação às outras espécies em estudo. À esquerda marcador de peso molecular 1Kb (Fermentas).

\begin{tabular}{|c|c|c|}
\hline & $\mathbf{5 S m}$ & $\mathbf{5 S M}$ \\
\hline $\mathbf{2 n}=\mathbf{3 8 X Y} / \mathbf{2 n}=\mathbf{3 8}$ & 0,004 & 0,007 \\
\hline $\mathbf{2 n}=\mathbf{3 8} / \mathbf{2 n}=\mathbf{3 6}$ & 0,029 & 0,038 \\
\hline $\mathbf{2 n}=\mathbf{3 8} / \mathbf{2 n}=\mathbf{2 8}$ & 0,105 & 0,083 \\
\hline $\mathbf{2 n}=\mathbf{3 8 X Y} / \mathbf{2 n}=\mathbf{3 6}$ & 0,032 & 0,036 \\
\hline $\mathbf{2 n}=\mathbf{3 8 X Y} / \mathbf{2 n}=\mathbf{2 8}$ & 0,109 & 0,076 \\
\hline $\mathbf{2 n}=\mathbf{3 6} / \mathbf{2 n}=\mathbf{2 8}$ & 0,121 & 0,085 \\
\hline
\end{tabular}

Tabela 3: Comparação entre distâncias genéticas par a par obtidas para as sequências de menor (5Sm) e maior tamanho (5SM) do gene ribossômico 5S. 


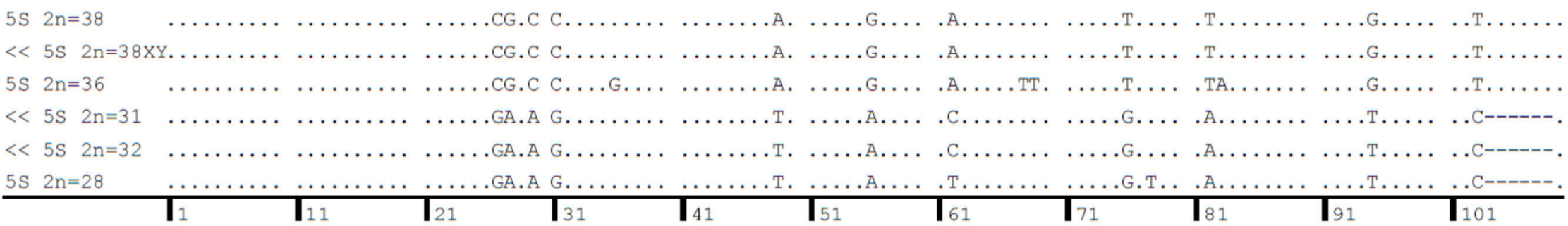

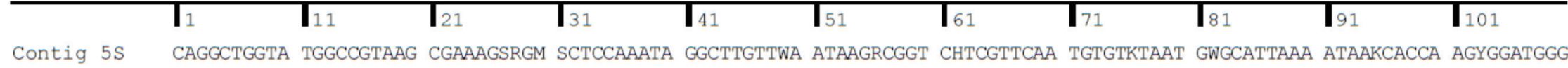
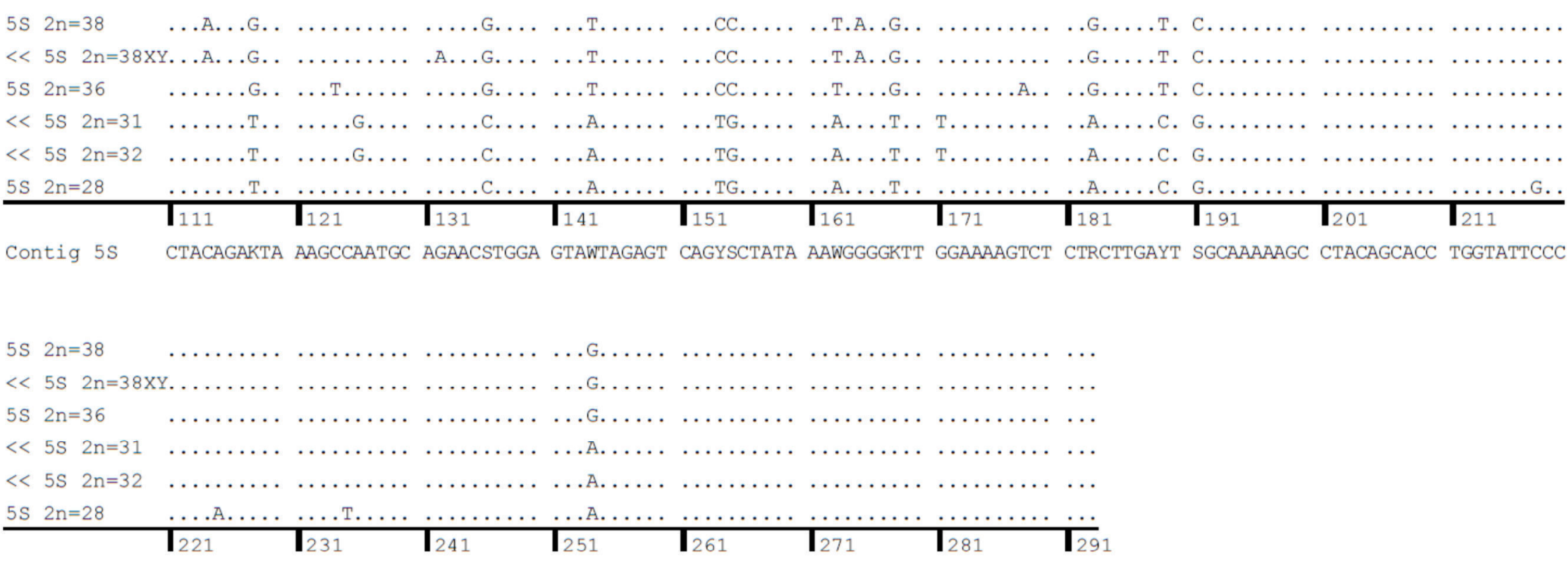

Contig 5s AGGCGGTCTC CCATCCAAGT ACTGACCAGG CCCRACCCTG CTTAGCTTCC GAGATCGGAC GAGATCGGGC GTA

Figura 4: Alinhamento das sequências do gene ribossômico 5S juntamente com seu NTS. Pontos indicam bases iguais e traços indicam deleções. Abaixo sequência consenso entre as espécies determinado pelo programa CodonCode Aligner. 


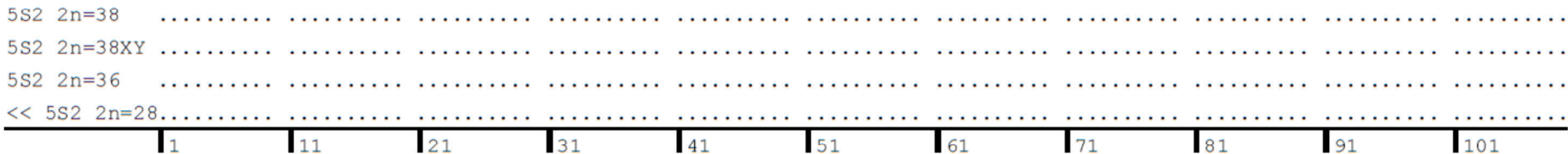

5 S2 Contig TACGCCCGAT CTCGTCCGAT CTCGGAAGCT AAGCAGGGTC GGGCCTGGTC AGTACTTGGA TGGGAGACCG CCTGGGAATA CCAGGTGCTG TAAGCTTTTTT GCGAGTCAAG

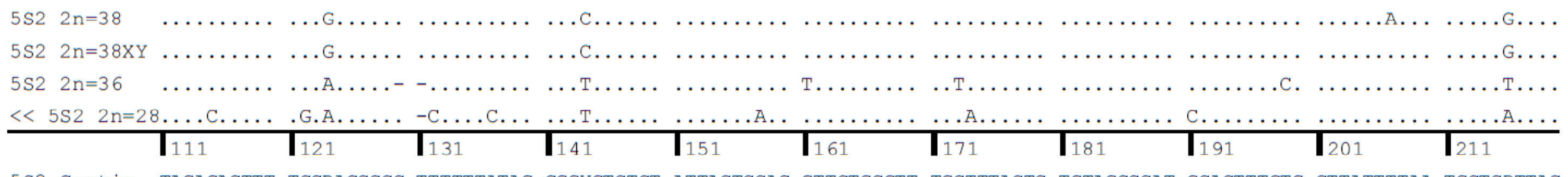

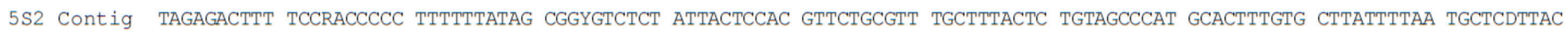

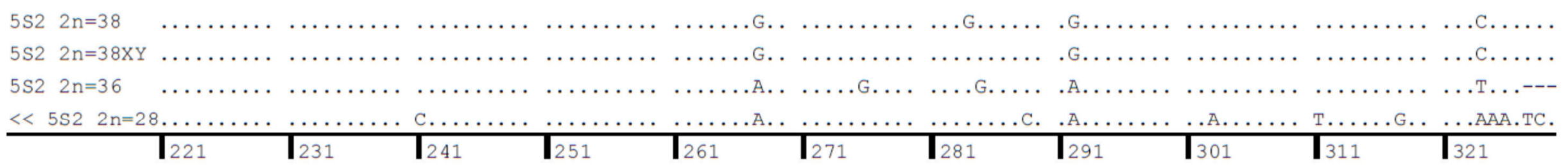

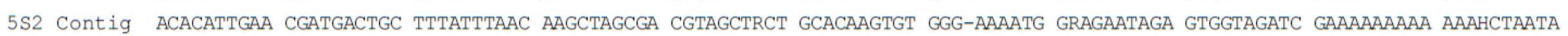




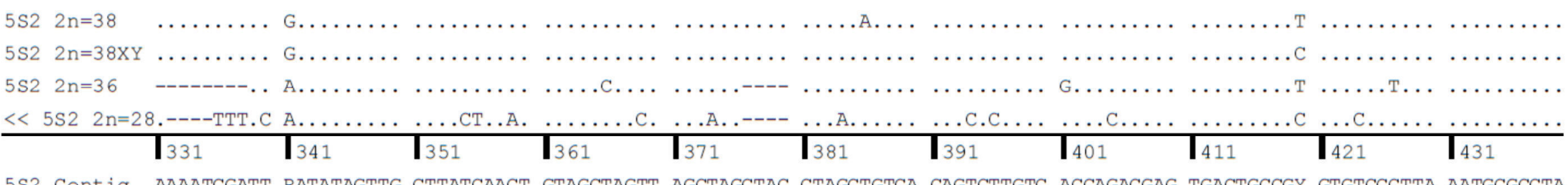

5 s2 Contig AAAATCGATT RATATAgTtG CTTATCAACT GTAGCTAGTT AGCTAGCTAC CTAGCTGTCA CAGTCTTGTC ACCAGACGAg TGACTGCCGY GTGTCCCTTA AATGCGCCTA

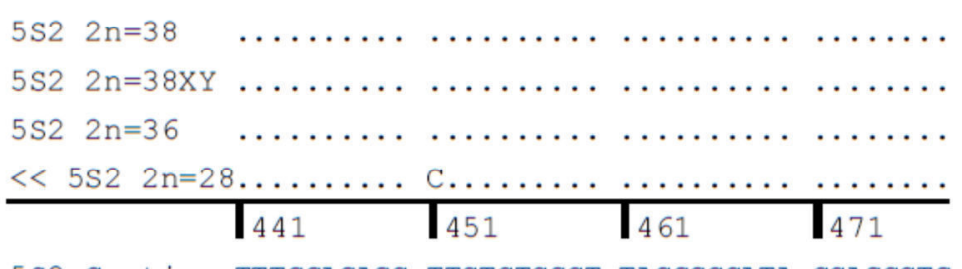

5 S2 Contig TTTGGAGAGC TTCTCTCGCT TACGGCCATA CCAGCCTG

Figura 5: Alinhamento das sequências do gene ribossômico 5S, oriundas da banda de maior tamanho, juntamente com seu NTS. Pontos indicam bases iguais e traços indicam deleções. Abaixo sequência consenso entre as espécies determinado pelo programa CodonCode Aligner. 


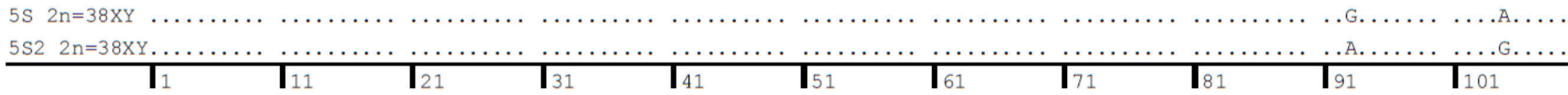

4356 5S/5S2TACGCCCGAT CTCGTCCGAT CTCGGAAGCT AAGCAGGGTC GGGCCTGGTC AGTACTTGGA TGGGAGACCG CCTGGGAATA CCAGGTGCTG TARGCTTTTT GCGARTCAAG

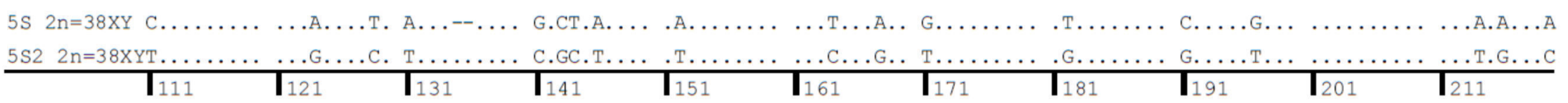

4356 5S/5S2YAGAGACTTT TCCRACCCYC WTTTTTATAG SGSYGWCTCT AWTACTCCAC GTTYTGCRTT KGCTTTACTC TKTAGCCCAT SCACTTKGTG CTTATTTTAA TGCWCRTTAM

5S $2 n=38 X Y \ldots \ldots \ldots \ldots \ldots \ldots$... C............ TTATTT G.AG.--..C ..TTTC.CT. AC.GCC. .AC C..CC.G

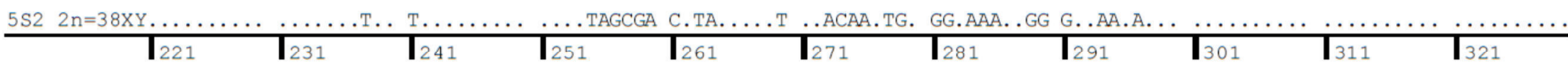

4356 5S/5S2ACACATTGAA CGATGACYGC YTTATTTAAC AAGCYWRYKW SGWRGCTGCY GCWYWMGYKT RSGRMMATRS SAGMMTRGAG TGGTAGATCG AAAAAAAAAA AACCTAATAA

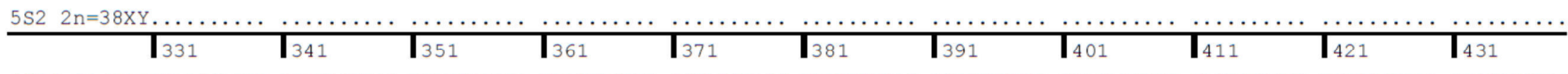

4356 5S/5S2AAATCGATTG ATATAGTTGC TTATCAACTG TAGCTAGTTA GCTAGCTACC TAGCTGTCAC AGTCTTGTCA CCAGACGAGT GACTGCCGCG TGTCCCTTAA ATGCGCCTAT

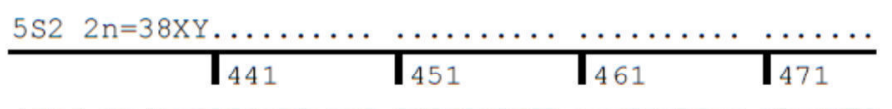

4356 5S/5S2TTGGAGAGCT TCTCTCGCTT ACGGCCATAC CAGCCTG

Figura 6: Alinhamento das sequências de menor e maior tamanho do gene ribossômico 5S, juntamente com seu NTS para a espécie $2 \mathrm{n}=38 \mathrm{XY}$.

Pontos indicam bases iguais e traços indicam deleções. Abaixo sequência consenso entre as espécies determinado pelo programa CodonCode Aligner. 


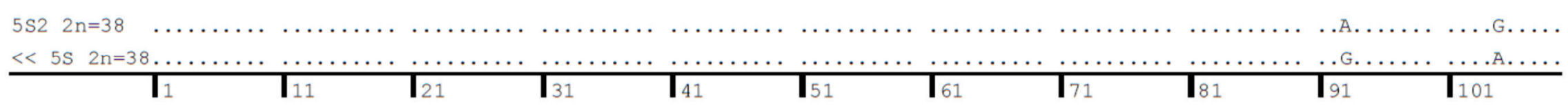

3524 5S/5S2TACGCCCGAT CTCGTCCGAT CTCGGAAGCT AAGCAGGGTC GGGCCTGGTC AGTACTTGGA TGGGAGACCG CCTGGGAATA CCAGGTGCTG TARGCTTTTT GCGARTCAAG

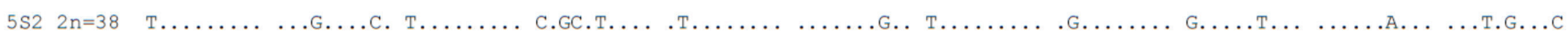

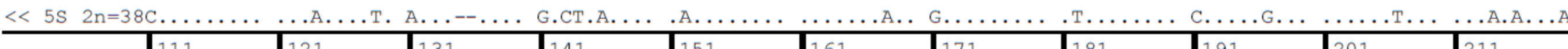

3524 5S/5S2YAGAGACTTT TCCRACCCYC WTTTTTATAG SGSYGWCTCT AWTACTCCAC GTTCTGCRTT KGCTTTACTC TKTAGCCCAT SCACTTKGTG CTTATTWTAA TGCWCRTTAM

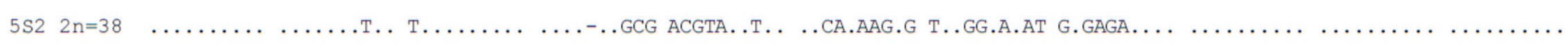

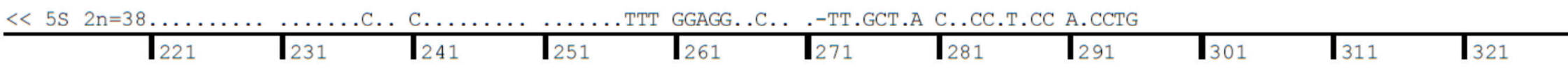

3524 5S/5S2ACACATTGAA CGATGACYGC YTTATTTAAC AAGCCTAKYK RSRKRGCYGC TGYWCRMKTR YGGSSAWAMY RGSMKRATAG AGTGGTAGAT CGAAAAAAAA AAAACCTAAT

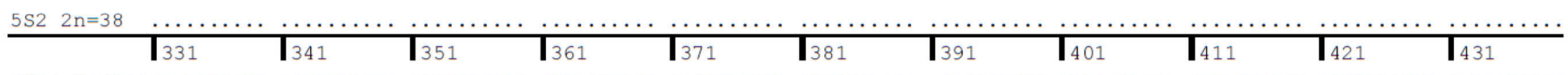

3524 5S/5S2AAAAATCGAT TGATATAGTT GCTTATCAAC TGTAGCTAGT TAGCTAGCTA CCTAGCAGTC ACAGTCTTGT CACCAGACGA GTGACTGCCG TGTGTCCCTT AAATGCGCCT

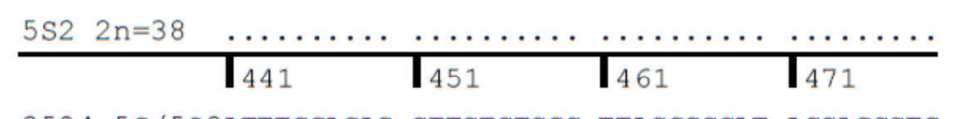

3524 5S/5S2ATTTGGAGAG CTTCTCTCGC TTACGGCCAT ACCAGCCTG

Figura 7: Alinhamento das sequências de menor e maior tamanho do gene ribossômico $5 \mathrm{~S}$, juntamente com seu NTS para a espécie $2 \mathrm{n}=38$.

Pontos indicam bases iguais e traços indicam deleções. Abaixo sequência consenso entre as espécies determinado pelo programa CodonCode Aligner. 


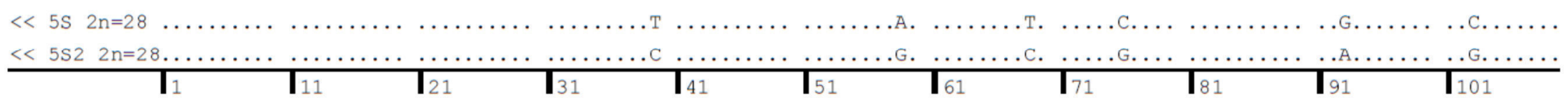

3178 5S/5S2 TACGCCCGAT CTCGTCCGAT CTCGGAAGCT AAGCAGGGTY GGGCCTGGTC AGTACTTGRA TGGGAGACYG CCTGGSAATA CCAGGTGCTG TARGCTTTTT GCSAGTCAAG

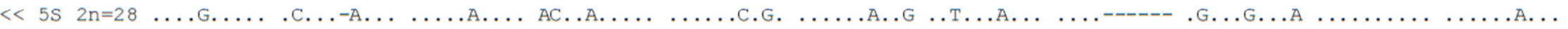

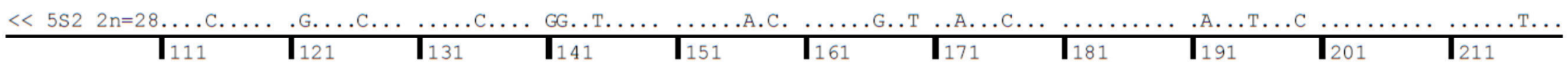

3178 5S/5S2 TAGASACTTT TSCAACMCCC CTTTTMTAGC RSTGWCTCTA TTACTCMASG TTCTGCRTTK GCWTTAMTCT GTAGCCCATC CRCTTKGTGM TTATTTTAAT GCTCATWACA

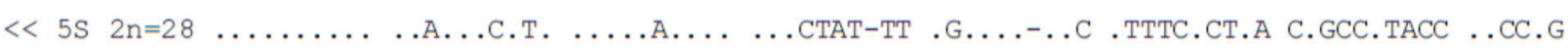

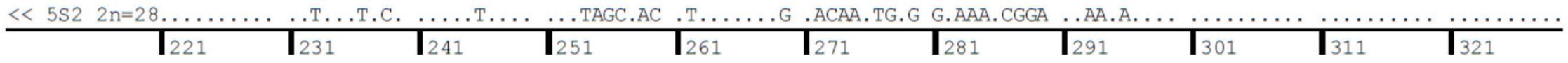

3178 5S/5S2 CACATTGAAC GAWGACYGYC TTATTWAACA AGCYWRYGWY GKAGCTACTS CWYWMGYKTR SGRMMAYRSM AGMMTRGAGT AGTAGATCTA AAAAAGAAAA AAAAATCAAT

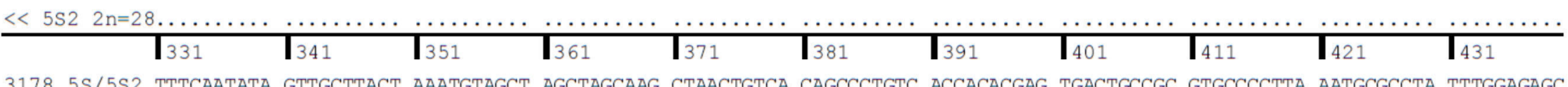

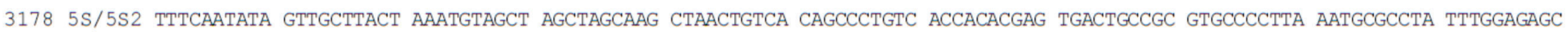

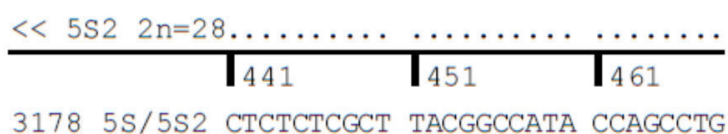

Figura 8: Alinhamento das sequências de menor e maior tamanho do gene ribossômico $5 \mathrm{~S}$, juntamente com seu NTS para a espécie $2 \mathrm{n}=28$. Pontos indicam bases iguais e traços indicam deleções. Abaixo sequência consenso entre as espécies determinado pelo programa CodonCode Aligner. 


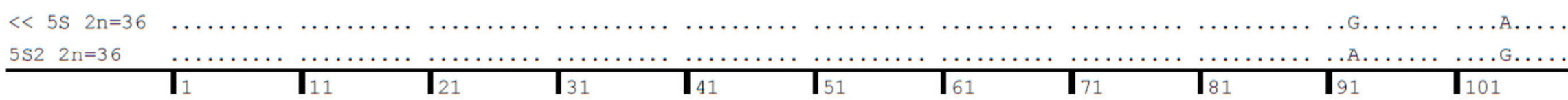

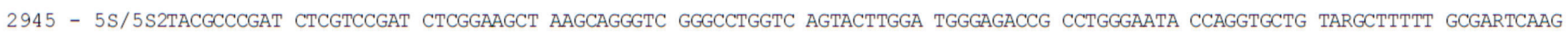

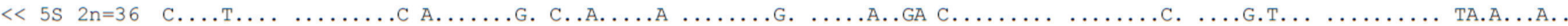

\begin{tabular}{l}
$5 \mathrm{~S} 2 \mathrm{n}=36$ \\
\hline
\end{tabular}

2945 - 5S/5S2YAGAGWCTTT TCCAACCCCY WTTTATAGSG STGWCTCTAW TACTCCACKT TCTGCRTTKR YTTTACTCTG TAGCCCATSC ACTTKGYGCT TATTTTAATG YWCWTTAMAC

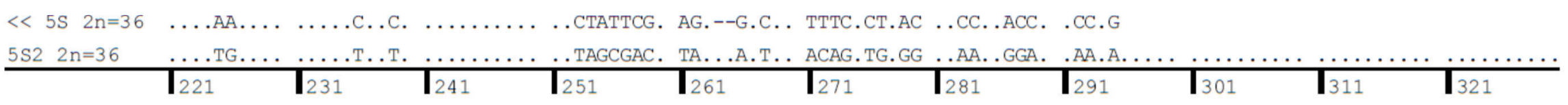

2945 - 5S/5S2ACATWRAACG ATGACYGCYT TATTTAACAA GCYWRYKMSG WRGCTRCYGC WYWSGYKTRS GGMMATRSMA GMMTRGAGTG GTAGATCGAA AAAAAAAAAA TCTATTAATA

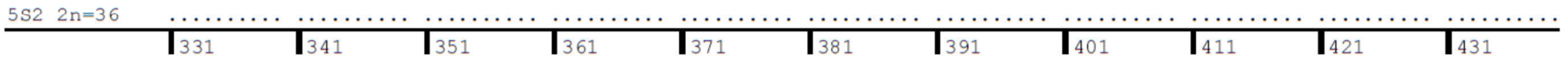

2945 - 5S/5S2TAGTTGCTTA TCAACTGTAG CCAGTTAGCT AGCTAGCTGT CACAGTCTTG TCGCCAGACG AGTGACTGCC GTGTGTCCTT TAAATGCGCC TATTTGGAGA GCTTCTCTCG

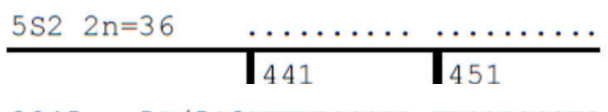

2945 - 5S/5S2CTTACGGCCA TACCAGCCTG

Figura 9: Alinhamento das sequências de menor e maior tamanho do gene ribossômico $5 \mathrm{~S}$, juntamente com seu NTS para a espécie $2 \mathrm{n}=36$. Pontos indicam bases iguais e traços indicam deleções. Abaixo sequência consenso entre as espécies determinado pelo programa CodonCode Aligner 


\begin{tabular}{|l|c|l|l|l|l|}
\hline & $2 \mathrm{n}=38$ & $2 \mathrm{n}=38 \mathrm{XY}$ & $2 \mathrm{n}=36$ & $2 \mathrm{n}=31 / 32$ & $2 \mathrm{n}=28$ \\
\hline $2 \mathrm{n}=38$ & - & & & & \\
\hline $2 \mathrm{n}=38 \mathrm{XY}$ & 0.0035 & - & & & \\
\hline $2 \mathrm{n}=36$ & 0.0284 & 0.0320 & - & & \\
\hline $2 \mathrm{n}=31 / 32$ & 0.0965 & 0.1005 & 0.1126 & - & \\
\hline $2 \mathrm{n}=28$ & 0.1045 & 0.1085 & 0.1207 & 0.0248 & - \\
\hline
\end{tabular}

Tabela 1: Distâncias genéticas para as sequências de menor tamanho entre os cariomorfos em estudo, utilizando-se o modelo Jukes-Cantor.

\begin{tabular}{|l|r|r|r|c|}
\hline & $2 \mathrm{n}=38$ & $2 \mathrm{n}=38 \mathrm{XY}$ & $2 \mathrm{n}=36$ & $2 \mathrm{n}=28$ \\
\hline $2 \mathrm{n}=38$ & - & & & \\
\hline $2 \mathrm{n}=38 \mathrm{XY}$ & 0,007 & - & & \\
\hline $2 \mathrm{n}=36$ & 0,038 & 0,036 & - & \\
\hline $2 \mathrm{n}=28$ & 0,083 & 0,076 & 0,085 & - \\
\hline
\end{tabular}

Tabela 2: Distâncias genéticas para as sequências de maior tamanho entre os cariomorfos em estudo, utilizando-se o modelo Kimura-2-Parâmetros. 
a.

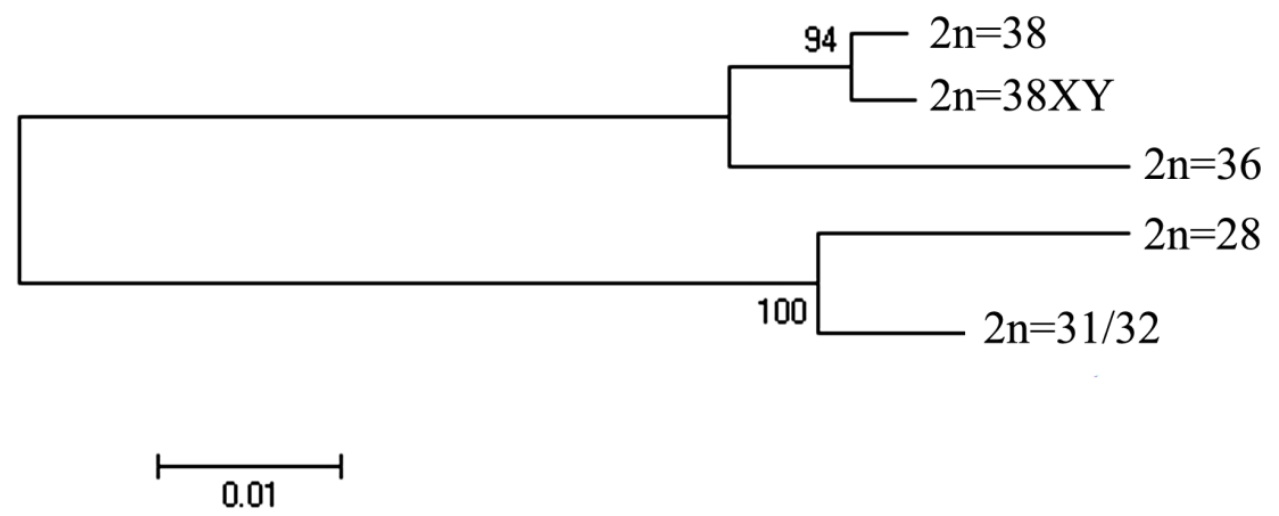

b.

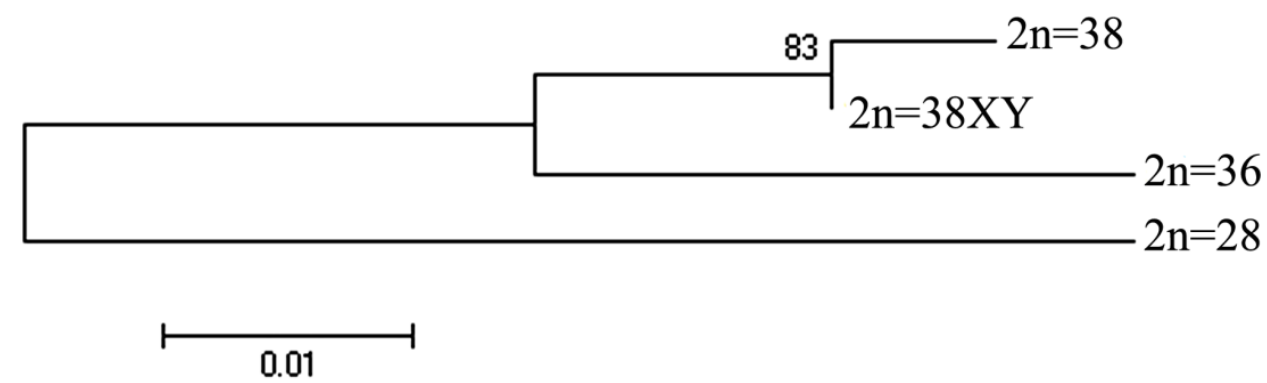

Figura 10: Comparação das topologias das árvores de Máxima Verossimilhança (MV) com cálculo de bootstrap (1000 pseudoréplicas), utilizando-se o modelo Kimura-2Parâmetros, para as sequencias de menor (a) e maior (b) tamanho do gene ribossômico $5 \mathrm{~S}$. 
a.

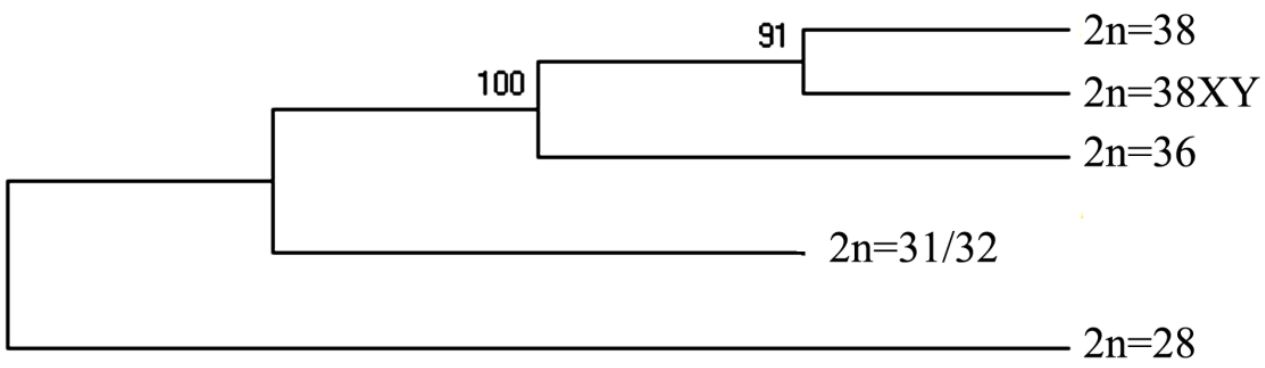

b.

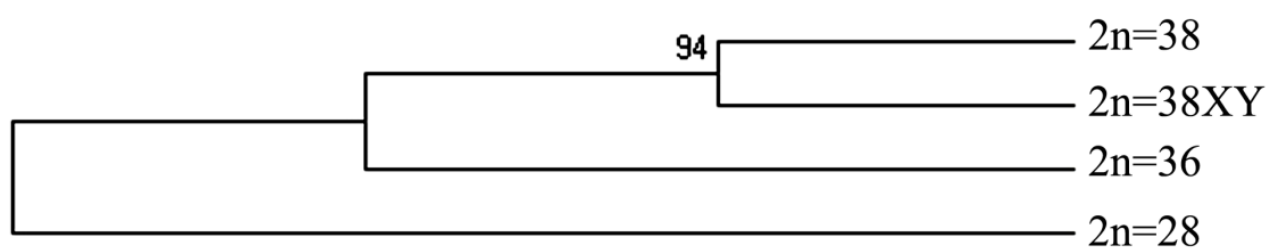

Figura 11: Comparação das topologias das árvores de Máxima Parcimônia (MP) com cálculo de bootstrap (1000 pseudoréplicas), utilizando-se o modelo Kimura-2Parâmetros, para as sequencias de menor (a) e maior (b) tamanho do gene ribossômico $5 \mathrm{~S}$. 
a.
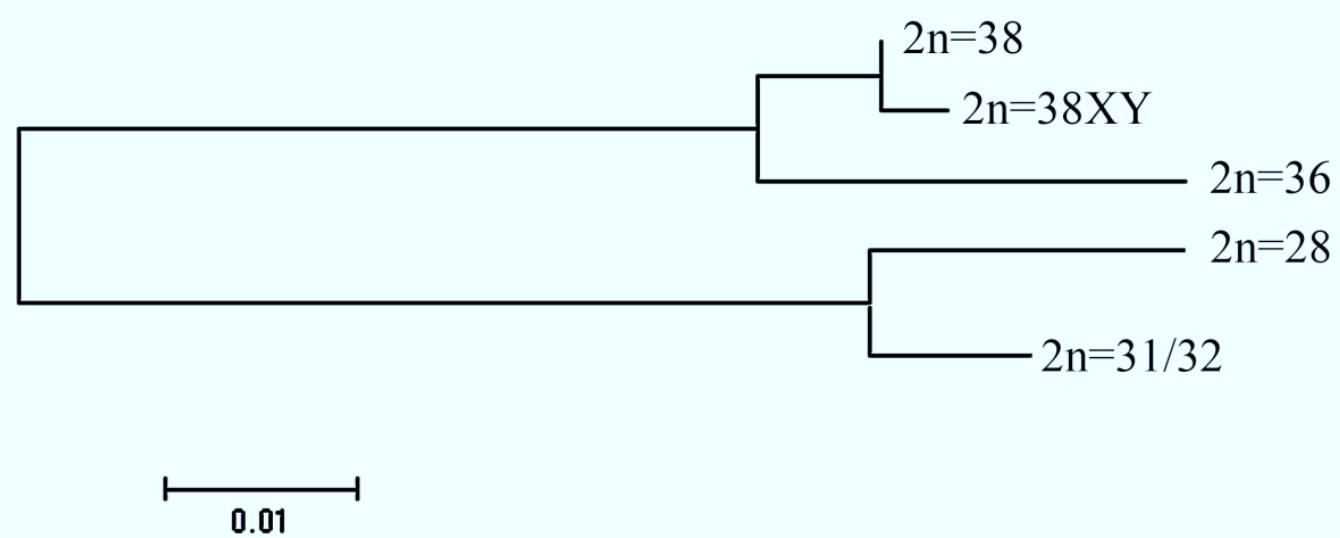

b.
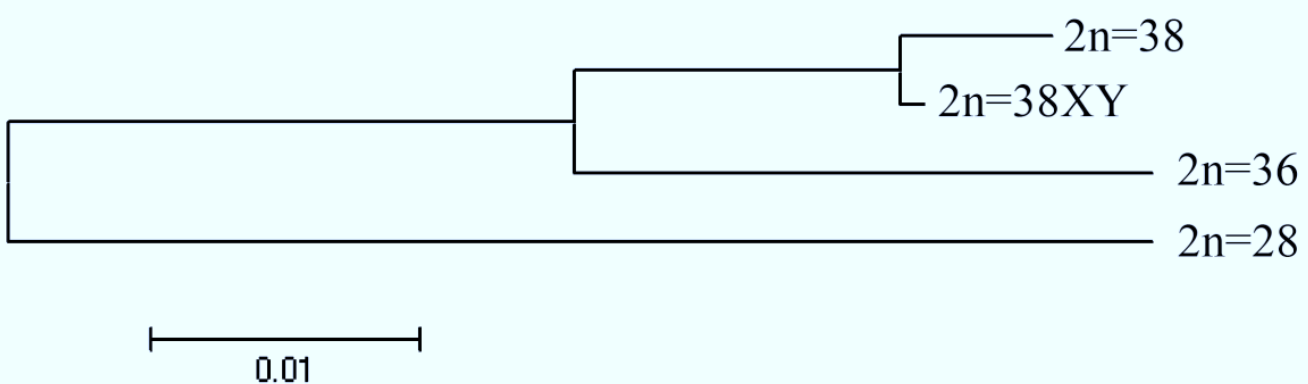

Figura 12: Comparação das topologias das árvores de Neighbour-Joining (NJ) com cálculo de bootstrap (1000 pseudoréplicas), utilizando-se o modelo Kimura-2Parâmetros, para as sequências de menor (a) e maior (b) tamanho do gene ribossômico $5 \mathrm{~S}$. 


\section{$2 n=38$}

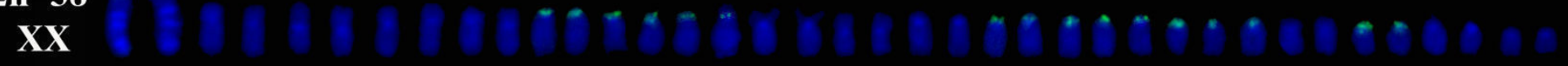
$2 \mathrm{n}=38$
$\mathrm{XY}$

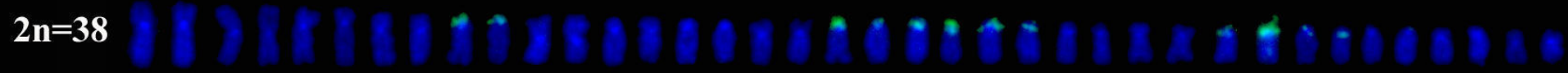

$\mathbf{2 n = 3 6} 000000000000 * 000000 * 0000000000$

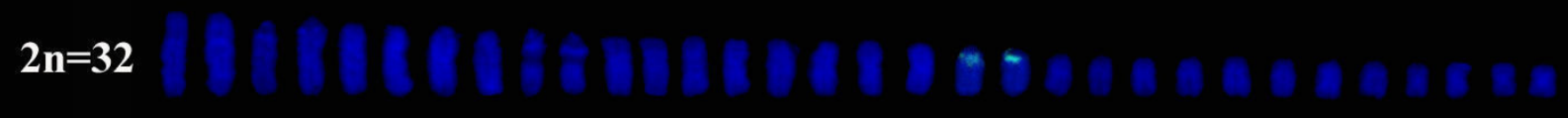

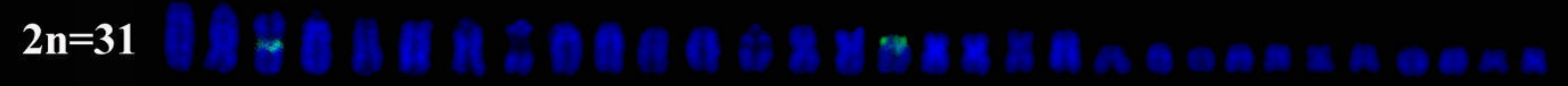

$2 n=28$

1)

Figura 13: Hibridação in situ em espécies do gênero Eigenmannia, utilizando-se como sonda o gene ribossômico 5S juntamente com seu NTS isolados para cada uma das espécies. 
$2 n=38$

XX

$\mathbf{2 n}=\mathbf{3 8}$

4

XY

Figura 14: Detalhe da hibridação in situ com sonda ribossômica 5S evidenciando a presença de 18 sítios marcados nas fêmeas (a) e apenas 17 nos $\operatorname{machos}(\mathrm{b})$.

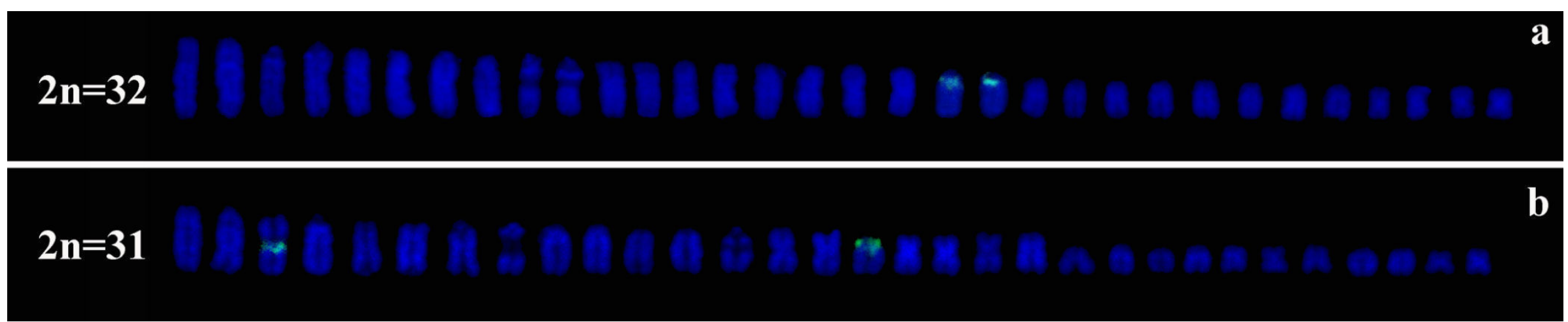

Figura 15: Detalhe da hibridação in situ com sonda ribossômica 5S evidenciando a presença de 2 sítios marcados em cromossomos submetacêntricos nas fêmeas (a) e marcação diferencial nos machos, onde um dos sítios encontra-se associado à região centromérica de um cromossomo metacêntrico o qual corresponde ao cromossomo Y (b). 


\section{Discussão}

A análise das sequências do gene ribossômico $5 \mathrm{~S}$ de maior e menor tamanho presente nos cariomorfos em estudo permitiu visualizar certa variabilidade, a qual se acreditava seria suficientemente informativa para a delimitação dos diferentes cariomorfos, bem como para o esboço das relações filogenéticas. O resultado obtido, utilizando-se os três diferentes testes forneceram duas hipóteses, uma oriunda da árvore de máxima parcimônia, que indica um aumento gradual do número cromossômico ao longo da evolução desses cariomorfos, enquanto que a outra hipótese mostra dois grupos distintos, um composto pelos cariomorfos $2 n=31 / 32$ e $2 n=28$ (A) e o outro composto pelos cariomorfos $2 n=36,2 n=38$ e $2 n=38 X Y$ (B), os quais compartilharam um ancestral comum em algum momento de sua história evolutiva e que a partir de então, tiveram uma evolução paralela. Estudos prévios já demonstraram que os sistemas cromossômicos apresentados nesses grupos, $\mathrm{XX}$ :XY no cariomorfo $2 \mathrm{n}=38 \mathrm{XY}$ e $\mathrm{X}_{1} \mathrm{X}_{1} \mathrm{X}_{2} \mathrm{X}_{2}: \mathrm{X}_{1} \mathrm{X}_{2} \mathrm{Y}$ no cariomorfo $2 \mathrm{n}=31 / 32$, surgiram de forma independente ao longo da evolução desses cariomorfos (Henning et al. 2010). Com relação à reconstrução com base na sequência de maior tamanho do gene ribossômico $5 \mathrm{~S}$ todas apresentaram a mesma topologia, sendo o cariomorfo $2 \mathrm{n}=28$ o ancestral em todas as reconstruções, levando em conta que o cariomorfo $2 n=31 / 32$ está ausente nessa reconstrução, pois não partilha dessa mesma sequência com os demais cariomorfos. Com base nesses dois fatos é provável que a segunda hipótese, de um ancestral comum entre os dois grupos de cariomorfos A e B e a evolução desses grupos de forma independente seja a mais provável, uma vez que é a mais recorrente utilizando-se diferentes marcadores moleculares e citogenéticos (Henning et al., 2010; Claro, 2013 - capítulo 2).

A ausência de diferentes classes de DNA ribossômico 5S, como verificado para o cariomorfo $2 \mathrm{n}=31 / 32$ foi já observada em peixes por Campo et al. (2009), trabalho no 
qual quatro espécies do gênero Merluccius em estudo apresentaram dois tipos de DNA ribossômico 5S, enquanto as demais espécies apresentaram apenas um único tipo, demonstrando que a evolução dessa região do genoma se dá de forma complexa. Apesar dessa complexidade, verificou-se uma proporção similar de sítios variáveis entre as sequências, fato esse que pode ser explicado pela característica mais marcante do DNA ribossômico, a evolução em concerto (Drouin \& Moniz de Sá, 1995). Esse fato pode ser um indício de que essas regiões estejam sofrendo pressões seletivas similares, resultado de uma possível proximidade e até mesmo associação física, a nível cromossômico, entre as sequências de maior e menor tamanho, fato que precisa ainda ser verificado. No que diz respeito à hibridação in situ e à variação verificada em número de sítios presente nos cariomorfos $2 n=31 / 32$ e $2 n=38 X Y$, nos quais os machos apresentam uma marcação a menos do que as fêmeas, fato já verificado por Moran et al. (1996) em Oncorhynchus mykiss, sendo essa diminuição do número associada a uma fusão cromossômica, fato observado no cariomorfo $2 n=31 / 32$, no qual o macho apresenta número diploide $2 n=31$, sendo o único metacêntrico presente, o cromossomo $\mathrm{Y}$, o resultado da fusão cêntrica de dois cromossomos X da fêmea (Almeida-Toledo et al., 1988).

De modo geral, o presente estudo permitiu a caracterização de duas classes distintas de DNA ribossômico 5S, um diferencial uma vez que somente a banda de menor tamanho tem sido isolada (Wasko et al., 2001) com os mais diferentes objetivos, dentre os quais podemos destacar a análise e caracterização da sequência desse gene ribossômico (Martins \& Galetti, 2001), bem como sua utilização como sonda para determinação de sua localização cromossômica através da técnica hibridação in situ (Santos et al., 2006). Já a hibridação in situ, permitiu por sua vez o mapeamento cromossômico do gene ribossômico 5S para a banda de menor tamanho, evidenciando assim a ocorrência de sítios associados aos cromossomos sexuais nos cariomorfos 
$2 n=38 X Y$ e $2 n=31 / 32$, bem como forneceu nova evidência sobre a ocorrência da fusão cêntrica no cariomorfo $2 n=31 / 32$, dando origem ao neo-Y, ampliando os conhecimentos sobre essa família multigênica para diferentes cariomorfos do gênero Eigenmannia em estudo.

\section{Referências}

ALBERT, J. S., 2001. Species diversity and phylogenetic systematics of American knifefishes (Gymnotiformes, Teleostei), Division of Ichthyology, Museum of Zoology, Univ. of Michigan.

ALBERT, J. S., CAMPOS-DA-PAZ, R., 1998. Phylogenetic systematics of Gymnotiformes with diagnoses of 58 clades: a review of avaible data. In: MALABARBA, L. R., REIS, R. E., VARI, R. P., LUCENA, Z. M., LUCENA, C. A. (Eds.). Phylogeny and classification of Neotropical fishes, p. 419-446, EDIPUCRS, Porto Alegre.

ALBERT, J. S., FERNANDES-MATIOLI, F. M. C., ALMEIDA-TOLEDO, L. F., 1999. New species of Gymnotus (Gymnotiformes, Teleostei) from southeastern Brazil: toward the deconstruction of Gymnotus carapo. Copeia 1999 (2): 410-421.

ALBERT, J.S., 2003. Sternopygidae (Glass knifefishes, Rattail knifefishes). p. 487-491. In: R.E. Reis, S.O. Kullander and C.J. Ferraris, Jr. (eds.) Checklist of the Freshwater Fishes of South and Central America. Porto Alegre: EDIPUCRS, Brasil.

ALJANAB, S. M. I., MARTINEZ, I., 1997. Universal and rapid salt-extraction of high quality genomic DNA for PCR-based techniques. Nucleic Acids Res. 25(22): 46924693.

ALMEIDA TOLEDO L. F., DANIEL-SILVA M. F., MOYSES, C. B., FONTELES, S. B., LOPES, C. E., AKAMA, A., FORESTI, F., 2002. Chromosome evolution in fish: sex chromosome variability in Eigenmannia virescens (Gymnotiformes: Sternopygidae) Cytogenetic and Genome Research 99(1-4): 164-9.

ALMEIDA TOLEDO L. F., FORESTI F., 2001. Morphologically differentiated sex chromosomes in Neotropical freshwater fish Genetica 111(1-3): 91-100.

ALMEIDA-TOLEDO L. F., FORESTI F., PEQUIGNOT E. V. AND DANIEL-SILVA M. F., 2001. XX:XY sex chromosome system with X heterochromatinization: an early stage of sex chromosome differentiation in the Neotropic electric eel Eigenmannia virescens Cytogenetics and Cell Genetics 95(1-2): 73-8.

ALMEIDA-TOLEDO, L. F., FORESTI, F., DANIEL, M. F. Z., TOLEDO-FILHO, S. A., 2000. Sex chromosome evolution in fish: the formation o the neo-Y chromosome in Eigenmannia (Gymnotiformes). Chromosoma 109: 197-200. 
ALMEIDA-TOLEDO, L. F., STOCKER, A. J., FORESTI, F., TOLEDO-FILHO, S. A., 1996. Fluorescent in situ hybridization with rDNA probes on chromosomes of two nucleolus organizer region phenotypes of a species of Eigenmannia (Pisces, Gymnotoidei, Sternopygidae). Chromosome Res. 4: 301-305.

ALMEIDA-TOLEDO, L. F., VIEGAS-PEQUIGNOT, E., FORESTI, F., TOLEDO FILHO, S. A., DUTRILlAUX, B., 1988. BrdU replication patterns demonstrating chromosome homoeologies in two fish species, genus Eigenmannia. Cytogenetics and Cell Genetics 48(2): 117-20.

ALVES-GOMES, J. A., 2001. The evolution of electroreception and bioelectrogenesis in teleost fish: a phylogenetic perspective Journal of Fish Biology 58(6): 1489-511.

ALVES-GOMES, J. A., ORTÍ, G., HAYGOOD, M., HEILINGENBERG, W., MEYER, A., 1995. Phylogenetic analysis of the South American Eletric Fishes (Order Gymnotiformes) and the evolution of their eletrogenic system: a synthesis based on morphology, eletrophysiology, and mitochondrial sequence data. Mol. Biol. Evol. 12: 298-318.

CONWAY, S. J., 1996. Procedures for In Situ Hybridization to Chromosomes, Cells, and Tissue Sections in: Molecular Diagnosis of Cancer 6: 193-206.

DROUIN, G., MONIZ DE SÁ, M., 1995. The concerted evolution of 5S ribosomal genes linked to the repeat units of other multigene families. Mol Biol Evol 12:481-493.

FERNANDES-MATIOLI, F. M. C., ALBERT, J. S., LOPES, C. E., CRAMPTON, W. G. R., ALMEIDA-TOLEDO, L. F., 2005. A new Gymnotus (Teleostei: Gymnotiformes: Gymnotidae) from the Pantanal Matogrossense of Brazil and adjacent drainages: continued documentation of a cryptic fauna. Zootaxa 933: 1-14.

FERREIRA, I. A., OLIVEIRA, C., VENERE, P. C., GALETTI JR, P. M., MARTINS, C., 2007. 5S rDNA variation and its phylogenetic inference in the genus Leporinus (Characiformes: Anostomidae). Genetica 129: 253-257.

HENNING, F., 2007. Evolução de cromossomos sexuais no gênero Eigenmannia (Teleostei: Gymnotiformes). São Paulo, 2007, 62p. Dissertação de Mestrado. Instituto de Biociências - Universidade de São Paulo.

HENNING, F., MOYSÉS, C. B., CALCAGNOTTO, D., MEYER, A., ALMEIDATOLEDO, L. F., 2010. Independent fusions and recent origins of sex chromosomes in the evolution and diversification of glass knife fishes (Eigenmannia). Heredity (2010): $1-10$.

KOMIYA, H., AND TAKEMURA, S., 1979. Nucleotide sequence of 5S ribosomal RNA from rainbow trout (Salmo gairdneri) liver. J. Biochem. 86: 1067-1080.

LANGEANI, F., CASTRO, R.M.C., OYAKAWA, O.T., SHIBATTA, O.A., PAVANELLI, C.S., CASATTI, L., 2007. Diversidade da ictiofauna do Alto Rio Paraná: composição atual e perspectivas futuras. Biot. Neotrop. 7(3):181-197, 
http://www.biotaneotropica.org.br/v7n3/pt/fullpaper?bn03407032007+pt (último acesso em 29/07/2010).

LONG, E. O., AND DAVID, I. D. 1980. Repeated genes in eukaryotes. Annu. Rev. Biochem. 49: 727-764.

LOWE-MCCONNELL, R.H., 1999. Estudos ecológicos de comunidades de peixes tropicais. Edusp, São Paulo.

MAGO-LECCIA, F., 1994. Eletric fishes of the continental waters of America. Bibl de La Acad. Cienc. Fis. Mat. Nat. 29: 1-225. Caracas, Venezuela.

MARTINS, C., GALETTI JR., P. M., 2001. Organization of 5S rDNA in species of the fish Leporinus: two different genomic locations are characterized by distinct nontranscribed spacers. Genome 44: 903-910.

MORAN, P., MARTINEZ, J. L., GARCIA-VAZQUEZ, E., PENDAS, A. M., 1996. Sex chromosome linkage of 5S rDNA in rainbow trout (Oncorhynchus mykiss). Cytogent and Cell Genet 75: 145-150.

NELSON, J.S. (2006). Fishes of the world. 4th Edition. New York, John Willey \& Sons, Inc. 601p.

SANTOS, L. V. R., FORESTI, F., WASKO, A. P., OLIVEIRA, C., MARTINS, C., 2006. Nucleotide sequence, genomic organization and chromosome localization of $5 \mathrm{~S}$ rDNA in two species of Curimatidae (Teleostei, Characiformes). Genetics and Molecular Biology, 29, 2, 251-256.

SUZUKI, H., MORIWAKI, K., SAKURAI, S., 1994. Sequences and evolutionary analysis of mouse 5S rDNAs. Mol. Biol. Evol. 11: 704-710.

TRIQUES, M. L., 1993. Filogenia dos gêneros de Gymnotiformes (Actinopterygii, Ostariophysi), com base em caracteres esqueléticos. Comum. Mus. Ciênc. PUCRS, sér Zool. 6: 85-130.

WASKO, A. P., MARTINS, C., WRIGHT, J. M., GALETTI JR., P. M., 2001. Molecular organization of 5S rDNA in fishes of the genus Brycon. Genome (44): 893902.

ZHU, X. Y., CAI, D. T., DING, Y., 2008. Molecular and cytological characterization of 5S rDNA in Oryzia species: genomic organization and phylogenetic implications. Genome 51: 33234 


\section{Capítulo 4}

Physical mapping and molecular studies of transposable elements in different caryomorphs of the genus

Eigenmannia (Teleostei: Gymnotiformes: Sternopygidae) from Upper Parana River basin. 


\section{Introdução}

\section{DNA Repetitivo}

O genoma dos organismos eucariotos, apesar de sua grande complexidade, pode ser subdividido em dois grandes grupos, sendo um deles composto pelas sequências de cópia única, as quais constituem uma porção considerável dos genes funcionais, enquanto o outro grupo engloba as sequências de caráter repetitivo, fração considerável do genoma de muitos eucariotos (Wagner et al.1993). A classe repetitiva é composta tanto por sequências funcionais, como é caso dos genes ribossomais, quanto por sequências não codificantes, as quais podem estar dispersas no genoma, como os elementos transponíveis, ou arranjadas em cadeia, como os mini e microssatélites, com repetições curtas, não maiores do que 64 bases, e do DNA satélite, que envolve repetições complexas com tamanhos superiores a $100 \mathrm{~kb}$.

Muitos estudos têm por objetivo o isolamento e a caracterização das sequências de DNA repetitivo nos mais diversos grupos animais e vegetais. Essas sequências são relativamente homogêneas dentro de uma mesma espécie, apresentando, contudo, grandes diferenças quando tratamos de espécies distintas, mesmo considerando apenas um único gênero (Smith, 1976). Yamada et. al (2005) clonou famílias de sequências de DNA repetitivo de Mesocricetusauratus, e as caracterizou pelo sequenciamento e da hibridação in situ. As sequências foram obtidas através da digestão do DNA total com as enzimas $B g l$ II e $E c o$ RI e o padrão de hibridação foi coincidente com a distribuição das regiões bandas $\mathrm{C}$ positivas, que estão presentes em metade dos cromossomos autossomos, nos braços longos dos cromossomos 20 e $\mathrm{X}$ e no cromossomo $\mathrm{Y}$ por inteiro. Com esse estudo, foi possível determinar que o DNA satélite centromérico e as sequências repetitivas presentes em cromossomos sexuais e nas regiões teloméricas 
eram conservados dentro do gênero, mas diferiam em gêneros distintos. Foi possível verificar ainda que a sequência repetitiva nos braços heterocromáticos dos cromossomos apresenta similaridades com uma sequência LINE em roedores e se manteve conservada nas três subfamílias de Mesocricetus. As sequências repetitivas desse gênero ou subfamília, portanto, se mostraram excelentes marcadores taxonômicos e moleculares para a sistemática do grupo.

Utilizando essa mesma abordagem, Parise-Maltempiet. al (2007) pela a digestão pela enzima Spe I em Leporinus elongatus obteve um padrão de bandas, identificado através da técnica de Southern Blotting, padrão esse diferente entre machos e fêmeas, apresentando uma concentração mais elevada em fêmeas, um possível indicativo de um maior número de cópias. Posteriormente a clonagem e a hibridação in situ dos fragmentos corroboraram essa hipótese e evidenciaram a ocorrência de um sistema sexual múltiplo $\left(\mathrm{Z}_{1} \mathrm{Z}_{1} \mathrm{Z}_{2} \mathrm{Z}_{2} / \mathrm{Z}_{1} \mathrm{~W}_{1} \mathrm{Z}_{2} \mathrm{~W}_{2}\right)$. A marcação em fêmeas foi visualizada em dois cromossomos exclusivos, $\mathrm{W}_{1}$ identificado pela morfologia e acúmulo de sequências repetitivas e heterocromáticas e $\mathrm{W}_{2}$ pela presença de dois blocos de sequências repetitivas em seu braço longo. No macho, verificou-se uma pequena marcação na região telomérica de apenas um par $\left(Z_{2} Z_{2}\right)$, marcação também presente na fêmea. Esse evento, no qual temos o acúmulo de elementos repetitivos sem a ocorrência de troca gênica, leva a cromossomos morfologicamente distintos e à fixação da determinação sexual heterogamética neste caso múltipla, demonstrando a importância das sequências repetitivas neste processo.

O estudo de sequências repetitivas, como o DNA satélite, no gênero Eigenmannia, portanto, deverá permitir uma melhor compreensão da importância, conservação e evolução dessa porção do genoma entre as diferentes espécies do gênero, bem como permitirá verificar sua relação com regiões heterocromáticas e cromossomos 
sexuais pela identificação de marcadores citogenéticos e moleculares para cada uma das espécies a serem estudadas.

Elementos transponíveis são sequências móveis capazes de se movimentar de um locus a outro no genoma no qual estão presentes, com grande potencial mutagênico, levando a ocorrência de inúmeras alterações nos genomas em que estão presentes (Kidwell \& Lish, 2000). Entre essas, incluem-se modificações no tamanho e organização dos genomas, substituições, inserções/deleções e rearranjos cromossômicos como duplicações, inversões e translocações recíprocas (Kidwell, 2002). Os elementos transponíveis podem ser classificados em dois tipos principais: os denominados autônomos, que codificam para a transposase ou para a transcriptase reversa e são capazes de deslocamento no genoma sem qualquer tipo de auxílio, e aqueles que carregam deleções ou mutações no gene da transposase ou transcriptase, sendo mobilizados apenas na presença de elementos transponíveis autônomos (Hurst \& Werren, 2001). Apesar de esses elementos conterem informações a princípio não significativas, sua capacidade de auto-replicação e a presença de diversas cópias no genoma devem ser consideradas como uma das forças que atuariam na evolução do genoma. São comumente encontrados nas porções heterocromáticas dos genomas ou ainda dispersos nos cromossomos (Capriglione et al. 2002). Nos peixes, fragmentos de sequências LINE foram identificadas em Salmo gairdneri (Winkfeinet al., 1998), Anguilla anguilla (Ohshimaet al., 1996), Oryzialatipes (Duvernell \& Turner, 1998) e Daniorerio (Okada et al., 1997). Oliveira et al. (1999) identificaram em Oreochromis niloticus um elemento transponível do tipo LINE, o qual se assemelha ao LINE2 encontrado em mamíferos. Verificou-se, através da técnica de Southern Blotting, que sua distribuição genômica é ampla, estando presente em todas as espécies de Oreochromis, Tilapia e Sarotherodon, amostradas, com pequenas variações nas 
intensidades das bandas obtidas. A distribuição cromossômica da sequência LINE2 foi determinada através da utilização da técnica de FISH e foram identificados pequenos blocos de sinais espalhados ao longo dos cromossomos, com maior concentração na sua porção terminal, o que, de acordo com Higashiyamaet al. (1997), atuaria de modo importante na estabilização dos telômeros ou mesmo atuaria como uma barreira de proteção à região cromossômica onde estão os localizados os genes.

Os elementos transponíveis podem ainda estar associados a regiões funcionais, tal qual o SINE3 identificado em Danio rerio, o qual compõe uma nova classe de SINE derivada do gene ribossomal 5S (Kapitonov \& Jurka 2003). Pertencentes à família AFC, os elementos que a compõem são SINEs clássicos, derivados do $\mathrm{RNA}_{\mathrm{t}}$, cuja ocorrência já foi verificada em ciclídeos (Takahashi et al., 1998) e Gymnotiformes (Claro, 2008), sendo o processo de transposição mediado pela maquinaria enzimática do retrotransposon CR1 (Teraiet al., 1998). A possível origem desse elemento corresponderia a uma composição acidental de parte do gene/pseudogene ribossômico 5S e parte do retrotransposon $\mathrm{CR} 1$, aliado a uma mutação no sitio de término de transcrição, garantindo assim todos os elementos necessários para a transcrição, clivagem da região alvo e reinserção desse elemento, pontos fundamentais para a manutenção do SINE no genoma (Kapitonov \& Jurka 2003).

Além da associação com regiões funcionais e regiões heterocromáticas, os elementos transponíveis podem estar associados a cromossomos sexuais. Morescalchi et al. (1996) verificaram essa associação entre o transposon TC1, isolado em Chinodraco hamatus, espécie pertencente à subordem de Perciformes, endêmica nos oceanos do leste (Eastman, 1993). A localização desse elemento transponível restringiu-se a regiões heterocromáticas, porém foi verificado ainda um sinal na região terminal no braço longo do cromossomo $\mathrm{Y}$, o que sugere que esse transposon esteja relacionado à diferenciação 
dos cromossomos sexuais (Morescalchi et al. 1996). O elemento TC1 pertence a uma superfamília de elementos transponíveis, que possui repetições terminais invertidas com sequências altamente conservadas. Integram-se em locais onde há ocorrência da sequência TA e possuem um quadro de leitura que codifica para a transposase (Henikoff, 1992). Capriglione et al (2002) amplificaram e caracterizaram o elemento TC1 na família Nototheniade. Nos resultados de hibridação genômica verificou-se uma conservação desse elemento, entretanto a amplificação por PCR revelou uma grande variabilidade entre as espécies da família, fato que o torna o elemento TC1 um potencial marcador para essas espécies.

\section{O Gênero Eigenmannia}

O gênero Eigenmannia (Sternopygidae) faz parte da ordem Gymnotiformes, grupo no qual a morfologia das espécies é tipicamente serpentiforme (Fig. 1) e que apresenta distribuição exclusivamente neotropical (Albert, 2001). Uma característica notória nas espécies de Gymnotiformes, a qual está intimamente relacionada aos hábitos noturnos e ambientes de rios, é a emissão contínua de descargas elétricas de baixas voltagens, voltadas para as funções de eletro-localização (navegação, defesa e localização de presas) e eletro-comunicação (Alves-Gomes, 2001). 


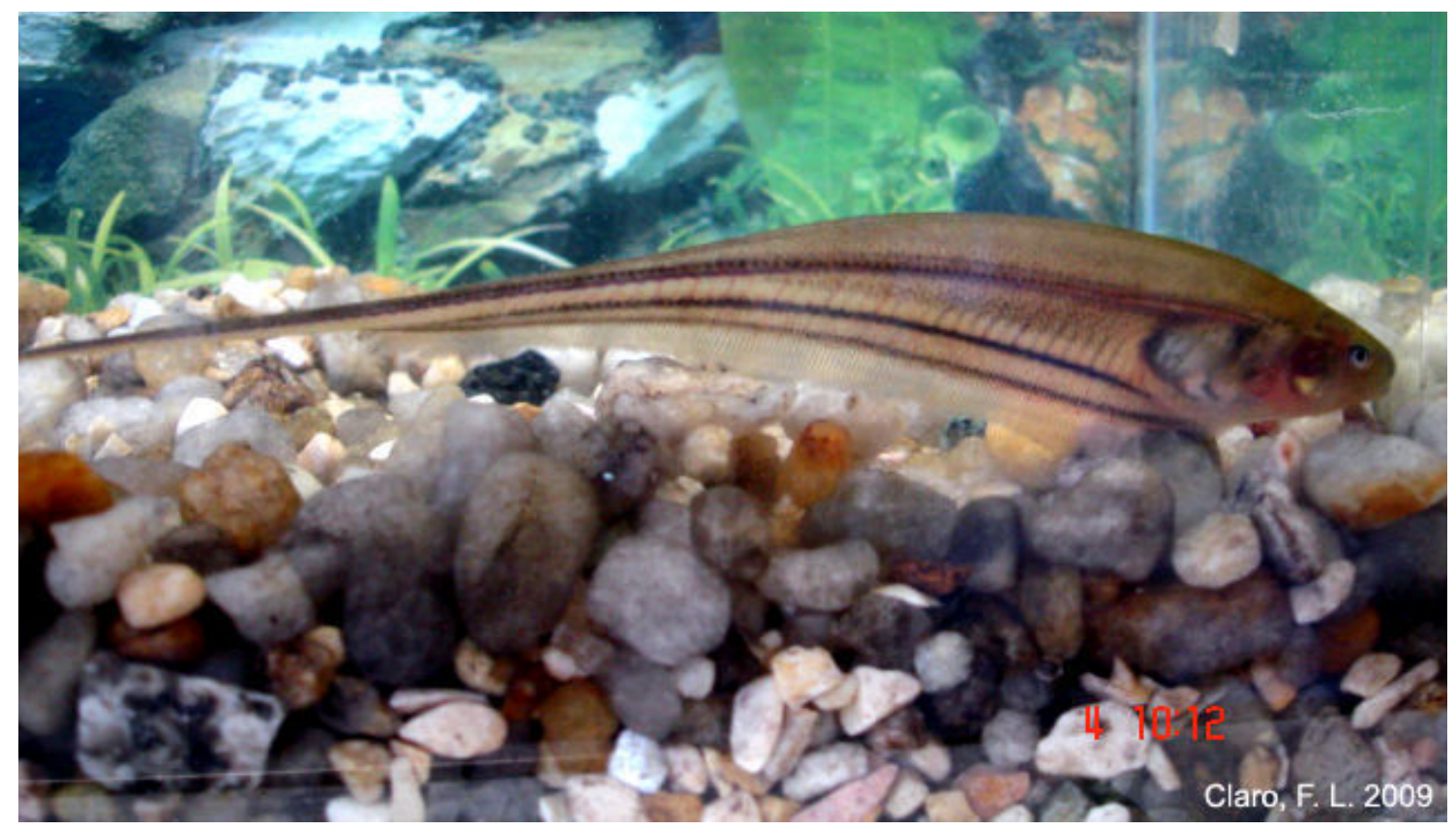

Figura 1: Imagem de um exemplar do gênero Eigenmannia oriundo da região de Santa Albertina/SP e mantido em laboratório.

São descritas oito espécies válidas para o gênero Eigenmannia com data de separação estimada em 16Ma. A diversidade de espécies não pode ainda ser estabelecida devido à necessidade de uma revisão taxonômica no gênero e as espécies já descritas para esse gênero são, provavelmente, na realidade, grupos de espécies crípticas morfologicamente (Albert, 2003; Henninget al., 2010).

Um número expressivo de estudos citogenéticos já foi publicado sobre as populações de Eigenmannia, com enfoque basicamente na bacia superior do Rio Paraná e na bacia do Rio São Francisco. As populações de Eigenmannia já descritas citogeneticamente apresentam ampla variabilidade cariotípica e diversos sistemas sexuais incluindo sistemas XY e ZW (Almeida-Toledo et al. 2002). Nas bacias dos rios Tietê, Paranapanema e Mogi-Guaçu (SP), ocorrem populações com cariótipos que apresentam números cromossômicos variando entre 28 e 38 , com presença ou não de cromossomos sexuais heteromórficos (Almeida Toledo \& Foresti, 2001). Uma análise filogenética recente destes citótipos revelou um padrão de labilidade dos sistemas de 
determinação sexual e uma maior conservação do número cariotípico (Henninget al., 2010). Segundo Henning (2010), a reconstrução filogenética das diversas espécies de Eigenmannia com base em genes mitocondriais mostrou que aqueles que possuem sistemas sexuais agrupam com aqueles nos quais os sistemas não estão presentes. Esse seria um indício de que a diferenciação dos cromossomos sexuais é recente, levantando assim uma hipótese sobre a origem múltipla desse sistema, fato também verificado por Henning (2007), em estudo no qual a realização de um experimento com sondas específicas para os cromossomos sexuais não demonstrou similaridades entre espécies que possuem sistemas sexuais distintos, reforçando a possível origem múltipla do sistema.

Atuando como marcadores espécies-específicos, associados a regiões funcionais, heterocromáticas e a cromossomos sexuais, os elementos transponíveis representam um modelo interessante para estudo da dinâmica evolutiva das regiões às quais esses elementos estão associados. A aplicação dessa abordagem no gênero Eigenmannia permitirá uma melhor compreensão no que diz respeito à distribuição e conservação desses elementos nas diferentes espécies, sua possível relação com regiões heterocromáticas e a diferenciação de cromossomos sexuais. A análise de elementos transponíveis do tipo SINE associados à família multigênica composta pelo rDNA 5S, associação essa já identificada em Gymnotiformes (Claro, 2008), permitirá uma melhor compreensão da dinâmica evolutiva não só do rDNA 5S, mas também da dinâmica e conservação desse elemento transponível em espécies do gênero Eigenmannia. 


\section{Material e Métodos}

\section{Preparações Citogenéticas}

Para a análise citogenética, a estimulação de mitoses foi feita pela inoculação de fermento biológico (Cole e Levans, 1971) e os cromossomos mitóticos foram obtidos pela preparação direta de células renais (Forestiet al., 1993).

\section{Hibridação in situ}

A hibridação in situ, realizada conforme Conway (1996) incluiu um pré tratamento das lâminas que consiste em uma incubação em solução a $100 \mu \mathrm{g} / \mathrm{ml}$ de RNase, seguida de uma lavagem em solução de $10 \mathrm{mM}$ de $\mathrm{HCl}$ contendo $0.02 \%$ de pepsina e um passo de pós fixação em PBS contendo $50 \mathrm{mM}$ de $\mathrm{MgCl} 2$ e $1 \%$ de formaldeído. Uma vez feito o pré tratamento, as lâminas são desnaturadas numa solução de formamida $70 \%$ em $2 \times S S C$ a $72^{\circ} \mathrm{C}$ e a sonda a $100^{\circ} \mathrm{C}$ em uma solução contendo $50 \%$ de formamida, $10 \%$ de sulfato de dextrano e 2XSSC. Para a hibridação, as lâminas são incubadas overnight em câmara úmida a $37^{\circ} \mathrm{C}$. A amplificação do sinal, consiste em duas incubações com Fitc-Avidina e uma com Anti-Avidina-Biotina a $37^{\circ} \mathrm{C}$ em câmara úmida, seguida após cada incubação de uma lavagem em solução contendo $0.5 \%$ de Tween 20 e 4xSSC. O passo final consistiu na desidratação das lâminas e posterior montagem com antifade contendo DAPI.

\section{Elementos Transponíveis}

A busca por elementos transponíveis conservados para o gênero Eigenmannia será realizada com base nas sequências já descritas para peixes, nos gêneros Oryzias, Danio, Salmo e Oncorhynchus. Para o elemento Tc1 serão utilizados os primersTC1 5'-TACAGTGCCTTGCATAAGTATTCACC; Rex1 - RTX1-F1 (TTCTCCAGTGCCT 
TCAACACC) e RTX1-R3 (TCCCTCAGCAGAAAGAGTCTGCTC) (Volffet al. 2001a). A reação teve volume final de $25 \mu 1$ tendo como concentrações finais $1 \mathrm{mM}$ de $\mathrm{Mg}^{2+}, 0.4$ pmol para cada primer, $1 \mathrm{x}$ de tampão Taq Polimerase $\mathrm{KCl}, 1 \mathrm{x}$ de tampão Taq Polimerase (NH4) $)_{2} \mathrm{SO}_{3}, 0.04 \mathrm{mM}$ dNTP Mix, 0.1U de Taq Polimerase. Para todos os elementos transponíveis (TC1, Rex1 e Rex6) foi utilizado um mesmo programa, que consiste em 4 minutos a $94^{\circ} \mathrm{C}$, seguidos de 29 ciclos de 1 minuto a $94^{\circ} \mathrm{C}, 1$ minuto a $60^{\circ} \mathrm{C}, 2$ minutos a $72^{\circ} \mathrm{C}$, tendo como passo final 10 minutos a $72^{\circ} \mathrm{C}$. Uma vez amplificados, os produtos obtidos foram submetidos a reação para produção dos fragmentos de pontas cegas, através da utilização da $P f x 50{ }^{\mathrm{TM}}$ DNA Polymerase para posterior clonagem, tal qual descrito anteriormente. Nesse caso as temperaturas de anelamento foram de $66^{\circ} \mathrm{C}$ e $68^{\circ} \mathrm{C}$ para os elementos $\mathrm{TC} 1$ e Rex1, respectivamente. Após amplificação, os produtos foram clonados e posteriormente sequenciados, pelos métodos já mencionados anteriormente.

\section{Análises das sequências}

As sequências foram editadas e analisadas através da utilização do programa CodonCodeAligner v. 3.5.7 e, para o cálculo das distâncias intra e interespecíficas, foi utilizado o programa MEGA 5.0 (Tamura et al., 2011), utilizando-se o modelo K2P (Kimura 2 Parâmetros) para o elemento Rex1 e T92 (Tamura 3 Parâmetros) para o elemento TC1. Para a construção das árvores filogenéticas e cálculo de bootstrap, utilizaram-se os modelos de Máxima Verossimilhança (MV), Máxima Parcimônia (MP) e NeighbourJoining (NJ), para ambas as sequências em estudo. 


\section{Resultados}

A amplificação do elemento transponível TC1 gerou sequências de tamanho considerável, com aproximadamente $1006 \mathrm{pb}$, dentre as quais 453 se mostraram informativos para análise molecular da sequência (Fig. 2). Foi calculada a distância entre os cariomorfos (Tabela 1), utilizando-se como modelo Tamura3 parâmetros (Tamura et al. 2007), demonstrando que as espécies $2 n=31 / 32$ e $2 n=36$ apresentam a menor distância (0.0044) enquanto que as espécies $2 n=31 / 32$ e $2 n=38$ apresentam a maior distância (0.7801). O esboço das relações utilizando-se os modelos de Máxima Verossimilhança (Fig. 3a), Máxima Parcimônia (Fig. 3b) e NeighbourJoining (Fig. 3c), foram obtidas reconstruções idênticas entre si, porém com uma topologia que difere das já obtidas em trabalhos anteriores (Henning et al., 2010; Claro et al., 2011), entretanto com resultado igualmente interessante. Os cariomorfos foram separados em dois grandes grupos, o primeiro composto pelas espécies $2 n=38 X Y, 2 n=38$ e $2 n=28$ e o segundo com as espécies $2 n=31 / 32$ e $2 n=36$. É possível observar a inexistência de correlação dessa separação com o número cromossômico dos cariomorfos, entretanto essa correlação existe quando analisado o padrão de distribuição de cada um dos cariomorfos ao longo do estado de São Paulo (Fig. 4). Sabe-se que o sistema de cromossomos sexuais da espécie $2 \mathrm{n}=38 \mathrm{XY}$ teve origem recente, na qual a supressão da recombinação e o acúmulo de heterocromatina no cromossomo $X$, a partir de um ancestral $2 \mathrm{n}=38$, tenham ocorrido após uma separação geográfica recente (Henning et al., 2010), o que corrobora a pequena distância genética visualizada para as espécies $2 n=38 X Y$ e 2 n=38 (0.0179). Foi verificado ainda que a distância de ambas as espécies também é pequena em relação à espécie $2 \mathrm{n}=28$ (0.0553 e 0.0446 respectivamente) a qual já foi encontrada em simpatria com a espécie 2n=38 (Icem/SP, Araras/SP, Luiz Antônio/SP), fato esse que justificaria uma distância genética baixa. O segundo grupo 
formado envolve as espécies $2 n=36$ e $2 n=31 / 32$, as quais também são comumente encontradas em simpatria (Santa Albertina/SP, Botucatu/SP e Auriflama/SP), também justificaria a distância genética pequena entre as espécies (0.0044) para esse transposon. Quando calculada a distância, entre os grupos $2 n=38 / 2 n=38 X Y / 2 n=28$ e $2 n=36$ / $2 n=31 / 32$, utilizando-se os mesmos parâmetros para o cálculo das distâncias entre espécies, a distância obtida se mostrou elevada, com valor aproximado de 0.7036 . Apesar de esse valor de distância em comparação àqueles obtidos para os cariomorfos, ser considerado elevado, as distâncias dentro dos grupos se mostram relativamente pequenas (Tabela 2). 
CodonCode Aligner: TC1 Alinhamento, TC1

Page 1 of 4

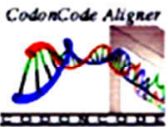

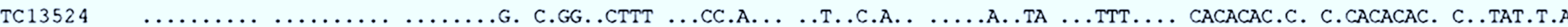

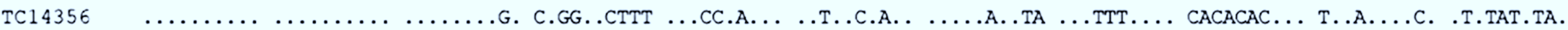

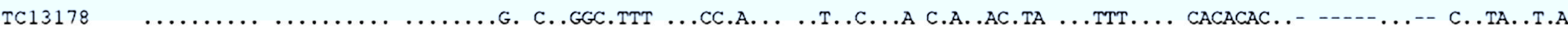

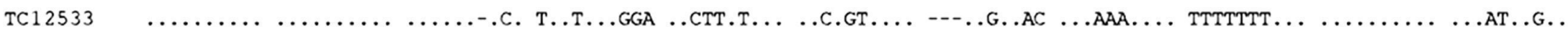

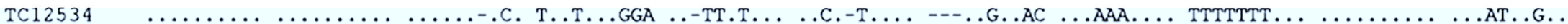

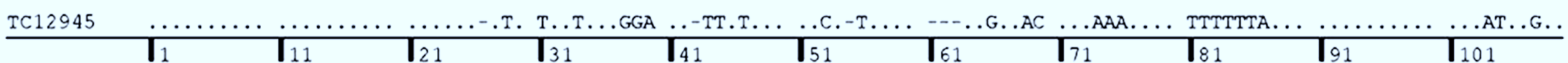
TC1 TACAGTGCCT TGCATAAGTA TTCACCCABC YCTK--TKKW TTAYYCWTTT TCYTAYATT- TACTTRTTWM ATTWWWAACA YWYWYWHA-A AATGT---TA TAAWWCAKCT

TC13524 T.ATT.T.T. TATATA.A.. T.GA...T.T .G..A...AG A..T.TA..T .G.A.A..G. AA..TGCCA. GTA..C.TGT ATTCACC.TC T.T.C..TG. TGCCCTTA.C TC14356 ..AT-.T.T. TA.AGAGAG. G.GA..T.T.G..A...AG A..T.TA.T .G.A.A..G. AA..TGCCA. GTA..C.TGT ATTCACC.TC T.T.C..TG. TGCCCTTA.C TC13178 T.A---.T. TAAATA.A.. T.GA...T.T.G..A...A--.T.TA.T .G.A.A..G. AA..TGCCA. GTA..C.TGT ATTCACC.TC T.T.C..TG. TGCCCTTA.C TC12533 ..G.....G. CG.GAG.G-. CGTG...C.A .A..G.-.C. ...C.CT.-C .C.C.C..t. GC..CAGAG. AGC..G.AAA GGCATTA.CT A.A.A..AA. AATGGGAG.G TC12534 ..G....G. CG.GAG.G-. C.TG...C.A.A..G.-.C. ...C.CT.-C .C.C.C..T. GC..CAGAG. AGC..G.AAA GGCATTA.CT A.A.A..AA. AATGGGAG.C TC12945 ..G.....G. CG.GAG.G-. C.TG...C.A .A..G.-.C. ...C.CT.-C .C.C.C..T. GC..CAGAG. AGC..G.AAA GGCATTA.CT A.A.A..AA. AATGGGAG.G

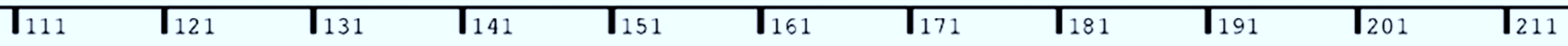

TC1 ATRCCAGAKA YRGRDRTRTA BAKRGGAYAW ARATRAATMC CTAYAYWAAY ASAMAMCTKG RMTTYRSMRT RKMCASAWRW RKYMWYMCYY WAWGMTAWRA WRYSSKWRAS

TC13524 CCT.ACC.T. AGAA.T..C. GAATT....A A.T.AAGT.. .CT.G.G..C ..TC...C. T.G.TC..A CA..GT.C.. T...AAACCT ...AG..G GG..CCAAC TC14356 CCT.ACC.T. AGAA.T..C. GAATT..... A.T.AAGT.. .CT.G.G..C ..TC..... T.G.TC...A CA..GT.C.. T...AAACCT ....AG...G GG...CCAAC TC13178 CCT.ACC.T. AGAA.T..C. GAATT...A A.T.AGGT.. .CT.G.G..C ..TCC.... T.G.TC...A CA..GT.C.. T...AAACCT ...GG..G GG..ACCAC TC12533 AAC.TTT.A. TrTT.C..A. AGGCA....G G.G.CTCA.. .AA.A.A. .A ..CT.--.. G.C.GA...G AC..AA.T-. G...TTTTGG ....CC...C CA...TGGTG TC12534 AAC.TTT.A. TTTT.C..A. AGGCA...G G.G.CTCA.. .AA.A.A..A ..CT.--.. G.C.GA...G AC..AA.T-. G..TTTTGG ...CC...C CA...TGGTG TC12945 AAC.TTT.A. TTTT.C..A. AGGCA....G G.G.CTCA.. .AA.A.A..A ..CT.--.. G.C.GA...G AC..AA.T-. G...TTTTGG ...CC...C CA..TGGTG \begin{tabular}{|l|l|l|l|l|l|l|l|l|}
221 & $\left.\right|_{21}$ & 241 & $\left.\right|_{251}$ & $\left.\right|_{261}$ & $\left.\right|_{271}$ & $\left.\right|_{21}$ & $\left.\right|_{321}$
\end{tabular}

MMYAWYYTWC WKWWGYCAMA RRRYWTGTGR RAKAMDSWCC AMWTRTRTGM AAYYTAAGTG KTSAKMTGAR MMTGRWAYCA KAACWWWYSK GCCAVSAAGS SRCCAHSVWS 


\section{CodonCode Aligner: TC1 Alinhamento, TC1}

Page 2 of 4

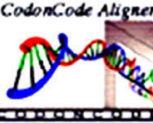

TC13524 ..C.A.TC.. .GACC.GGAA AG...GG.AT .AAT..G... .G..GCACA. AGA.CAG.GG .AAC.G.GAC AGGG.TG.A. TGA..CACAG ..GA.ACTG. .T.TC-..T TC14356 ..C.A.TC.. .GACC.GGAA AG...GG.AT .AAT..G... .G..GCACA. AGA.CAG.GG .AAC.G.GAC AGGG.TG.A. TGA..CACAG ..GA.ACTG. ..T.TC-..T TC13178 ..C..TC.. GGAGC.GGAG AG...GG.AT .AAT..G... .G..GCACA. AGA.CAG.GG .AACCG.GAC GGGG.TG.A. TGA..CACAG ..GA.ACTG. .T.TC-..T TC12533 ..A...CA.. .CGTT.CTCC GA...CA.CA .CCC..C... .A-.ATGTG. TTG.AGC.TT .TTT.T.CTT TTTT.AA.T. CAG..TGGGA ..CT.GTCA. ..A.GG...G TC12534 ..A...CA.. .CGTT.CTCC GA...CA.CA .CCC..C... .A-.ATGTG. TTG.AGC.TT .TTT.T.CTT TTTT.AA.T. CAG..TGGGA ..CT.GTCA. ..A.GG...G TC12945 ..A...CA.. .CGTT.CTCC GA...CA.CA .CCC..C... .A-.ATGTG. TTG.AGC.TT .TTT.T.CTT TTTT.AA.T. CAG..TGGGA ..CT.GTCA. ..A.GG...G \begin{tabular}{|l|l|l|l|l|l|l|l|l|}
\hline 331 & 341 & 351 & 361 & 371 & 381 & 391 & 401 & 431 \\
\hline
\end{tabular}

TC1 CAMACCYMAC ASRBYASKMV RRGAASRCMW TMMYCASAGA GRCARYRYRG WKRCMRSAKK TWWYTKTSWY DKKKCWRCWG YRRTCYRSRR AASWGRYYRG AAWAKSGTGK

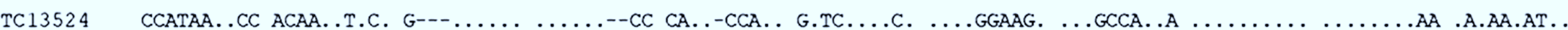
TC14356 CCATAA..CC ACAA..T.CC GGA.CTCAAT ATACTCA... .A..-CCA.. G.TC...C. ...GGAAG. ..GCCA..A ........................ TC13178 CCATAA..CC A.AA..T.G. GCC-.........--C. .A...CCA.. G.TC...C. .C..GGAAG. ..GCCA..A ....AA..C A.....AA CA.AA.AT. TC12533 AGGCTG..TG G.GC..A.T. C.................GAG.. A.AT..--T. ...CTGCT. ...ATTT..G .-.-.-.......TG .C.GG.CA..

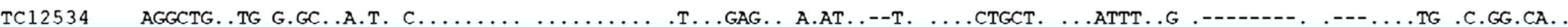
TC12945 AGGCTG..TG G.GC..A.T. C...............T...GAG.. A.AT..--T. ...CTGCT. ...ATTT..G .-------. .---...TG .C.GG.CA.. \begin{tabular}{l|l|l|l|l|l|l|l|l|l|l|}
\hline 441 & 451 & 461 & 471 & 481 & 491 & 501 & 511 & 521 & 531 & 541
\end{tabular}

TC1 MSRYWRGAYS RTRMTAWABT STGT---- ---GATA TWCTTSMRCA RAWYTGGGYT TTGTSKRMKA GTGRYYWGAR AAAAAGCCA- -TTACTTAWR GMTRRAMWAT

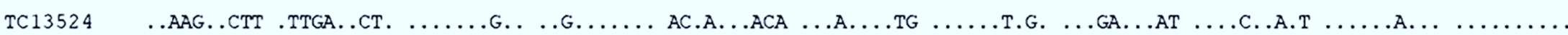

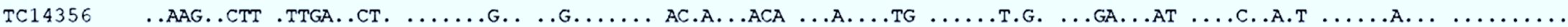

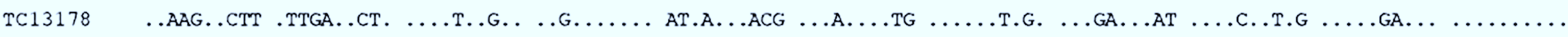

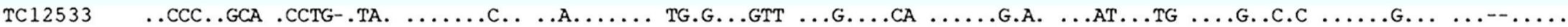

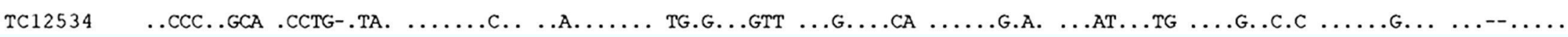

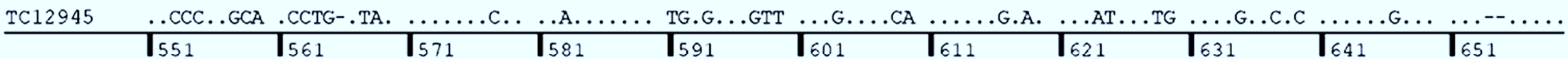

GAMMSAASYW TYYKRTCYWA AGCAACASTC GARTGGTTTA WBGRGAARYD TTTRAATGYR TTGGAAKGRC CTARWCAAWK CCCASACHTB AATCCARTTG AGATTATCTG 
CodonCode Aligner: TC1 Alinhamento, TC1

Page 3 of 4

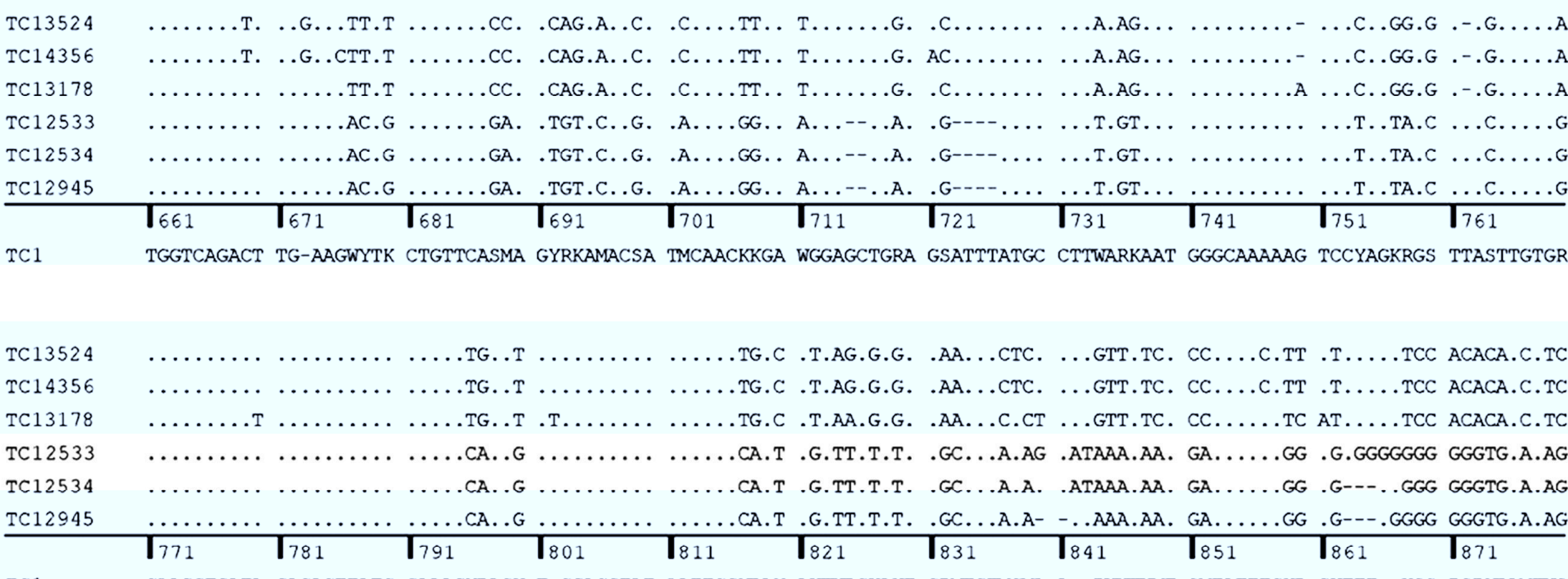

TC1

CAAGCTCATA CAGACTTATC CAAAGYRACK T-GCAGCTAT AATTGCYRAY AKTWDGKAKT GRMTGTMCMA A--RWWTWMT SMTATTTGKB GKTTT--KSS RSRYRAMTWS

.T..A.G.-. G.A.GCA... T....AAATG AA..........CA... CAA...........G A.CCGACAAA AC...AA.. T..CAAAGA.

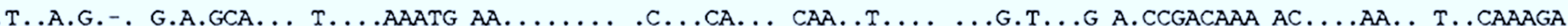

rC13178 .T..A.G.-. G.A.GCA... T....AAATG AA...........CA... CAA..T.......T..G A.CCAACAAA AC..G.AA.. T..CAAAGA.

TC12533 .G..G.T... T.T.TTT... C....TTGCA TC...... -T...AT... GTC..C..----A.A...A G.TATGTTCT GT.-..TG.. G..GGGTTG.

TC12534 .G..G.T... T.T.TTT... C...TTTGCA TC...--- -T..AT... GTC..C..-- --A.A...A G.TATGTTCT GT.-..TG.. G..GGGTTG.

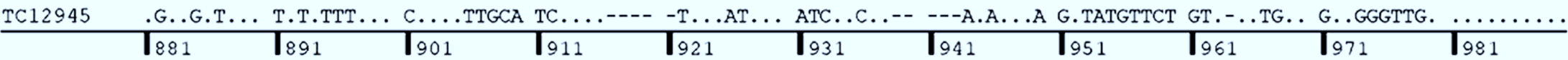

TKCARAKTGT KTWGKYWTGT YCTGTWWRYR WMACAAACCC TYAAAMWCTC VWMTTYAATT CCARGWTGTR RGYMDRYWMW RYACAAWRAA KGCSRRWKRG GGTGAATACT 
CodonCode Aligner: TC1 Alinhamento, TC1

Page 4 of 4

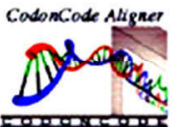

\begin{tabular}{|c|c|}
\hline TC14356 & $\ldots$ \\
\hline TC13178 & $\ldots \ldots$ \\
\hline TC12533 & .. \\
\hline TC12534 & G......... \\
\hline TC12945 & $\ldots \ldots \ldots$ \\
\hline & $T_{991}$ \\
\hline
\end{tabular}

Figura 2: Alinhamento das sequências do elemento transponível TC1. Pontos indicam bases iguais e traços indicam deleções. Abaixo sequência consenso entre as espécies, determinado pelo programa CodonCodeAligner. 


\begin{tabular}{|l|c|c|c|c|c|}
\hline & $2 n=38$ & $2 n=38 X Y$ & $2 n=36$ & $2 n=31 / 32$ & $2 n=28$ \\
\hline $2 n=38$ & - & & & & \\
\hline $2 n=38 X Y$ & 0.0179 & - & & & \\
\hline $2 n=36$ & 0.7048 & 0.6986 & - & & \\
\hline $2 n=31 / 32$ & 0.7081 & 0.7018 & 0.0044 & - & \\
\hline $2 n=28$ & 0.0446 & 0.0553 & 0.7009 & 0.7042 & - \\
\hline
\end{tabular}

Tabela 1: Distâncias genéticas entre as espécies em estudo para o elemento transponível TC1, utilizando-se o modelo Kimura-2-Parâmetros. 


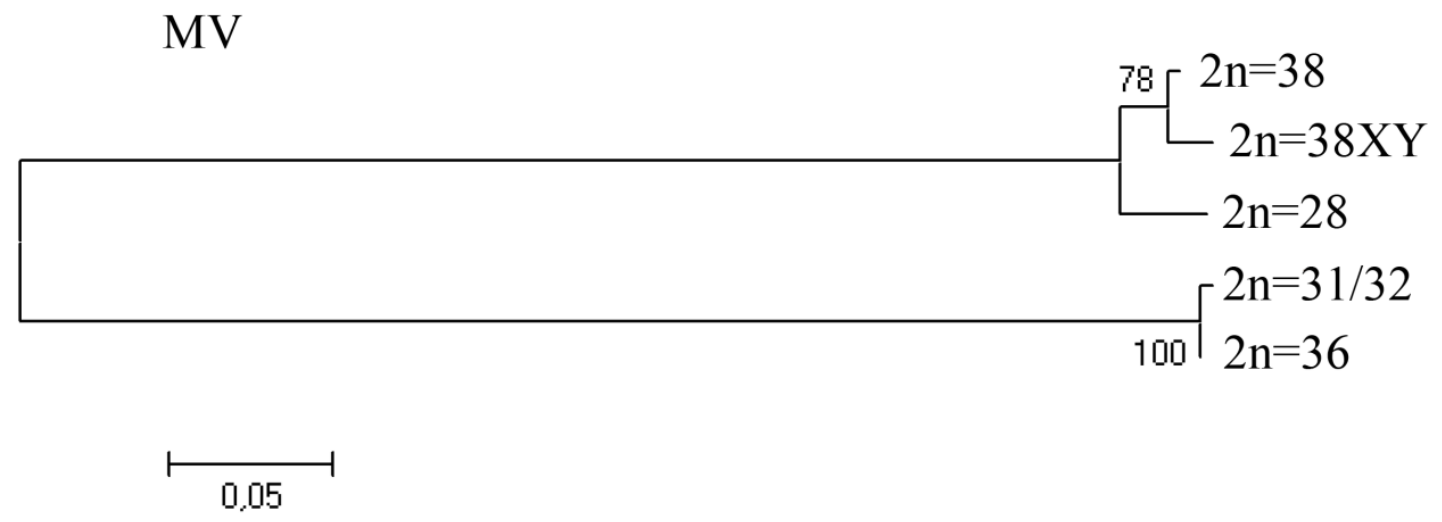

MP

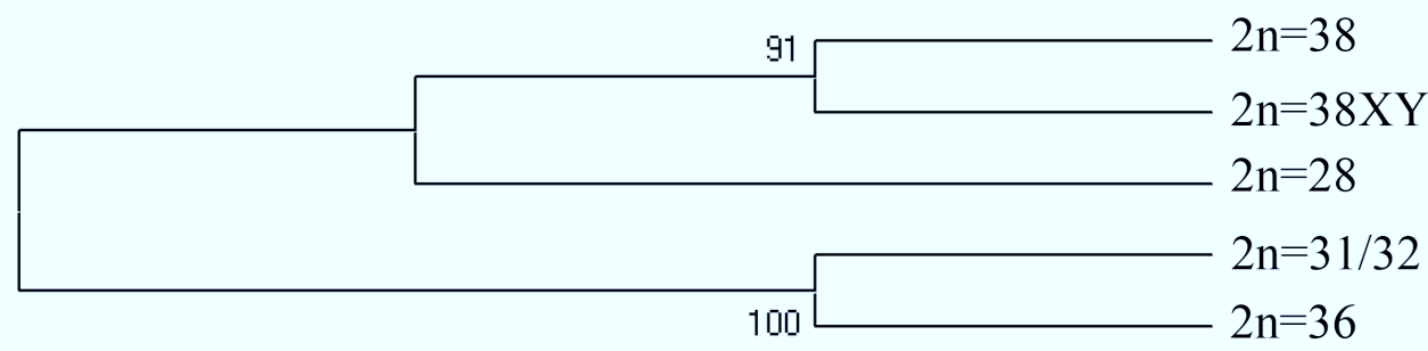

NJ

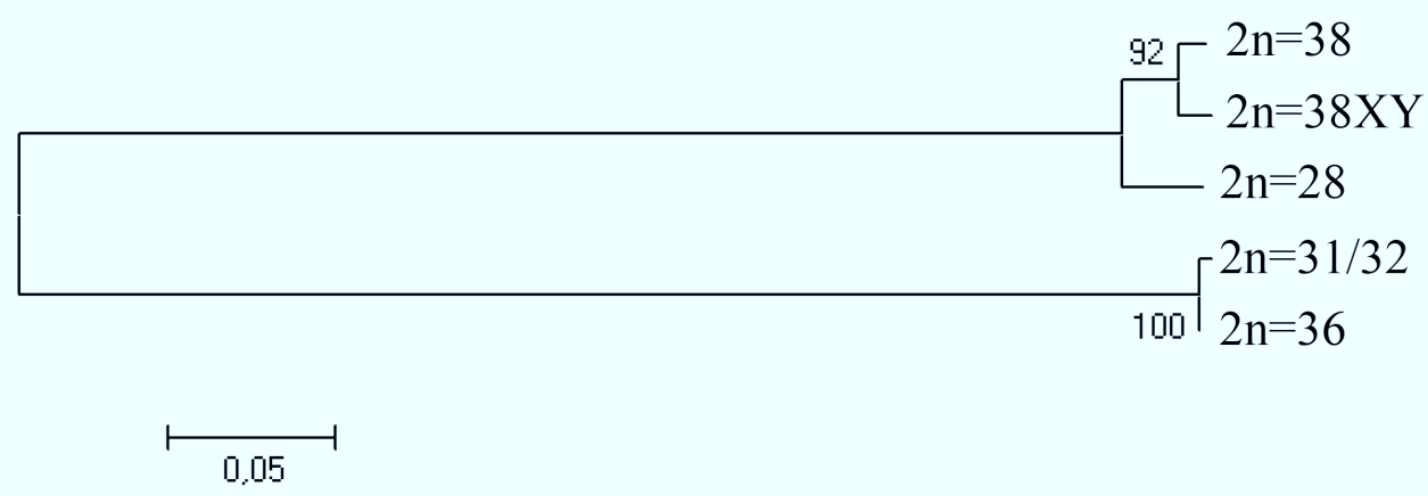

Figura 3: Árvores de Máxima Verossimilhança (a), Máxima Parcimônia (b) e Neighbour-Joining (c) para o elemento transponível TC1. 


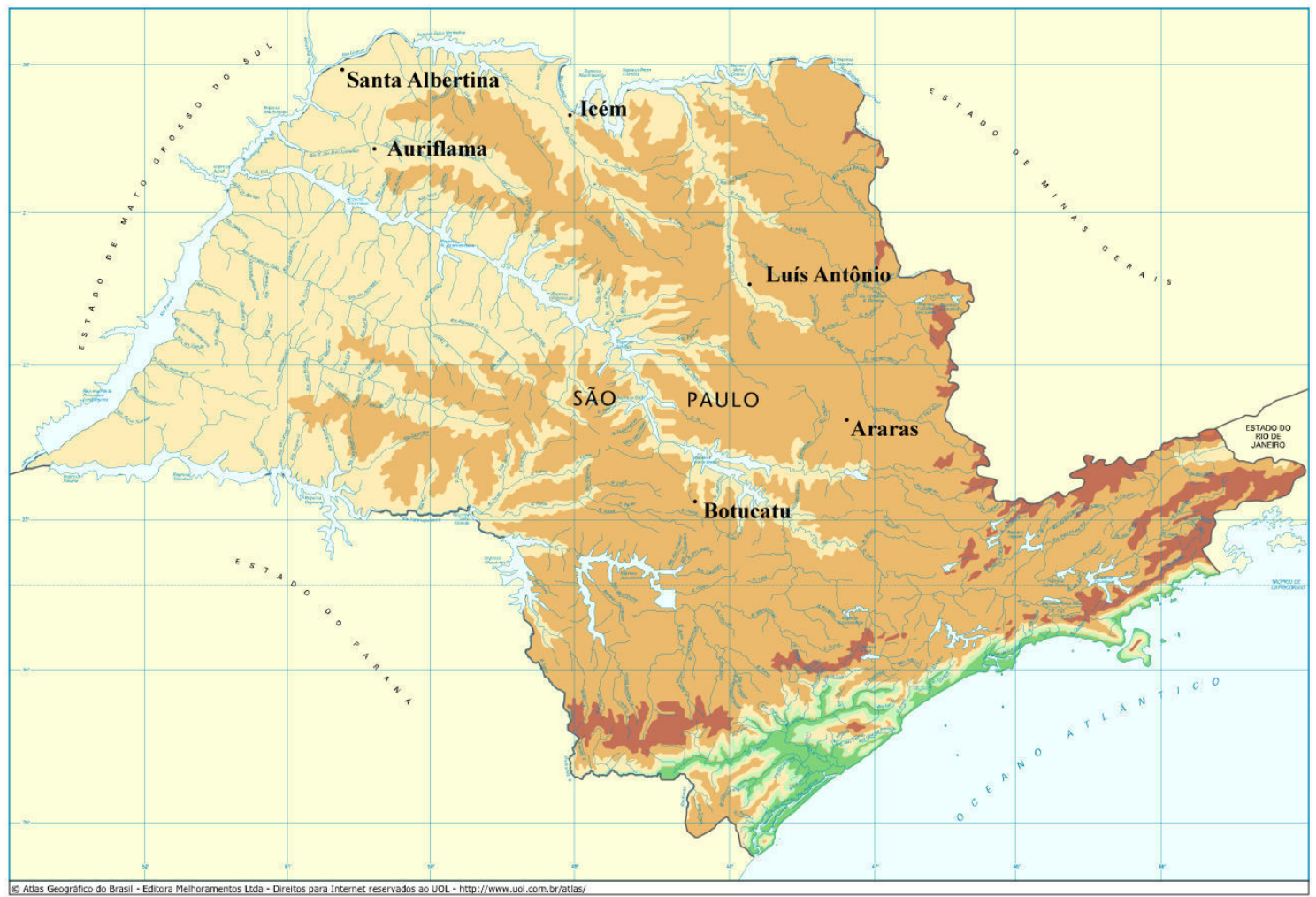

Figura 4: Mapa evidenciando regiões onde já foi verificada a simpatria dos cariomorfos $2 n=31 / 32$ e $2 n=36$ (Santa Albertina/SP, Botucatu/SP e Auriflama/SP) e $2 n=38$ e $2 n=28$ (Icem/SP, Araras/SP, Luiz Antônio/SP).

\begin{tabular}{|c|c|c|}
\hline & $2 n=38 / 2 n=38 X Y / 2 n=28$ & $2 n=36 / 2 n=31 / 32$ \\
\hline $2 n=38 / 2 n=38 X Y / 2 n=28$ & - & \\
\hline $2 n=36 / 2 n=31 / 32$ & 0.7036 & - \\
\hline
\end{tabular}

Tabela 2: Distâncias genéticas entre dois grupos de espécies $(2 n=38 / 2 n=38 X Y / 2 n=28$ e $2 n=36 / 2 n=31 / 32$ ) para o elemento transponível TC1, utilizando-se o modelo Kimura2-Parâmetros.

O retrotransposon Rex1 por sua vez teve sequências de tamanho muito inferior ao transposon $\mathrm{TC} 1$, com um total aproximado de $575 \mathrm{pb}$ e apresentando uma 
conservação significativa entre as espécies, possuindo apenas 31 sítios variáveis (Fig. 5). As distâncias genéticas foram calculadas de acordo com o modelo Kimura 2 Parâmetros (Tamura et al. 2007). Novamente foi evidenciada uma grande proximidade entre as espécies 2 n=38XY e 2 n=38 (0.0113), fato esse já esperado, tal qual visto para o elemento transponível $\mathrm{TC} 1$, devido à possível origem recente do sistema sexual da espécie 2n=38XY (Henning et al., 2010). A maior distância por sua vez foi verificada para as espécies $2 \mathrm{n}=38$ e $2 \mathrm{n}=36(0.0325)$, diferindo do resultado encontrado para o transposon TC1. O esboço das relações também foi feito utilizando-se máxima verossimilhança utilizando-se o modelo Kimura 2 Parâmetros (Fig. 6), entretanto a topologia obtida diferiu, de modo geral, daquela observada para o transposon TC1, sendo mantida apenas a relação de distância entre as espécies $2 n=38 X Y$ e $2 n=38$, fato já esperado e discutido anteriormente. Foi formado também um segundo grupo que inclui as espécies $2 n=31 / 32$ e $2 n=28$, apresentando valor de distância próxima ao grupo já mencionado enquanto que a espécie 2 n=36 apresentou-se como separada das demais nesse esboço. Cabe ressaltar ainda que as distâncias genéticas obtidas para o retrotransposon Rex1 são sensivelmente menores quando comparadas com as obtidas para o elemento TC1. Essa grande proximidade entre as espécies, observada após o cálculo das distâncias (Tabela 3), pode significar um processo de invasão recente desse retrotransposon (Volff et al., 2000). Para melhor delinear a história evolutiva desse elemento um novo cálculo de distância foi levado a efeito para determinar o quão distante estão os grupos $2 n=28 / 2 n=31 / 32$ e $2 n=38 / 2 n=38 X Y$ em relação à espécie $2 n=36$ (Tabela 4). 


\section{CodonCode Aligner: Rex1 Alinhamento, Rex1}

Page 1 of 2

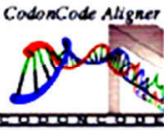

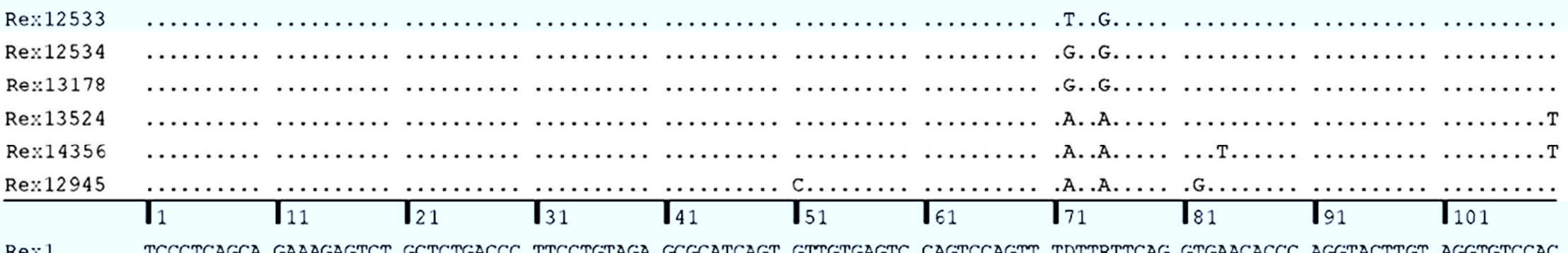

Rex 12533

$\operatorname{Re} 12534$

Re:13178

Rex13524

Re:14356

$\operatorname{Re} 12945$

TCCCTCAGCA GAAAGAGTCT GCTCTGACCC TTCCTGTAGA GCGCATCAGT GTTGTGAGTC CAGTCCAGTT TDTTRTTCAG GTGAACACCC AGGTACTTGT AGGTGTCCAC

$\operatorname{Re} * 1$

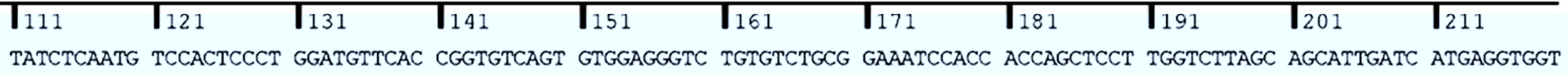

Rex 12533

$\operatorname{Rex} 12534$

Re:13178

Rex 13524

$\operatorname{Re}: 14356$

Rex12945

I22

231

241

251

261

271

281

291

301

311

321

$\operatorname{Re} \times 1$

TCTGCTGGCA CCAGTCCACA AAGTCCTGAG TCAACTGTCT ATACATTGCA TCATCCCCGT CTGTGATGAG GCCCACTATG GCAGAGTCAT CAGAGAACTT CTGTAGATGG 


\section{CodonCode Aligner: Rex1 Alinhamento, Rex1}

Page 2 of 2

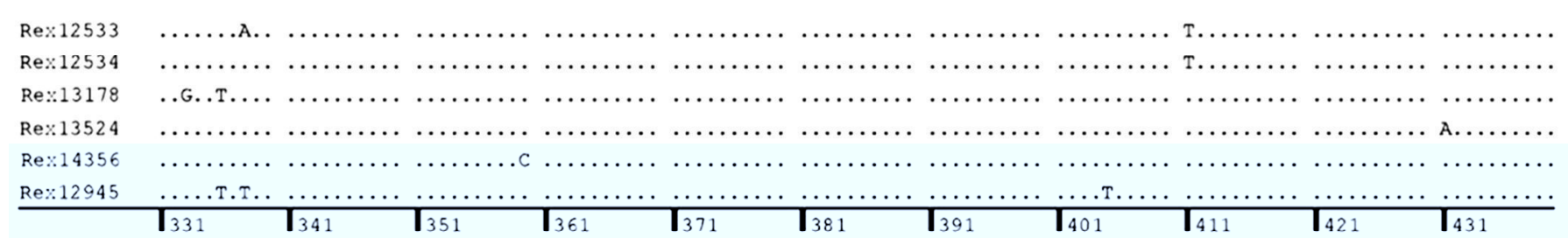

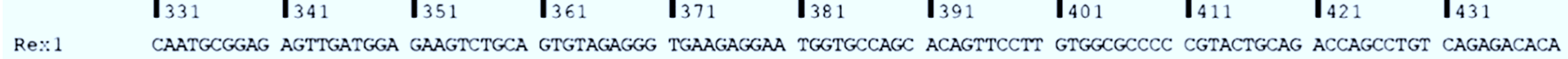

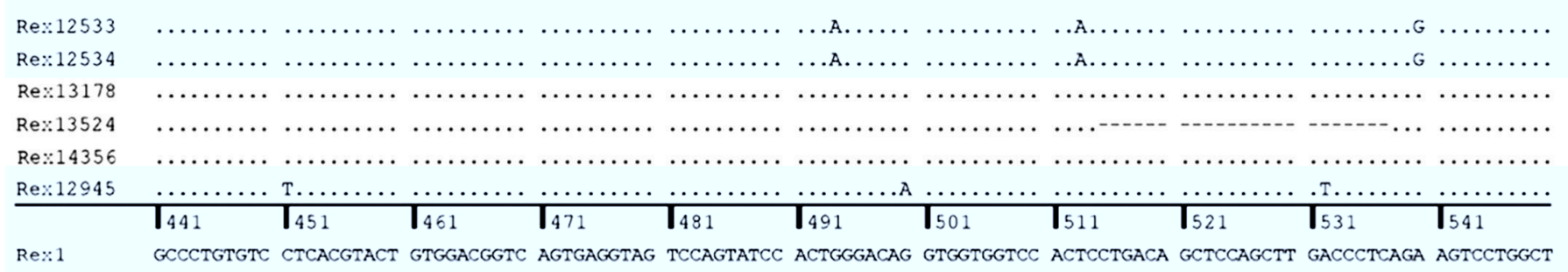

Re:1 GCCCTGTGTC CTCACGTACT GTGGACGGTC AGTGAGGTAG TCCAGTATCC ACTGGGACAG GTGGTGGTCC ACTCCTGACA GCTCCAGCTT GACCCTCAGA AGTCCTGGCT

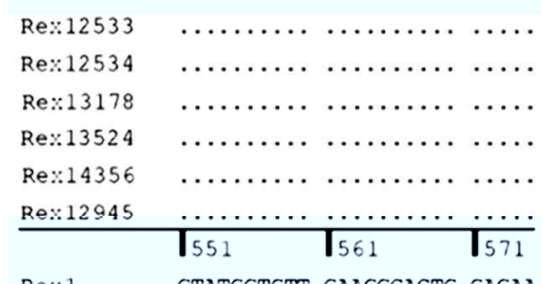

Re:1 GTATGGTGTT GAAGGCACTG GAGAA

Figura 5: Alinhamento das sequências do elemento transponível Rex1. Pontos indicam bases iguais e traços indicam deleções. Abaixo sequência consenso entre as espécies, determinado pelo programa Codon Code Aligner 
a.

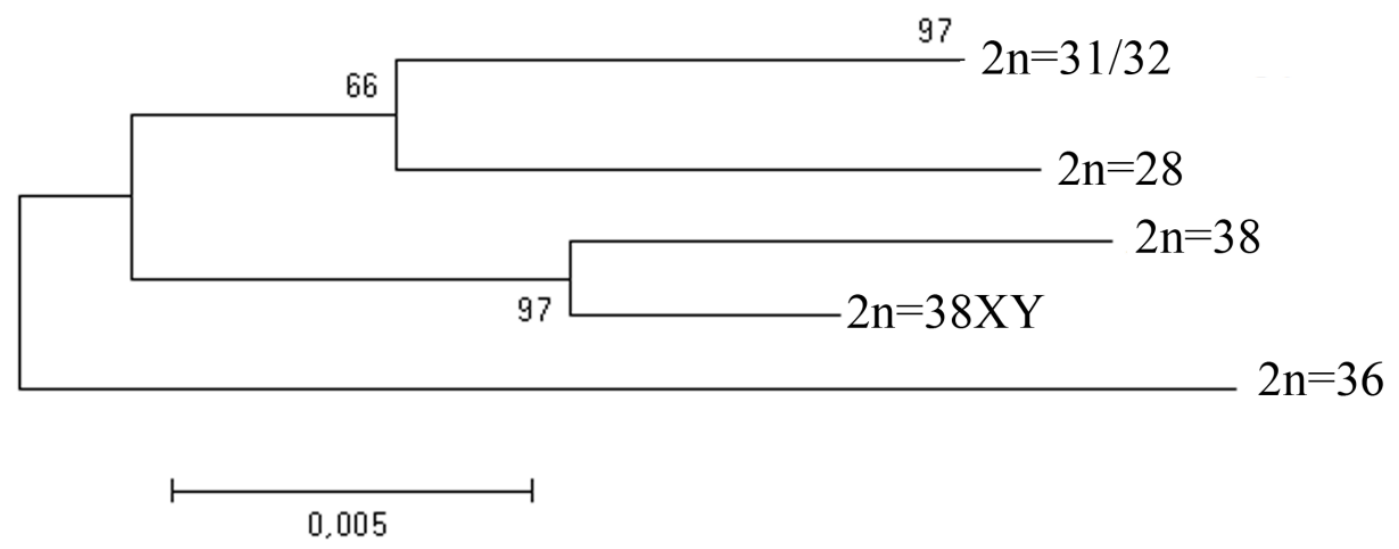

b.

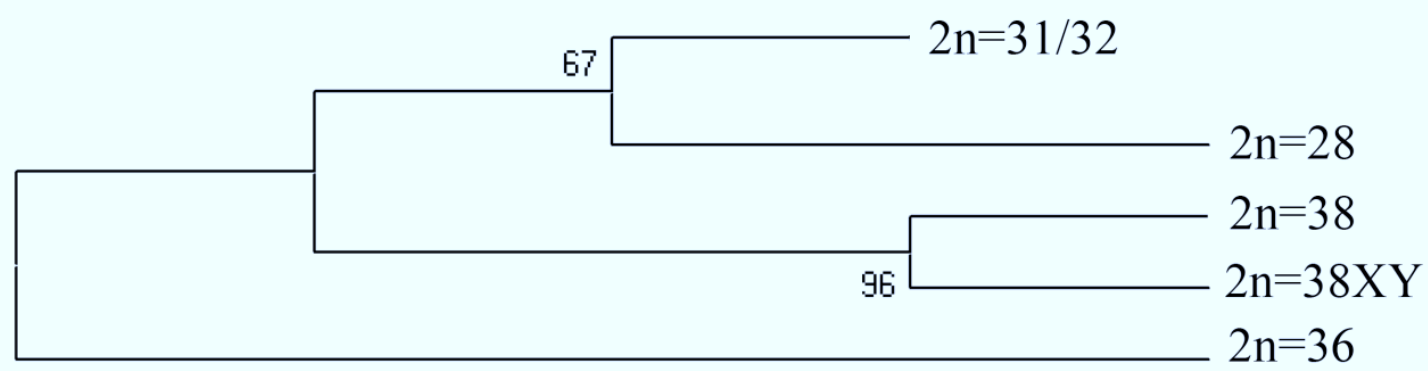

c.

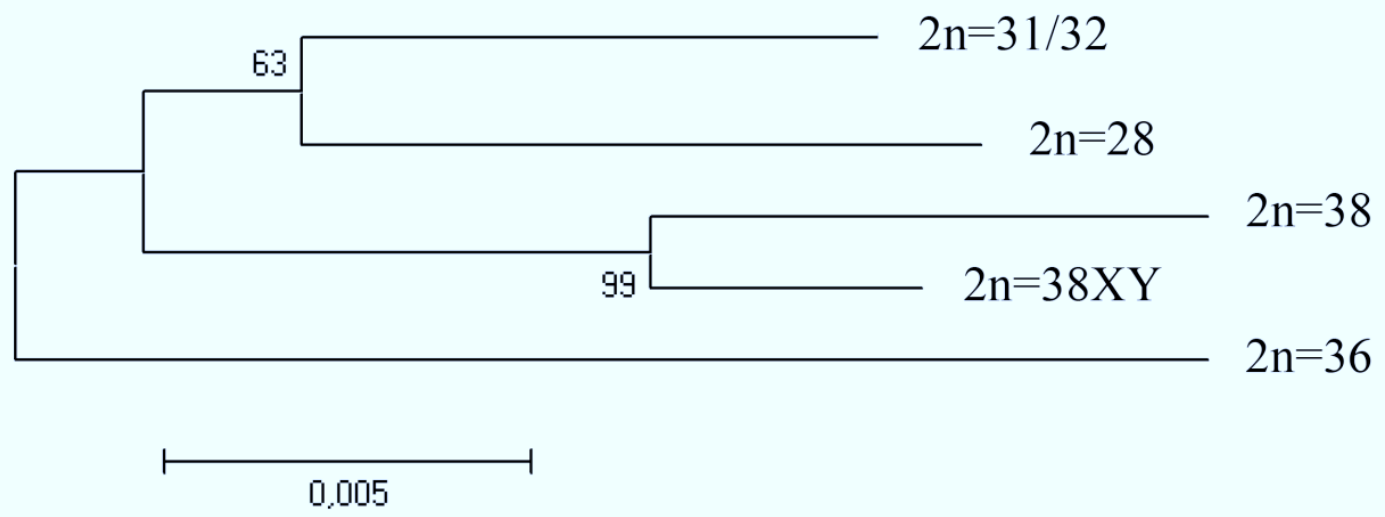

Figura 6: Árvore de verossimilhança com cálculo de bootstrap, utilizando-se o modelo Kimura-2-Parâmetros, para a sequência do elemento transponível Rex1. 


\begin{tabular}{|l|c|c|c|c|c|}
\hline & $2 n=38$ & $2 n=38 X Y$ & $2 n=36$ & $2 n=31 / 32$ & $2 n=28$ \\
\hline $2 n=38$ & - & & & & \\
\hline $2 n=38 X Y$ & 0.0113 & - & & & \\
\hline $2 n=36$ & 0.0325 & 0.0286 & - & & \\
\hline $2 n=31 / 32$ & 0.0267 & 0.0228 & 0.0316 & - & \\
\hline $2 n=28$ & 0.0267 & 0.0228 & 0.0287 & 0.0199 & - \\
\hline
\end{tabular}

Tabela 3: Distâncias genéticas entre as espécies em estudo para o elemento transponível Rex1, utilizando-se o modelo Kimura-2-Parâmetros.

\begin{tabular}{|c|c|c|c|}
\hline & $2 n=28 / 2 n=31 / 32$ & $2 n=38 / 2 n=38 X Y$ & $2 n=36$ \\
\hline $2 n=28 / 2 n=31 / 32$ & - & & \\
\hline $2 n=38 / 2 n=38 X Y$ & 0.0247 & - & \\
\hline $2 n=36$ & 0.0306 & 0.0306 & - \\
\hline
\end{tabular}

Tabela 4: Distâncias genéticas entre dois grupos de espécies $(2 n=28 / 2 n=31 / 32$ e $2 n=38 / 2 n=38 X Y)$ para o elemento transponível Rex1, utilizando-se o modelo Kimura2-Parâmetros.

A hibridação in situ dos elementos Rex1 (Fig. 7) e TC1 (Fig. 8) nos cariomorfos em estudo, permitiu observar a distribuição de tais elementos em nível cromossômico e a existência ou não uma possível relação com os cromossomos sexuais nas espécies $2 n=38 X Y$ e $2 n=31 / 32$. O retroelemento Rex1 apresentou uma maior ocorrência nas espécies $2 n=28$ e $2 n=31 / 32$, permitindo inclusive a visualização de pequenos blocos em alguns cromossomos, sendo que na espécie 2 n=28 é possível visualizar ainda uma 
preferência de localização em um único par cromossômico metacêntrico de grande tamanho (destaque Fig. 3) mas, de modo geral, o sinal pode ser visto nos cromossomos como um todo. O transposon TC1, por sua vez mostrou-se com uma incidência mais homogênea no genoma das espécies em estudo e, novamente, fato também observado por Capriglione et al. (2002) na espécie Chionodraco hamatus. Outro ponto interessante verificado foi de que assim como para o elemento Rex1, na espécie $2 \mathrm{n}=28$ houve um acúmulo de elementos em um par cromossômico metacêntrico grande. 


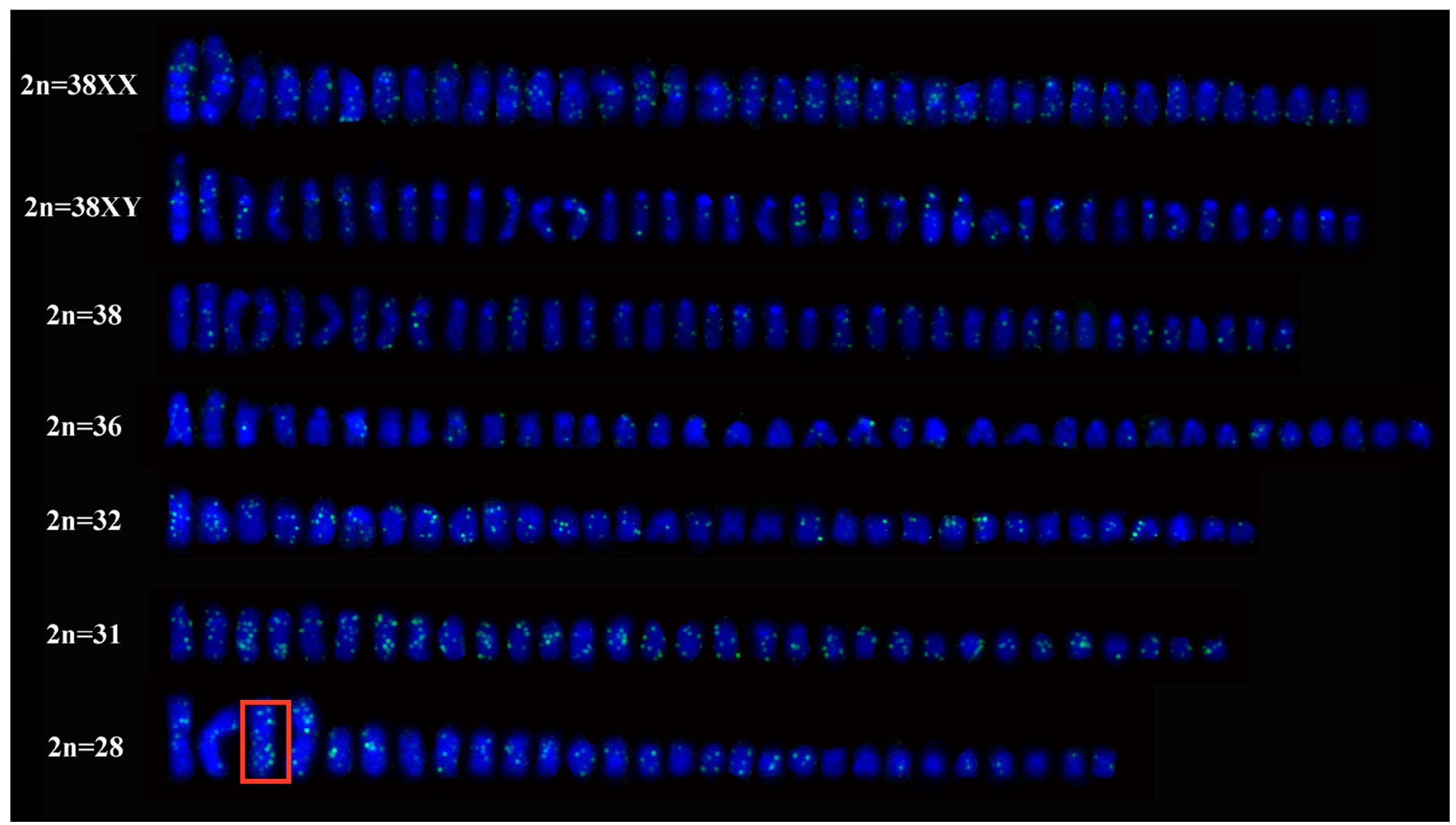

Figura 7: Hibridação in situ em cariomorfos do gênero Eigenmannia utilizando-se como sonda o elemento Rex 1. Em destaque metacêntrico com acúmulo de elementos transponíveis. 


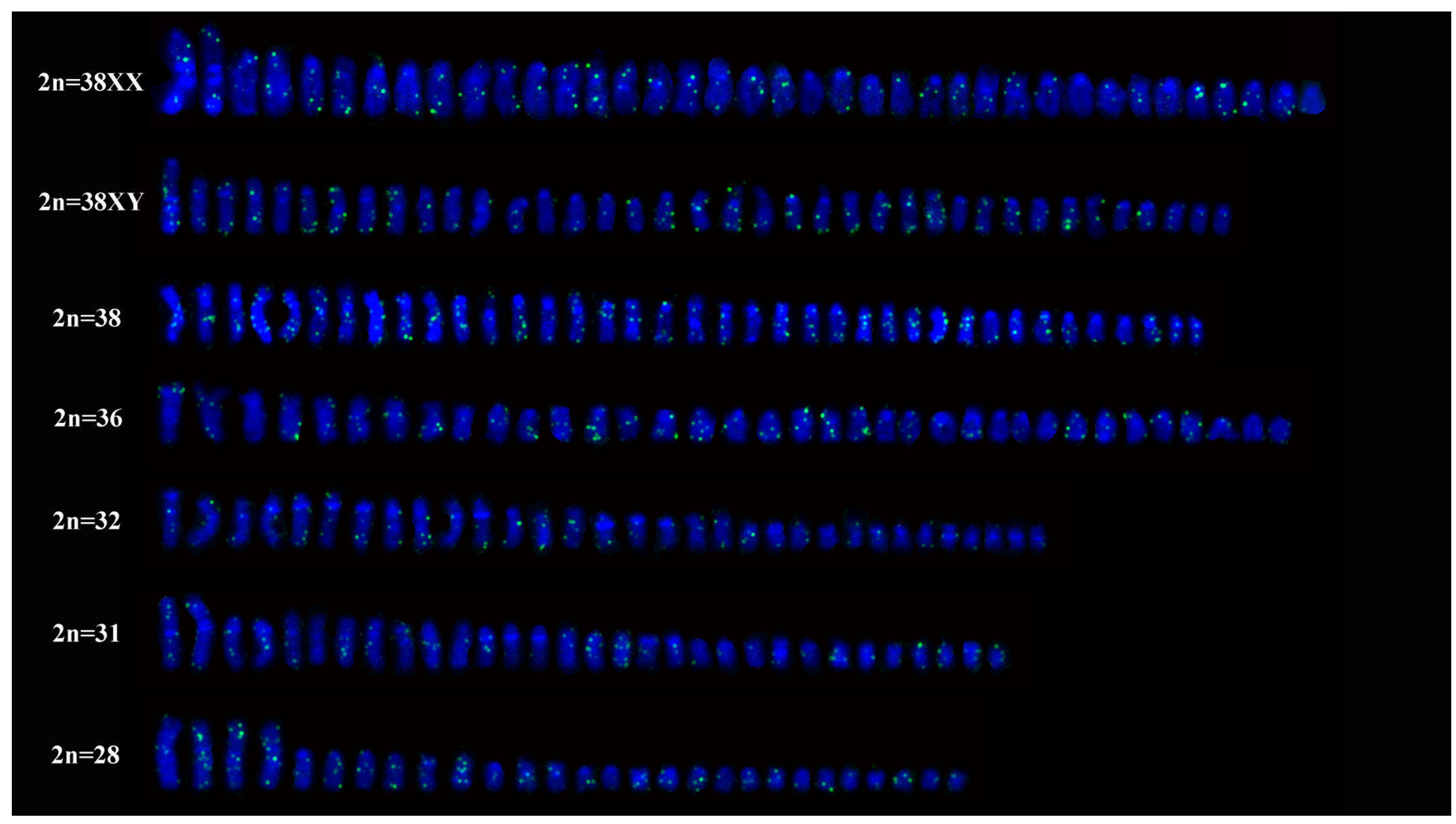

Figura 8: Hibridação in situ em cariomorfos do gênero Eigenmannia utilizando-se como sonda o elemento TC1. 


\section{Discussão}

Algumas famílias de retrotransposons têm sido utilizadas com sucesso em estudos filogenéticos (Wichmanet al., 1992; Deinniger\&Batzer, 1993), entretanto, geralmente existe certa inconsistência entre as filogenias dos elementos transponíveis e a espécie na qual ele é encontrado. Devido a isso, acredita-se que a transferência de um genoma para outro ocorra por transmissão vertical, no caso sexual, ou horizontal (Capriglione et al., 2002).

Sabe-se que o elemento TC1 está comumente associado a regiões de lesão cromossômica (Reite et al., 1996, 1999) e também de inversões (Cacereset al., 1999; Mathiopoulos et al., 1998), o que pode indicar que a invasão desse elemento no gênero não seja antiga e que as alterações observadas entre os grupos $2 n=38 / 2 n=38 X Y / 2 n=28$ e $2 n=36 / 2 n=31 / 32$, refletidas na pequena distância calculada entre os grupos, seja, na verdade, resultado do comportamento característico desse transposon, o de estar associado a regiões de rearranjos cromossômicos, acumulando assim inúmeras alterações em sua sequência em um curto período de tempo. Aliado a isso, o fato de a topologia obtida nos fornecer dois grupos distintos com números cromossômicos distantes $(2 n=38 / 2 n=38 X Y / 2 n=28$ e $2 n=36 / 2 n=31 / 32)$ nos leva a crer que a invasão tenha ocorrido uma única vez ao longo da história evolutiva dos grupos. Para tal, pelo menos quatro dos cinco cariomorfos já estariam diferenciados $(2 n=28,2 n=38$ (ancestral), $2 n=31 / 32$ e $2 n=36$ ), sendo, portanto a invasão simultânea nos grupos $2 n=28$ / $2 n=38$ (ancestral) e $2 n=36 / 2 n=31 / 32$, os quais seriam simpátricos (Fig. 15), tal qual visto atualmente, e cujas pressões do ambiente, associadas às características inerentes desse transposon de estar associado a regiões de alteração cromossômica, levaram à diferenciação dessa sequência entre os cariomorfos, do modo como as vemos hoje. Os dados sobre o retrotransposon Rex1 evidenciaram uma mesma distância dos grupos 
determinados em relação ao cariomorfo $2 \mathrm{n}=36$, demonstrando a presença de uma característica única, que o diferenciou do elemento presente na espécie $2 n=36$. Foi observada, como citada anteriormente uma grande conservação desse elemento e, sendo assim, a hipótese que melhor explicaria o padrão observado seria a de uma invasão única desse retrotransposon em um ancestral para todos os cariomorfos, seguida por alterações nessa sequência ancestral apenas na espécie $2 n=36$, fato que corrobora a presença das maiores distâncias observadas para a espécie em relação às demais (Tabela 7). Sendo assim é provável que a invasão desse elemento no gênero seja recente, fato evidenciado pelas pequenas distâncias encontradas e que essa invasão tenha ocorrido em um único evento, diferindo do padrão já descrito na literatura de apresentar inúmeras ondas de retrotransposição (Deiningeret al., 1992)

De modo geral, o sinal obtido para os elementos estudados foi disperso, diferindo, portanto, de inúmeros trabalhos da literatura, realizados em duas ordens da superordem Acanthopterygii (Wileyet al., 2000), nos quais os elementos transponíveis são encontrados em clusters comumente associados a regiões heterocromáticas (Da Silva et al. 2002; Bouneauet al. 2003; Fischer et al., 2004; Ozouf-Costazet al., 2004; Mazzuchelli\& Martins, 2009; Teixeira et al., 2009). Entretanto, Ferreira et al. (2011) obtiveram o mesmo padrão disperso, para os elementos Rex1 e Rex3 na subfamília Hypoptopomatinae, onde também é verificada predominância de ocorrência em regiões eucromáticas. Sendo assim, considerando a filogenia geral da superordemOstariophysi, tal padrão se mostra congruente, uma vez que Gymnotiformes, ordem a qual inclui o gênero Eigenmannia, é grupo irmão de Siluriformes, ordem que contém a subfamília Hypoptopomatinae (Fink\&Fink, 1981). Tal fato pode indicar um processo de invasão de elementos transponíveis da família Rex em um ancestral comum, sendo esse um provável processo paralelo de invasão na superordem Acanthopterygii, sendo possível 
que esse mesmo padrão disperso possa ser encontrado dentro de Ostariophysi, entretanto estudos nessa mesma linha dentro dessa superordem são necessários para que essa hipótese possa ser mais bem explorada.

Outro fato interessante com relação à localização desses elementos transponíveis é a sua localização em regiões eucromáticas, um possível indicativo de que esses elementos encontram-se ativos, transpondo em regiões onde haja a atuação da maquinaria de replicação, ponto fundamental para o processo de transposição ou retrotransposição dos elementos transponíveis (Sawyer \& Malik, 2006). Além disso, o acúmulo de sinal no cromossomo metacêncitrico do cariomorfo 2 n=28 pode ser um indício de convergência, uma vez que esses elementos apresentam métodos de mobilização genômica distintos, sendo o elemento TC1 (Ivics et al., 1997) por transposição e o elemento Rex1 por retrotransposição (Volff et al., 2000). Não foi possível observar uma preferência de localização nos cromossomos sexuais nas espécies $2 n=31 / 32$ e $2 n=38 X Y$, indicativo de que esses elementos provavelmente não atuaram no processo de diferenciação morfológica dos cromossomos sexuais, como já descrito na literatura (Cioffi et al., 2010), porém os resultados apresentados permitiram observar algumas peculiaridades associadas ao padrão de distribuição desses elementos, bem como aliado aos dados moleculares foi possível um início da compreensão da evolução desses elementos nos diferentes cariomorfos do gênero Eigenmannia

\section{Referências}

BOUNEAU L, FISHER C, OZOUF-COSTAZ C, FROSCHAUER A, JAILLON O, COUTANCEAU JP, 2003. An active Non-LTR retrotransposon with tandem structure in the compact genome of the pufferfish Tetraodonnigroviridis. Genome Res; 13:168695. 
CACERES, M., RANZ, J. M., BARBADILlA, A., LONG, M., RUIZ, A., 1999. Generation of widespread Drosophila inversion by a transposable element.Science 285 (5426), 415-418.

CAPRIGLIONE, T., ODIERNA, G., CAPUTO, V., CANAPA, A., OLMO, E., 2002. Characterization of a Tcl-like transposon in the Antartic ice fish, Chinodracohamatus.Gene 295: 193-198.

CAPRIGLIONE, T., ODIERNA, G., CAPUTO, V., CANAPA, A., OLMO, E., 2002. Characterization of a Tcl-like transposon in the Antartic ice fish, Chinodracohamatus.Gene 295: 193-198.

CIOFFI, M. B., MARTINS, C., BERTOLLO, L. A. C., 2010. Chromosome spreading of associated transposable elements and ribosomal DNA in the fish Erythrinus erythrinus.Implications for genome change and karyoevolution in fish. BMC Evolutionary Biology 10: 271.

CLARO, F. L., 2008. Gymnotus carapo e Gymnotus sylvius (Teleostei: Gymnotidae): uma abordagem citogenético-molecular Dissertação de Mestrado, Universidade de São Paulo.

COLE, C.J.; LEAVENS, C.R., 1971. Chromosome preparations of amphibians and reptiles: improved technique. Herpetol. Rev. 3 (6): 102. 
DA SILVA C, HADJI H, OZOUF-COSTAZ C, NICAUD S, JAILLON O, WEISSENBACH J, CROLLIUS HR., 2002. Remarkable compartmentalization of transposable elements and pseudogenes in the heterochromatin of the Tetraodon nigroviridis genome.ProcNatlAcadSciUSA; 99:1636-41.

DEININGER, P. L., BATZER, M. A., 1993. Evolution of retroposons. In: Hecht, M.K. (Ed.). Evolutionary Biology, Plenum Press, New York, pp. 157-196.

DUVERNELL, D. D., TURNER, B. J., 1998.Swimer1, a new LINE family in teleost genomes with sequence similarity by mammalian L1.MolBiolEvol 15: 1791-1793.

EASTMAN, J. T., DAVIDSON, W., 1994. Antartic Fish Biology.In: Hecht, M. K. (Ed.) Academic Press, San Diego.

FINK, S. V. AND W. L. FINK. 1981. Interrelationships of the ostariophysan fishes (Teleostei). Zool. J. Linn. Soc. 72: 297-353.

FISCHER C, BOUNEAU L, COUTENCEAU JP, WEISSENBACH J, VOLLF JN, OZOUF-COSTAZ C., 2004. Global heterochromatic colocalization of transposable elements with minisatellites in the compact genome of the pufferfish Tetraodon nigro viridis. Gene; 336:175-83.

FORESTI, F., OLIVEIRA, C., ALMEIDA-TOLEDO, L.F., 1993. A method for chromosome preparations from large specimens of fishes using in vitro short treatment with colchicine.Experientia, 49: 810-813. 
HENIKOFF, S., 1992. Detection of Caenorhabditis transposon homologs in diverse organisms. New Biologist 4: 382-388.

HENNING, F., MOYSÉS, C. B., CALCAGNOTTO, D., MEYER, A., ALMEIDATOLEDO, L. F., 2010.Independent fusions and recent origins of sex chromosomes in the evolution and diversification of glass knife fishes (Eigenmannia). Heredity (2010): $1-10$.

HIGASHIYAMA, T., NOUTOSHI, Y., FUJIE, M., YAMADA, T., 1997. Zeep, a LINE-like retrotransposon accumulated in the Chlorella telomeric region. EMBO J 16: $3715-3723$.

IVICS, Z., HACKETT, P.B., PLASTERK, R.H., IZSVAK, Z., Nov 1997. Molecular reconstruction of Sleeping Beauty, a Tc1-like transposon from fish, and its transposition in human cells. Cell 1491 (4), 501-510.

KAPITONOV, V. V., JURKA, J., 2003. A novel class of SINE derived from 5S rRNA. Mol Biol Evol 20 (5): 694-702.

KIDWELL, M. G., 2002. Transposable elements and the evolution of genome size in eukaryotes. Genetica 115: 49-63.

KIDWELL, M. G., LISH, D. R., 2000. Transposable elements and host genome evolution. Trends Ecol. Evol. 15: 95-99. 
MATHIOPOUlOS, K. D., DELlA TORRE, A., PREDAZZI, V., PETRARCA, V., COLUZZI, M., 1998. Cloning of inversion breakpoints in the Anopheles gambiae complex traces a transposable element at the inversion junction. Proc. Natl. Acad. Sci. USA 95 (21), 124444-124449.

MAZZUCHELLI J, MARTINS C., 2009. Genomic organization of repetitive DNAs in the cichlid fish Astronotus ocellatus.Genetica; 136:461-9.

MORESCALCHI, A., CAPRIGLIONE, T., LANNA, R., MORESCALCHI, M.A., ODIERNA, G., OLMO, E., 1996. Genome structure in notothenioid fish from the Ross Sea. Proc. Third Meeting on Antartic Biology, PP. 365-379.

NEI, M., ROONEY, A. P., 2005. Concerted evolution and birth-and-death evolution of multigene families. Annu. Rev. Genet. 39: 121-152.

OHSHIMA, K. HAMADA, M., TERAI, Y., OKADA, N., 1996. The 3' end of rRNAderived short interspersed repetitive elements are derived from the 3' ends Fo long interspersed repetitive elements. Mol Cell Biol 16: 3765-3764.

OKADA, N., HAMADA, M., OGIWARA, I., OHSHIMA, K., 1997. SINEs and LINEs share common 3' sequences: a review. Gene 205: 229-243.

OLIVEIRA, C., CHEW, J. S. K., PORTO-FORESTI, F., DOBSON, M. J., WRIGHT, J. M., 1999. A LINE2 repetitive DNA sequence from the cichlid fish, Oreochromisniloticus: sequence analysis and chromosomal distribution. Chromosoma 108: 457-468. 
OZOUF-COSTAZ C, BRANDT J, KORTING C, PISANO E, BONILLO C, COUTANCEAU JP, VOLFF JN. 2004. Genome dynamics and chromosomal localization of the non-LTR retrotransposons Rex1 and Rex3 in Antarctic fish. Antarctic Science; 16:51-7.

PARISE-MALTEMPI, P. P., MARTINS, C., OliVEIRA, C., FORESTI, F., 2007. Identification of a new repetitive element in the sex chromosomes of Leporinus elongatus (Teleostei: Characiformes: Anostomidae): new insights into the sex chromosomes of Leporinus. Cytogenet Genome Res 116: 218-223.

REITER, L. T., LIEHR, T., RAUTENSTRAUSS, B., ROBERTSON, H. M., LUPSKI, J. R., 1999. Localization of mariner DNA transposons in the human genome by PRINS. Genome Res. 9, 839-843.

REITER, L. T., MURAKEMI, T., KOEUTH, T., PENTAO, L., MUZNY, D. M., GIBBS, R. A., LUPSKI, J. R., 1996. A recombination hotspot responsible for two inherited peripheral neuropathies is located near a transposon-like element. Nat. Genet. $12(3), 288-297$.

SAWYER, S. L., MALIK, H. S., 2006. Eukaryotic Transposable Elements and Genome Evolution Special Feature:Positive selection of yeast non homologous end-joining genes and a retrotransposon conflict hypothesis. PNAS 103:17614-17619.

SMITH, G. P., 1976. Evolution of repeated DNA sequences by unequal crossover. Science, v.191, p.528-35. 
TAKAHASHI, K., Y. TERAI, M. NISHIDA, AND N. OKADA., 1998. A novel family of short interspersed repetitive elements (SINEs) from cichlids: the patterns of insertion of SINEs at orthologous loci support the proposed monophyly of four major groups of cichlid fishes in Lake Tanganyika. Mol. Biol. Evol. 15:391-407.

TAMURA K, DUDLEY J, NEI M, KUMAR S. 2007. MEGA 4: Molecular Evolutionary Genetics Analysis (MEGA) Software Version 4.0. Molecular Biology Evolution 24: 1596-1599.

TEIXEIRA WG, FERREIRA IA, CABRAL-DE-MELLO DC, MAZZUCHELLI J, VALENTE GT, PINHAL D. 2009 Organization of repeated DNA elements in the genome of the cichlid fish Cichlakelberi and its contributions to the knowledge of fish genomes. Cytogenet Genome Res; 125:224-34.

TERAI, Y., K. TAKAHASHI, AND N. OKADA., 1998. SINE cousins: the 39-end tails of the two oldest and distantly related families of SINEs are descended from the 39 ends of LINEs with the same genealogical origin. Mol. Biol. Evol. 15:1460-1471.

VOLFF, J.-N., KÖRTING, C. \& SCHARTL, M., 2000. Multiple lineages of the nonLTR retrotransposonRexl with varying success in invading fish genomes. Molecular Biology and Evolution, 17, 1673-1684.

VOLFF, J.-N., KÖRTING, C., FROSCHAUER, A., SWEENEY, K. \& SCHARTL, M., 2001a. Non-LTR retrotransposons encoding a restriction enzyme-like endonuclease in vertebrates.Journal of Molecular Evolution, 52, 351-360. 
WAGNER, R. P., MAGUiRE, M. P., STAllingS, R. L., 1993. Chromosomes: a stynthesis. Wiley-Liss, Inc., New York.

WICHMAN, H. A., VAN DEN BUSSCHE, R. A., HAMILTON, M. J., BAKER, R. J., 1992. Transposable elements and the evolution of genome organization in mammals.Genetica 86, 287-293.

WILEY, E. O., G. D. JOHNSON, AND W. W. DIMMICK. 2000. The interrelationships of acanthomorph fishes: a total evidence approach using morphological and molecular data. Biochem. Syst. Evol. 28(2000):319-350.

WINKFEIN, R. J., MOIR, R. D., KRAWETZ, A. S., BLANCO, J., STATES J. C., DIXON, G. H., 1998. A new family of repetitive, retrotransposon-like sequences in the genome of the raibow trout.Eur J Biochem 176: 255-264.

YAMADA, K., KAMIMURA E., KONDO, M., TSUCHIYA, K., NISHIDAUMEHARA, C., MATSUDA, Y., 2005. Nemfamiles of site-specific repetitive DNA sequences that comprise contitutivehetrochromatin of the Syrian hamster (Mesocricetusauratus, Cricetinae, Rodentia).Chromosoma 115: 36-49. 


\section{Capítulo 5}

Telomeric sequences reveal no fusion sites in karyomorphs of the genus Eigenmannia. 


\section{Introdução}

Resultado da evolução cromossômica, diferenças cariotípicas entre espécies próximas estão associadas à ocorrência de uma ampla variedade de rearranjos cromossômicos, como fusões cêntricas ou em tandem, inversões peri ou paracentroméricas, entre outros processos, levando à divergência dessas espécies em relação ao ancestral comum (Santani et al., 2002). Alguns processos de rearranjos geram vestígios, que auxiliam na compreensão da origem dos cromossomos de uma determinada espécie e entre esses processos podem-se destacar sítios centroméricos e teloméricos intersticiais, resquícios, por exemplo, de eventos de fusão, como os observados no Indian muntjac (Lee et al., 1993; Yang et al., 1997). Desse modo, sítios teloméricos intersticiais já foram observados em cromossomos de diversas espécies de vertebrados, incluindo humanos (Ijdo et al., 1991), camundongos (Yen et al., 1996, 1997), galinhas (Nanda \& Schmid, 1994) e peixes (Claro et al, 2010). Meyne et al. (1990), estudaram a localização de sítios teloméricos em três ordens de vertebrados (Chiroptera, Rodentia e Primates) e a hibridação in situ com essas seqüências, forneceu evidências da ocorrência da evolução cromossômica. Espécies que possuem cariótipos ancestrais apresentaram sítios teloméricos apenas nas regiões terminais, enquanto que espécies intermediárias e com altas taxas de evolução apresentam sítios teloméricos em regiões não terminais, evidenciando assim resquícios de ocorrência de fissões seguidas de fusões durante o processo de evolução cariotípica (Meyne et al, 1990).

Rearranjos que levam à fusão cêntrica de dois cromossomos acrocêntricos, formando um único metacêntrico, as fusões Robertsonianas (Robertson, 1916), e as fusões cromossômicas em tandem, como verificado no cariótipo do Indian muntjac (Yang et al., 1997), podem ocorrer quando há depleção da seqüência telomérica ou alterações nas proteínas associadas a essas 
regiões (Ferreira et al., 2004). Os telômeros são regiões de extrema importância para manutenção da estabilidade e integridade cromossômica, (Kipling, 1995) e quando há a depleção dessas seqüências, essas passam a ser reconhecidas como quebras nas moléculas de DNA, resultando na ativação da maquinaria de reparo da célula ocasionando assim a fusão dessas regiões (Ferreira et al., 2004). Em alguns grupos de vertebrados, verifica-se a ocorrência de fusões cromossômicas sem perda da seqüência telomérica, tendo como resultado a presença de sítios teloméricos intersticiais (ITS) remanescentes detectáveis por FISH, fato que é associado à possível inativação dos telômeros seguida da fusão dessas regiões (Meyne et al., 1990). Em peixes, a análise a distribuição das seqüências (TTAGGG)n mostrou que, de modo geral, elas encontravam-se nas regiões terminais; em alguns casos, pode-se verificar a presença de sítios teloméricos intersticiais (ITS) em regiões centroméricas, indicando assim, a ocorrência tanto processos de fusão cromossômica recente (Holmquist \& Dancis, 1979), como evidências de rearranjos cromossômicos envolvendo seqüências teloméricas (Phillips \& Reed, 1996). Devido à grande variedade de cariomorfos pertencentes ao gênero Eigenmannia este trabalho tem por intuito verificar se há indícios de ITS nesses cariomorfos, indicando se houve ou não rearranjos cromossômicos recentes, na história evolutiva da espécie, envolvendo as regiões teloméricas.

\section{Material e Métodos}

\section{Preparações Citogenéticas}

Para a análise citogenética, a estimulação de mitoses foi feita pela inoculação de fermento biológico (Cole e Levans, 1971) e os cromossomos mitóticos foram obtidos pela preparação direta de células renais (Foresti et al., 1993). 


\section{Amplificação de Sequências teloméricas}

Para obtenção das sequências teloméricas, utilizamos os primers degenerados $(\text { TTAGGG })_{5}$ e (CCCTAA $)_{5}$, de modo que na reação de PCR esses pimers atuem como templates para si mesmos e, portanto a cada ciclo temos o aumento no tamanho do fragmento. A reação de PCR para um volume de $100 \mu \mathrm{l}$ continha $50 \mathrm{mM} \mathrm{KCl,} 10 \mathrm{mM}$ Tris- $\mathrm{HCl}(\mathrm{pH} 8.3), 1.5 \mathrm{mM} \mathrm{MgCl}_{2}$, $200 \mu \mathrm{M}$ de cada dNTP, $0.1 \mu \mathrm{M}$ de cada primer e $2 \mathrm{U}$ de Taq Polimerase. A amplificação consiste em primeiramente 10 ciclos, sendo 1 minuto $94^{\circ} \mathrm{C}, 30$ segundos a $55^{\circ} \mathrm{C}$ e 1 minuto a $72^{\circ} \mathrm{C}$, seguido de 30 ciclos sendo 1 minuto $94^{\circ} \mathrm{C}, 30$ segundos $60^{\circ} \mathrm{C}, 90$ segundos $72^{\circ} \mathrm{C}$ e um passo final de 5 minutos a $72^{\circ} \mathrm{C}$. Após a realização da PCR os produtos amplificados foram visualizados em gel de agarose $1 \%$ para verificação do tamanho dos produtos.

\section{Hibridação in situ}

A hibridação in situ, realizada conforme Conway (1996), incluiu um pré tratamento das lâminas que consiste em uma incubação em solução a $100 \mu \mathrm{g} / \mathrm{ml}$ de RNase, seguida de uma lavagem em solução de $10 \mathrm{mM}$ de $\mathrm{HCl}$ contendo $0.02 \%$ de pepsina e um passo de pós fixação em PBS contendo $50 \mathrm{mM}$ de $\mathrm{MgCl} 2$ e $1 \%$ de formaldeído. Uma vez feito o pré tratamento, as lâminas são denaturadas numa solução de formamida $70 \%$ em $2 x S S C$ a $72^{\circ} \mathrm{C}$ e a sonda a $100^{\circ} \mathrm{C}$ em uma solução contendo $50 \%$ de formamida, $10 \%$ de sulfato de dextrano e 2XSSC. Para a hibridação, as lâminas são incubadas overnight em câmara úmida a $37^{\circ} \mathrm{C}$. A amplificação do sinal, consiste em duas incubações com Fitc-Avidina e uma com Anti-Avidina-Biotina a $37^{\circ} \mathrm{C}$ em câmara úmida, seguida, depois de cada incubação, de uma lavagem em solução contendo $0.5 \%$ de Tween 20 e 4xSSC. O passo final consistiu na desidratação das lâminas e posterior montagem com antifade contendo DAPI. 


\section{Resultados e Discussão}

A hibridação in situ das sequências teloméricas nas cinco espécies do gênero Eigenmannia (Fig. 1) evidenciou sinais apenas em regiões terminais, não apresentando sinais intersticiais. Sabe-se que na espécie $2 n=31 / 32$ houve a ocorrência de uma fusão de dois cromossomos $\mathrm{X}$ levando à formação de um neo Y já previamente descrita (Almeida-Toledo et al., 1992), dando origem a um sistema de determinação sexual múltiplo $\left(\mathrm{X}_{1} \mathrm{X}_{1} \mathrm{X}_{2} \mathrm{X}_{2} / \mathrm{X}_{1} \mathrm{X}_{2} \mathrm{Y}\right)$, padrão esse já diversas vezes verificado nas mais diversas espécies de peixes. A presença de sítios intersticiais já foi verificada em espécies da ordem Gymnotiformes (Claro et al., 2010), estudo que demonstrou a ocorrência de duas fusões em tandem, comprovada pela hibridação in situ de sequências teloméricas, bem como pela obtenção de bandas R, comprovando que houve uma redução do número cromossômico no ancestral comum do gênero Gymnotus que, associada a outros rearranjos, levou à diferenciação em duas espécies distintas Gymnotus sylvius com $2 \mathrm{n}=40$ cromossomos e Gymnotus carapo com 2 n=54 cromossomos. $\mathrm{O}$ fato de não ser possível encontrar qualquer resquício de sequências teloméricas intersticiais no gênero Eigenmannia, em especial na espécie 2 n=31/32 é um indicativo de que os rearranjos que ocorreram ao longo da história evolutiva, têm sua origem em um ponto muito antigo. Sendo assim, acredita-se que a diferenciação nos inúmeros cariomorfos, os quais correspondem a diferentes espécies do gênero Eigenmannia tenha ocorrido num tempo evolutivo distante, pensando principalmente na espécie $2 n=31 / 32$, nas qual a fusão foi comprovada por outras técnicas citogenéticas (Almeida Toledo et al., 1988) e seria esperado a presença de ITS nesse cromossomo, entretanto as sequências teloméricas intersticiais ali existentes foram depletadas com o tempo, sendo não mais possível detectá-las. Acredita-se ainda que a diferenciação dos cromossomos sexuais na espécie $2 n=38 X Y$ nada tem de relacionado com esses eventos de fusão e sim provavelmente um acúmulo 
de heterocromatina devido a outras pressões seletivas no cromossomo $\mathrm{X}$ da espécie, sendo inclusive muito provável que a formação dos dois sistemas sexuais presentes no gênero Eigenmannia $\left(\mathrm{XX}: \mathrm{XY} / \mathrm{X}_{1} \mathrm{X}_{1} \mathrm{X}_{2} \mathrm{X}_{2}: \mathrm{X}_{1} \mathrm{X}_{2} \mathrm{Y}\right)$ resulte da ocorrência de dois eventos de surgimento dos cromossomos sexuais nas espécies $2 n=31 / 32$ e $2 n=38 X Y$, tal qual sugerido por Henning et al. (2010). 


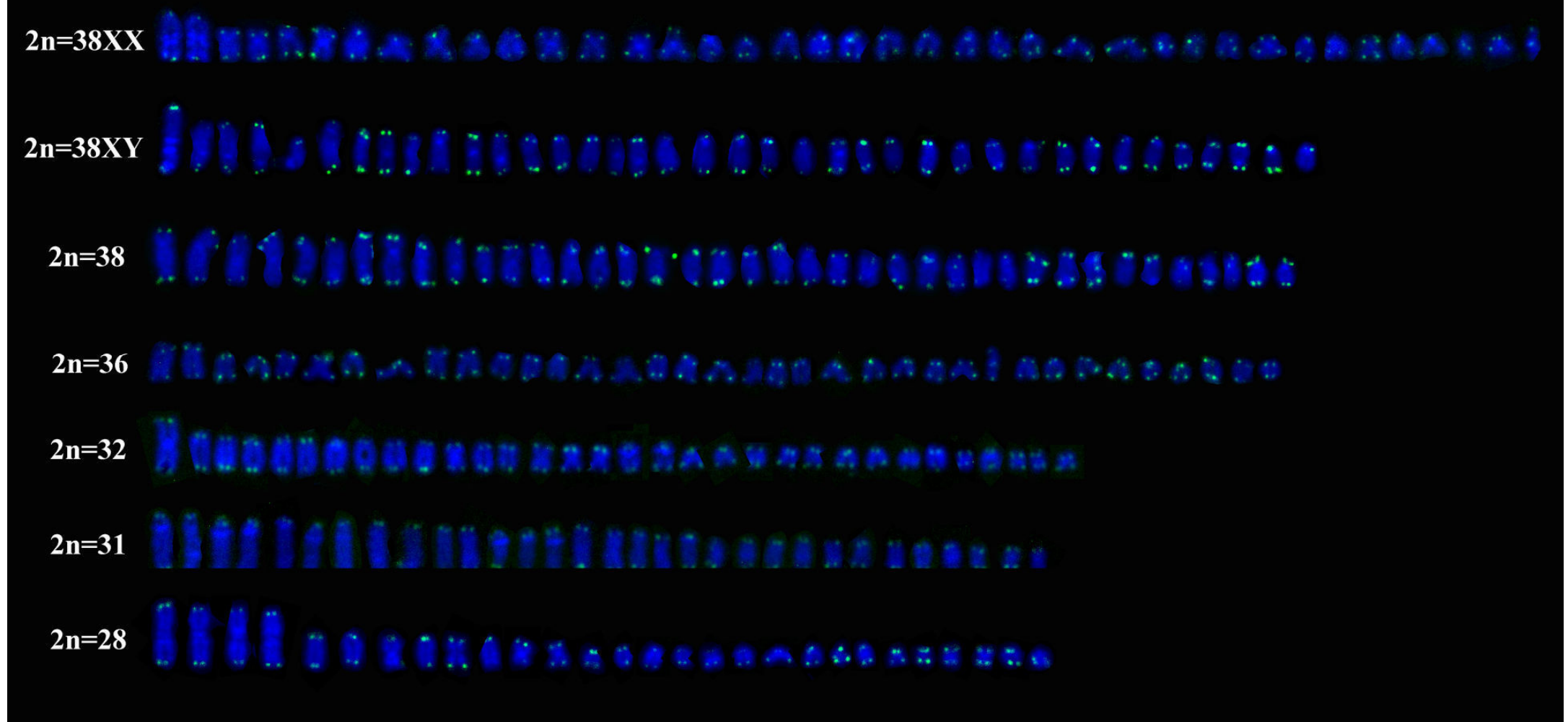

Figura 1: Hibridação in situ de sequências teloméricas em espécies do gênero Eigenmannia 


\section{Referências}

ALMEIDA-TOLEDO, L. F., VIEGAS-PÉQUIGNOT, E., FORESTI, F.,TOLEDO-FILHO, S. A., DUTRILlAUX, B., 1988. BrdU replication patterns demonstrating chromosome homeologies in two fish species, genus Eigenmannia. Cytogenet Cell Genet 48: 117-120.

ClARO, F. L., ALMEIDA-TOLEDO, L. F., 2010. Evidence of chromosome fusion in Gymnotus sylvius Albert \& Fernandes-Matoli, 1999 (Teleostei: Gymnotiformes) detected by telomeric probes and R-banding. Caryologia v. 63, n. 2, p. 134-141.

COLE, C.J.; LEAVENS, C.R., 1971. Chromosome preparations of amphibians and reptiles: improved technique. Herpetol. Rev. 3 (6): 102.

Ferreira MG, Cooper JP (2004) Two modes of DNA double-strand break repair are reciprocally regulated through the fission yeast cell cycle. Genes Dev 18: 2249-2254

FORESTI, F., OLIVEIRA, C., ALMEIDA-TOLEDO, L.F., 1993. A method for chromosome preparations from large specimens of fishes using in vitro short treatment with colchicine. Experientia, 49: 810-813.

HENNING, F., MOYSÉS, C. B., CALCAGNOTTO, D., MEYER, A., ALMEIDA-TOLEDO, L. F., 2010. Independent fusions and recent origins of sex chromosomes in the evolution and diversification of glass knife fishes (Eigenmannia). Heredity (2010): 1-10.

IJDO, J. W., WELLS, R.A., BALDINI, A., REEDERS, S.T., (1991) Improved telomere detection using a telomere repeat probe $(\mathrm{TTAGGG})_{\mathrm{n}}$ generation by PCR. Nucleic Acids Research 19 (17): 4870. 
LEE C, SASI R, LIN CC (1993) Interstitial localization of telomeric DNA sequences in the Indian muntjac chromosomes: further evidence for tandem chromosome fusions in the karyotypic evolution of the Asian muntjacs. Cytogenet Cell Genet 63: 156-159.

MEYNE, J., BAKER, R. J., HOBART, H. H., HSU, T. C., RYDER, O. A., WARD, O. G., WILEY, J. E., WURSTER-HILL, D. H., YATES, T. L., MOYZIS, R. K., 1990. Distribution of nontelomeric sites of (TTAGGG) $)_{n}$ telomeric sequences in vertebrate chromosomes. Chromosoma 99: 3-10.

PHILLIPS, R. B., REED, K. M., 1996. Application of fluorescence in situ hybridization (FISH) techniques to fish genetics: a review. Aquaculture 140: 197-216.

ROBERTSON, R. B., 1916 Chromosome studies. I. J. Morph. 27: 179-331.

SANTANI A, RAUDSEPP T, CHOWDHARYB P, 2002. Interstitial telomeric sites and NORs in Hartmann's zebra (Equus zebra hartmannae) chromosomes. Chromosome Res 10: 527-534.

YANG F, O'BRIEN PCM, WIENBERG M, FERGUSON-SMITH MA (1997) A reappraisal of the tandem fusion theory of karyotype evolution in the Indian muntjac using chromosome painting. Chromosome Research 5: 109-117.

YEN, C. H., J. PAZIK, Y. ZHANG, AND R. W. ELLIOTT. 1997. An interstitial telomere array proximal to the distal telomere of mouse chromosome 13. Mammalian Genome 8/6: 411-417. 


\section{Discussão Geral e}

Conclusões 
Muitos estudos citogenéticos foram já levados a efeito no gênero Eigenmannia, entretanto muito pouco se sabe ainda sobre a sistemática desse grupo (Albert, 1997) que apresenta uma distribuição exclusivamente tropical e uma grande diversidade. No presente trabalho foram analisados cinco cariomorfos do gênero, provenientes das regiões de São Miguel Arcanjo $(2 n=38 X Y)$, Botucatu $(2 n=31 / 32)$, Araras $(2 n=28$ e $2 n=38)$ e Santa Albertina $(2 n=36)$, de modo a verificar se esses cariomorfos poderiam ser potenciais espécies, o gene mitocondrial Citocromo Oxidase I (COI) amplamente utilizado em estudos de barcoding (referências) juntamente com o gene ribossômico 5S, já utilizado anteriormente para delimitação de espécies em peixes (referência). Comprovou-se o poder discriminatório do gene COI através do cálculo das distâncias genéticas em indivíduos de um mesmo cariomorfo e entre cariomorfos distintos, evidenciando grandes distâncias, resultado do acúmulo de mutações ao longo da história evolutiva do grupo e corroborado pelos dados obtidos do gene ribossômico 5S. Uma vez analisada a questão da delimitação dos cariomorfos como possíveis espécies, verificou-se a contribuição de porções repetitivas do genoma nesse processo evolutivo, desde regiões funcionais como o gene ribossômico 5S, e não funcionais como as regiões teloméricas, fundamentais na manutenção cromossômica (referência) e elementos transponíveis, verificando não só sua participação no processo evolutivo desses cariomorfos, como verificar se houve ou não acúmulo desses elementos em cromossomos sexuais morfologicamente distintos presentes em dois cariomorfos $(2 n=31 / 32$ e $2 n=38 X Y)$.

$\mathrm{O}$ gene ribossômico $5 \mathrm{~S}$ mostrou-se uma porção do genoma extremamente conservada, fato esse já esperado pela importância dessa região na produção de um elemento fundamental aos ribossomos (Albertset al., 2012), sendo a variação que permite a delimitação dos cariomorfos em possíveis novas espécies presente em seu 
espaçador não transcrito. Aliado a isso verificou-se a presença de duas classes de sequencias para o gene ribossômico $5 \mathrm{~S}$, de maior e menor tamanho, com exceção å do cariomorfo $2 \mathrm{n}=31 / 32$ que não apresenta a sequencia de maior tamanho. A análise dessas sequências sugere dois possíveis modelos evolutivos, um com aumento gradual do número cromossômico e o segundo dois grupos cromossômicos distintos, A ( $2 n=31 / 32$ e $2 n=28)$ e $B(2 n=36,2 n=38$ e $2 n=38 X Y)$, compartilhando um ancestral comum e apresentando uma evolução em paralelo, a partir da separação nesses grupos. A segunda hipótese já foi verificada na literatura e, portanto, talvez essa seja a hipótese mais provável. Foi vista ainda uma grande variação no número de sítios para o gene ribossômico, inclusive a presença desse gene em cromossomos sexuais morfologicamente distintos $2 n=31 / / 32$ e $2 n=38 X Y$ o que evidencia a grande complexidade dessa região de extrema importância no genoma. O estudo dessa família multigênica trouxe novas e importantes informações dessa região do genoma, fornecendo evidências do processo de evolução dessas sequencias para os diferentes cariomorfos em estudo.

Os elementos transponíveis analisados apresentaram dois padrões evolutivos distintos, sendo que o padrão associado ao transposon TC1 evidenciou grupos com números cromossômicos distintos $(2 n=31 / 32$ e $2 n=36 / 2 n=28$ e $2 n=38)$, porém já verificados, que ocorrem em simpatia e acredita-se que a invasão por esse elemento tenha ocorrido de forma simultânea nesses grupos. Para o retrotransposon Rex1 verifica-se um padrão de conservação maior devido às distâncias genéticas verificadas e, possivelmente, a invasão desse retrotransposon tenha ocorrido em um ancestral comum a todos os cariomorfos, seguida por alterações nessa sequência ancestral apenas na espécie $2 n=36$, fato que corrobora a presença das maiores distâncias observadas para a espécie em relação às demais. O padrão de dispersão verificado na hibridação in situ 
de ambos os elementos difere dos padrões já verificados na literatura (Da Silva et al. 2002; Bouneauet al. 2003; Fischer et al., 2004; Ozouf-Costazet al., 2004; Mazzuchelli\& Martins, 2009; Teixeira et al., 2009), entretanto dados recentes (Ferreira et al. 2011) evidenciam padrões muito similares, porém ainda são poucos os trabalhos voltados para o estudo dos elementos transponíveis. Com relação aos cromossomos sexuais, não foi verificada participação desses elementos em sua diferenciação morfológica e o acúmulo desses elementos não foi acentuado em nenhum dos cariomorfos.

A hibridação de sequencias teloméricas teve por objetivo verificar evidências de processos de fusão recentes envolvendo os cariomorfos, entretanto nenhum sinal intersticial (ITS) foi observado. Isso sugere que até mesmo a fusão no cariomorfo 2n=31/32 (Almeida-Toledo, 1998) que deu origem ao macho apresentando um cromossomo metacêntrico, e todos os outros processos de fusão que tenham ocorrido ao longo do processo evolutivo dos cariomorfos, deu-se em um tempo evolutivo suficiente para que evidências moleculares dessas fusões já não sejam mais detectáveis.

De uma forma geral foi possível estabelecer que os cariomorfos em estudo apresentem diferenças suficientes para sugerirmos que estes provavelmente componham espécies distintas e não apenas cariomorfos; verificaram-se duas classes de DNA ribossômico $5 \mathrm{~S}$ com tamanhos distintos de espaçadores e um padrão complexo de localização cromossômica para essa família multigênica; os elementos transponíveis como já esperado apresentam padrões evolutivos específicos tanto para suas sequências, quanto para a localização cromossômica. São necessários ,ainda mais estudos nesse gênero para uma melhor compreensão desses elementos e sua participação no processo evolutivo desses cariomorfos; a ausência de sítios teloméricos intersticiais que sugere que processo de fusão, dando origem aos diferentes cariomorfos, 
tenha ocorrido em um tempo evolutivo suficiente para que essas sequencias não mais possam ser detectadas molecularmente. 


\section{Resumo}

O DNA repetitivo constitui uma fração considerável do genoma de muitos organismos eucarióticos. Composto tanto por sequências funcionais, como os genes ribossômicos, quanto não codificantes, como é o caso dos elementos transponíveis, mini/microssatélites e o DNA satélite, essa porção do genoma tem sido amplamente utilizada como objeto de estudo, uma vez que sequências repetitivas podem estar associadas, por exemplo, a processos de diferenciação sexual. Esses estudos têm auxiliado tanto na melhor compreensão da dinâmica dessas regiões cromossômicas, como salientado a importância, a conservação e a evolução da porção repetitiva no genoma. O gênero Eigenmannia (Gymnotiformes, Sternopygidae) compreende espécies crípticas do ponto de vista morfológico que exibem variação no número cromossômico e podem apresentar sistemas sexuais XY ou ZW nos quais os elementos do par sexual diferem pela presença de blocos heterocromáticos maiores do que os encontrados em cromossomos autossomos, ou sistemas múltiplos envolvendo translocação Yautossomo. O presente trabalho tem por objetivos o estudo sobre do gene Citocromo Oxidase I(COI), de forma a verificar a capacidade discriminatória desse gene mitocondrial e sugerir possíveis espécies dos então cariomorfos do gênero Eigenmannia no estado de São Paulo, continuidade do estudo do DNA repetitivo no gênero Eigenmannia, tanto de regiões funcionais do genoma, no caso o gene ribossômico $5 \mathrm{~S}$, bem como de elementos transponíveis, permitindo assim uma melhor compreensão sobre a distribuição, conservação nos cariomorfos e verificar sua eventual participação no processo de diferenciação não só de cromossomos sexuais, mas também na evolução cariotípica do grupo. Os resultados obtidos com o gene COI, assim como aqueles obtidos pelo gene ribossômico $5 \mathrm{~S}$ evidenciam distâncias genéticas consistentes com a hipótese de que os cinco cariomorfos possam ser considerados como espécies distintas. Além disso, a hibridação in situ do gene ribossômico $5 \mathrm{~S}$ forneceu uma nova evidência para a fusão cromossômica que deu origem ao cromossomo sexual Y, já descrita na literatura, enquanto que a hibridação de sequências teloméricas não forneceu evidências de processos de fusão recentes envolvendo os cariomorfos. Com relação aos elementos transponíveis foi possível verificar padrões distintos nos elementos TC1 e Rex1 no que diz respeito às sequências, uma vez que o elemento TC1 delimitou dois grandes grupos o que pode indicar uma invasão simultânea nos grupos e no retrotransposon Rex1 a invasão tenha ocorrido em um ancestral comum a todos os cariomorfos. 


\begin{abstract}
The repetitive DNA constitutes a considerable fraction of the genome of many eukaryotic organisms. Compound by both functional sequences, such as ribosomal genes, and non-coding, such as transposable elements, mini / microsatellite DNA and the satellite, this portion of the genome has been widely used as a study object, since the repetitive sequences may be associated with, for example, the processes of sexual differentiation. These studies helped to understand the dynamics of these chromosomal regions, pointing the importance, conservation and evolution of the repetitive portion of the genome. The genus Eigenmannia (Gymnotiformes, Sternopygidae) comprises a morphological cryptic species that exhibit variation in chromosome number and may have sexual XY or ZW systems in which the elements of sexual pair differ by the presence of heterochromatic blocks larger than those found in chromosomes autosomes, or systems involving multiple $\mathrm{Y}$-autosome translocation. The present work aims to study the gene Cytochrome Oxidase I (COI) to verify the discriminatory capacity of this mitochondrial gene and suggest possible species of the so called karyomorphs of the genus Eigenmannia in the state of São Paulo. The study of repetitive DNA in Eigenmannia genus, includes $5 \mathrm{~S}$ ribosomal gene and transposable elements, thus allowing a better understanding of the distribution, conservation in karyomorphs and verify their possible participation in the process of differentiation not only of sex chromosomes, karyotypic evolution but also in the group. The results obtained with the COI gene, as well as those obtained by the $5 \mathrm{~S}$ ribosomal gene demonstrate genetic distances consistent with the hypothesis that the five karyomorphs can be regarded as separate species. In addition, in situ hybridization of ribosomal 5S gene provided new evidence for chromosomal fusion which led to the $\mathrm{Y}$ sex chromosome, as described in the literature, whereas hybridization of telomeric sequences did not provide evidence of recent fusion events involving the karyomorphs. Regarding transposable elements, it could be verified distinct sequence patterns between TC1 and Rex 1 elements, since the TC1 element delimited two groups which may indicate a simultaneously invasion in those groups and retrotransposon Rex1 invasion has occurred in a common ancestor to all karyomorphs.
\end{abstract}

